PNL-5272

UC-41, 32, 37

6

\title{
HEDL Air Filter Examination System Software
}

E. E. Stapleton

October 1984

Prepared for the U.S. Department of Energy under Contract DE-AC06-76RLO 1830

Pacific Northwest Laboratory Operated for the U.S. Department of Energy by Battelle Memorial Institute 


\title{
DISCLAIMER
}

This report was prepared as an account of work sponsored by an agency of the United States Government. Neither the United States Government nor any agency thereof, nor any of their employees, makes any warranty, express or implied, or assumes any legal liability or responsibility for the accuracy, completeness, or usefulness of any information, apparatus, product, or process disclosed, or represents that its use would not infringe privately owned rights. Reference herein to any specific commercial product, process, or service by trade name, trademark, manufacturer, or otherwise, does not necessarily constitute or imply its endorsement, recommendation, or favoring by the United States Government or any agency thereof. The views and opinions of authors expressed herein do not necessarily state or reflect those of the United States Government or any agency thereof.

\author{
PACIFIC NORTHWEST LABORATORY \\ operated by \\ BATTELLE \\ for the \\ UNITED STATES DEPARTMENT OF ENERGY \\ under Contract DE-AC06-76RLO 1830
}

\begin{tabular}{|c|c|}
\hline \multirow{2}{*}{\multicolumn{2}{|c|}{ Printed in the United States of America }} \\
\hline & \\
\hline \multicolumn{2}{|c|}{ Available from } \\
\hline \multicolumn{2}{|c|}{$\begin{array}{l}\text { National Technical Information Service } \\
\text { United States Department of Commerce }\end{array}$} \\
\hline \multicolumn{2}{|c|}{5285 Port Royal Road } \\
\hline \multicolumn{2}{|c|}{ Springfield, Virginia 22161} \\
\hline \multirow{2}{*}{\multicolumn{2}{|c|}{$\begin{array}{l}\text { NTIS Price Codes } \\
\text { Microfiche A01 }\end{array}$}} \\
\hline & \\
\hline \multicolumn{2}{|c|}{ Printed Copy } \\
\hline & Price \\
\hline Pages & Codes \\
\hline $001-025$ & $\mathrm{~A} 02$ \\
\hline $026-050$ & $\mathrm{~A} 03$ \\
\hline $051-075$ & $\mathrm{~A} 04$ \\
\hline 076-100 & A05 \\
\hline $101-125$ & A06 \\
\hline $126-150$ & $\mathrm{~A} 07$ \\
\hline $151-175$ & A08 \\
\hline $176-200$ & A09 \\
\hline $201-225$ & A010 \\
\hline $226-250$ & A011 \\
\hline $251-275$ & A012 \\
\hline $276-300$ & A013 \\
\hline
\end{tabular}


HEDL AIR FILTER EXAMINATION SYSTEM SOFTWARE

E. E. Stapleton

October 1984

Prepared for the U.S. Department of Energy under Contract DE-AC06-76RLO 1830

Pacific Northwest Laboratory

Richland, Washington 99352 


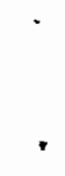

$+$

.

-

$\bullet$ 


\section{ACKNOWLEDGMENTS}

Acknowledgment is given to W. P. Howell, HEDL, for his guidance in implementing the radon subtraction and to D. J. Bruinek0ol, HEDL, for providing user feedback as changes were made. 
$?$

-

-

$\bullet$ 


\section{SUMMARY}

This document describes the system software and operation of the Hanford Engineering Development Laboratory (HEDL) air filter sample counting systems. Included are a description of how each program functions with flow charts, sample printouts, program listings and a listing with comments of test routines that exercise the hardware.

This effort is a result of a work order from HEDL Operational Safety to the Instrument Calibration and Evaluations section of the Pacific Northwest Laboratory (PNL) to upgrade the HEDL counting systems to include standardization, radon subtraction, and detector cooling. 
- 
ACKNOWLEDGMENTS $\ldots \ldots \ldots \ldots \ldots \ldots \ldots \ldots \ldots \ldots \ldots \ldots \ldots \ldots \ldots \ldots \ldots \ldots \ldots \ldots \ldots \ldots \ldots$

SUMMARY $\ldots \ldots \ldots \ldots \ldots \ldots \ldots \ldots \ldots \ldots \ldots \ldots \ldots \ldots \ldots \ldots \ldots \ldots \ldots \ldots \ldots \ldots \ldots$

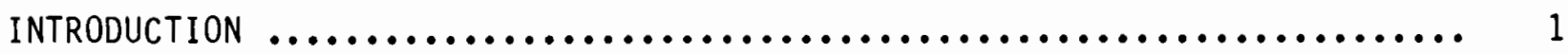

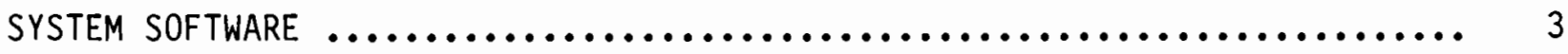

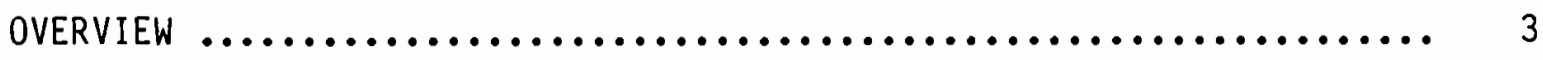

HEADER (AUTO-START) PROGRAM $\ldots \ldots \ldots \ldots \ldots \ldots \ldots \ldots \ldots \ldots \ldots \ldots \ldots \ldots \ldots \ldots$

FUNCTION SELECT PROGRAM $\ldots \ldots \ldots \ldots \ldots \ldots \ldots \ldots \ldots \ldots \ldots \ldots \ldots \ldots \ldots \ldots \ldots$

INITIALIZE PARAMETERS PROGRAM $\ldots \ldots \ldots \ldots \ldots \ldots \ldots \ldots \ldots \ldots \ldots \ldots \ldots \ldots$

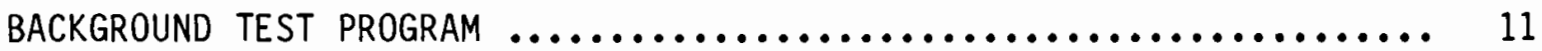

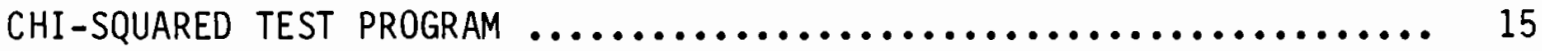

FILTER EXAMINATION PROGRAM $\ldots \ldots \ldots \ldots \ldots \ldots \ldots \ldots \ldots \ldots \ldots \ldots \ldots \ldots \ldots \ldots$

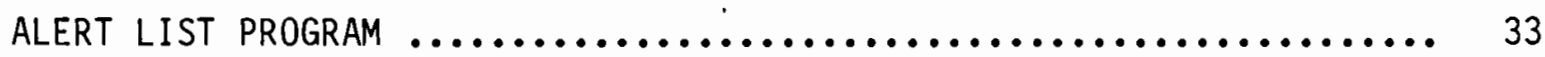

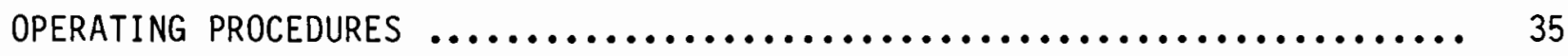

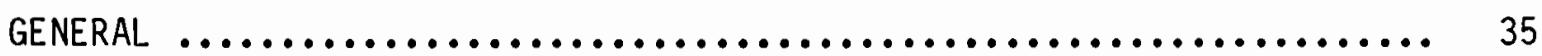

START-UP PROCEDURE ................................ 37

FUNCTION SELECT PROGRAM ............................ 37

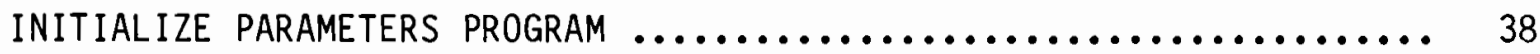

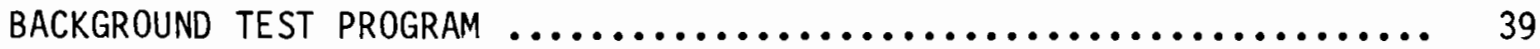

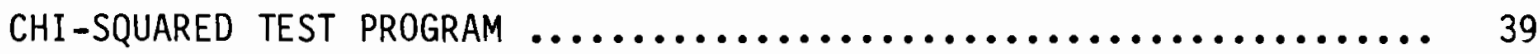

FILTER EXAMINATION PROGRAM .......................... 40

APPENDIX A - AIR FILTER EXAMINATION SYSTEM HARDWARE REFERENCES ........ A.1

APPENDIX B - PROGRAM LISTINGS OF THE 21 FILES USED BY THE AIR FILTER EXAMINATION SYSTEM ........................... B.I

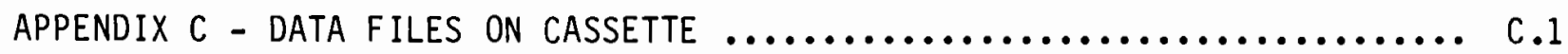


APPENDIX D - COPYING PROGRAM CASSETTES $\ldots \ldots \ldots \ldots \ldots \ldots \ldots \ldots \ldots \ldots \ldots \ldots \ldots \ldots . \ldots \ldots$

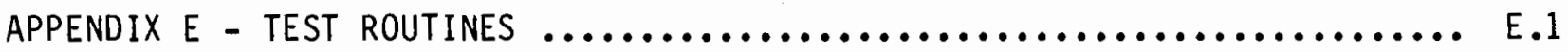




\section{FIGURES}

1 Hardware Configuration for Air Filter Examination System .......... 2

2 File 0 - Header (Auto-Start) Program Flow Diagram ................ 5

3 Printout of Header (Auto-Start) Program ....................... 5

4 File 1 - Function Select Program Flow Diagram .................. 7

5 Printout of Function Select Program $\ldots \ldots \ldots \ldots \ldots \ldots \ldots \ldots \ldots \ldots \ldots$

6 Files 2 and 3 - Initialize Parameters Program Flow Diagrams ........ 9

7 Sample Printouts from Initialize Parameters Program ............. 10

8 Sample Printouts from Background Test ...................... 12

9 Files 4, 5, and 6 - Background Test Program Flow Diagram ......... 13

10 Printout of Background Test Results $\ldots \ldots \ldots \ldots \ldots \ldots \ldots \ldots \ldots \ldots \ldots \ldots$

11 Files 7 and 8 - Chi-Squared Test Program Flow Diagrams ........... 18

12 Files 9 and 10 - Chi-Squared Test Program Flow Diagrams ........... 19

13 Files 11 and 12 - Chi-Squared Test Program Flow Diagrams .......... 20

14 Sample Printout from Chi-Squared Test Program .................. 21

15 Printout of Chi-Squared Test Results $\ldots \ldots \ldots \ldots \ldots \ldots \ldots \ldots \ldots \ldots \ldots \ldots$

16 Files 13 through 16 - Filter Examination Program Flow Diagrams ...... 27

17 File 17 - Filter Examination Program Flow Diagram .............. 28

18 File 18 - Filter Examination Program Flow Diagram ................ 29

19 Files 19 and 20 - Filter Examination Program Flow Diagram ......... 30

20 Sample Printouts from Filter Examination Program ................ 31

21 Printout of Filter Examination Program Results ............... 32 


\section{TABLES}

1 Program Placement on Cassette Files and Interaction Between

Programs .......................................... 3

2 Constants Accessible by the "Initialize Parameters" Program ........ 8

3 Register Use for Data Passage in Filter Examination .............. 26

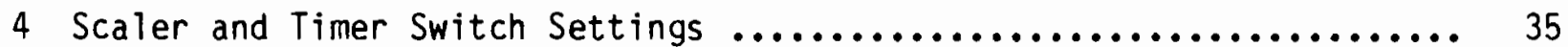




\section{INTRODUCTION}

Two automatic and one manual examining and counting systems were developed for reading Hanford Engineering Development Laboratory (HEDL) air sample filters. Before these new systems were developed, different computers, interfaces, and printouts had been used.

The three systems have now been standardized except for one software file that determines whether the tape is used on an automatic or a manual system. As shown in Figure 1, these systems are composed of a planchette sample changer (auto system shown), an alpha/beta detector and its cooling system, four single channel analyzers, four scalers, a timer, a computer interface, a desktop computer, and a dot-matrix printer. Data collection and control are performed by the Hewlett Packard 9815 desk top computer. This computer has up to 360 program steps with 20 data registers, a 16-character-wide thermal printer, and a high-speed cassette drive system. A detailed list of these hardware components and references to the manufacturer's literature can be found in Appendix $A$.

Data sent to the thermal printer is used to verify that the system is working properly while the test is in progress, and may be discarded or used for diagnosis in the event of a failure.

The system software consists of four callable functions that each use one or more programs. At the conclusion of any function, the system resumes its ready state; any of the four functions may then be selected.

System startup is initiated by the Auto-Start feature of the controlling HP9815 desk top computer. When power is applied to the system, the computer immediately runs a start program and assumes the ready state.

All programs for this system are resident on cassette. This cassette is also used for the storage of system constants and temporary data, and thus cannot be write protected. 


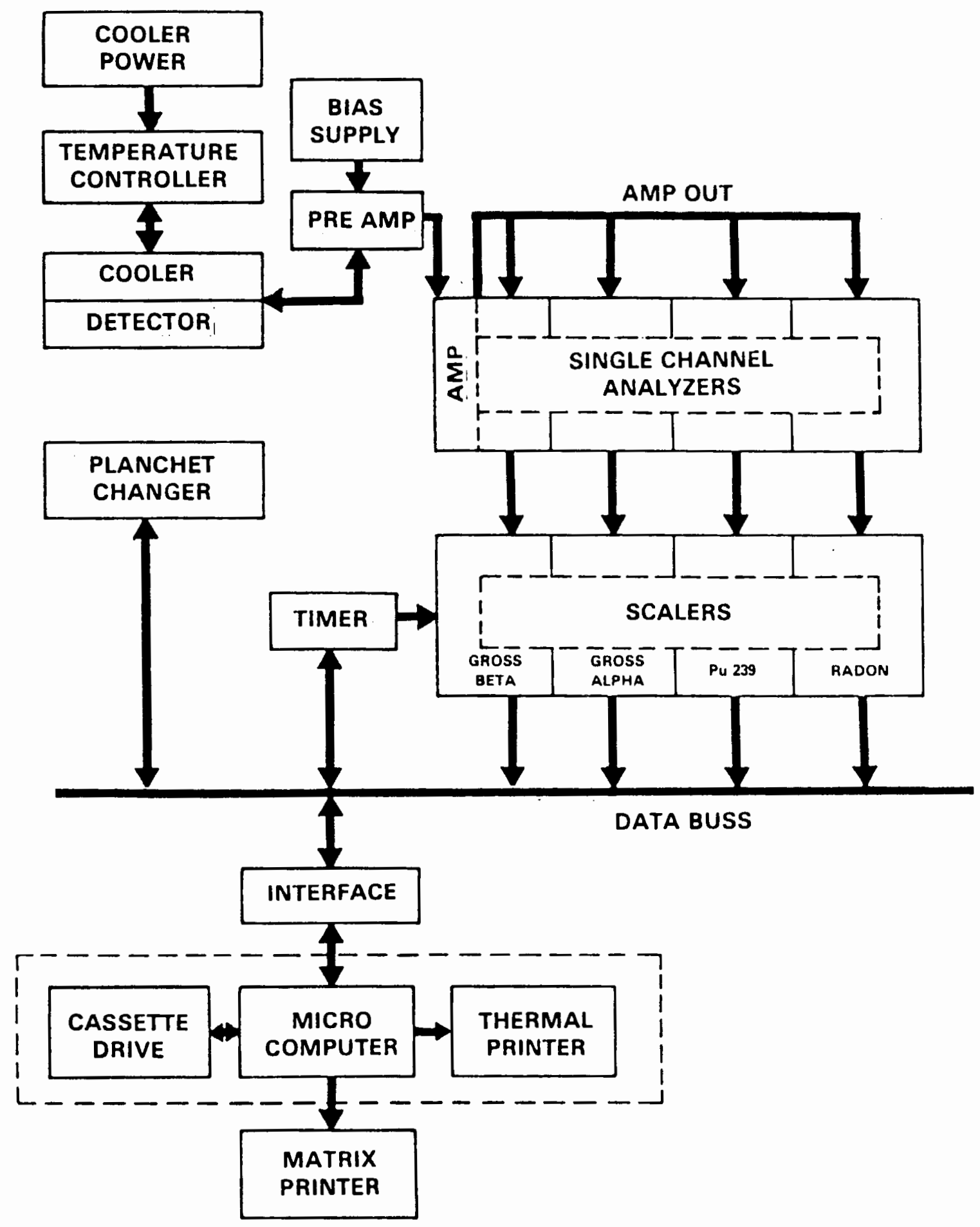

FIGURE 1. Hardware Configuration for Air Filter Examination System 


\section{SYSTEM SOFTWARE}

OVERVIEW

The software for the air filter examination system consists of four callable functions, a function select program, and an auto-start program. The four callable functions consist of twenty programs that interact by exchanging data via memory registers and the system's cassette drive. Twenty files on block 1 of the cassette hold these programs (see Table 1). Table 1 also lists the interaction of these functions. Although there are a total of 21 files, only 20 files are used on any system tape. This is because file 17 comes in two versions; one for the automatic systems (17A) and one for the manual systems (17M). Thus, there are a total of 21 files listed in Appendix A.

\section{TABLE 1. Program Placement on Cassette Files and Interaction Between Programs}

\begin{tabular}{|c|c|c|}
\hline File \# & Progran & Files Called \\
\hline$\emptyset$ & Header (Auto-Start) & 1 \\
\hline 1 & Function Select & $2,4,7,13$ \\
\hline 2 & Initialize Paraneters (1 of 2) (List) & 3,1 \\
\hline 3 & Initialize Parameters (2 of 2 ) (Change) & 2 \\
\hline 4 & Background Test (1 of 3 ) (Test) & 5,1 \\
\hline 5 & Background Test (2 of 3 ) (Print Header) & 6 \\
\hline 6 & Background Test ( 3 of 3 ) (Report) & 1 \\
\hline 7 & Chi-Squared Test (1 of 6) (Set up) & 8,1 \\
\hline 8 & Chi-Squared Test (2 of 6) (Test) & 9,1 \\
\hline 9 & Chi-Squared Test ( 3 of 6 ) (Calculate) & 10 \\
\hline 10 & Chi-Squared Test ( 4 of 6 ) (Report) & 11,1 \\
\hline 11 & Chi-Squared Test (5 of 6) (Report) & 12 \\
\hline 12 & Chi-Squared Test ( 6 of 6$)$ (Report) & 1 \\
\hline 13 & Filter Examination (1 of 6) (Prepared Registers) & 14,1 \\
\hline 14 & Filter Examination (? of 6 ) (Print Header) & 15 \\
\hline 15 & Filter Examination ( 3 of 6 ) (Print Header) & 16 \\
\hline 16 & Filter Examination ( 4 of 6 ) (Print Header) & 17 \\
\hline $17 \mathrm{~A}$ & Filter Examination ( 5 of 6 ) (Automatic Test) & 18,1 \\
\hline $17 \mathrm{M}$ & Filter Exarnination ( 5 of 6 ) (Manual Test) & 18,1 \\
\hline 18 & Filter Examination ( 6 of 6 ) (Print Result) & 19 \\
\hline 19 & Alert Record (Record Alerted Data) & $17,20,1$ \\
\hline 20 & Alert List (Listed Recorded Data) & 1 \\
\hline
\end{tabular}


HEADER (AUTO-START) PROGRAM

The HP9815A desktop computer uses an auto-start feature where the program in file $\emptyset$ of the cassette drive will be loaded and executed when the power is switched on. To use this option, the RUN/AUTO-START/PRGM switch must be in the AUTO-START position prior to switching the power on.

File $\emptyset$ contains the header program, which prints an introduction and instructions for selecting the functions to be listed. The program then instructs the computer to load and execute the function select program in file 1 .

The header program neither generates nor requires any data. The computer defaults the register set to 10 and program step size to 360 when power is applied. See Figure 2 for a flow diagram of the header program and Figure 3 for the printout. 


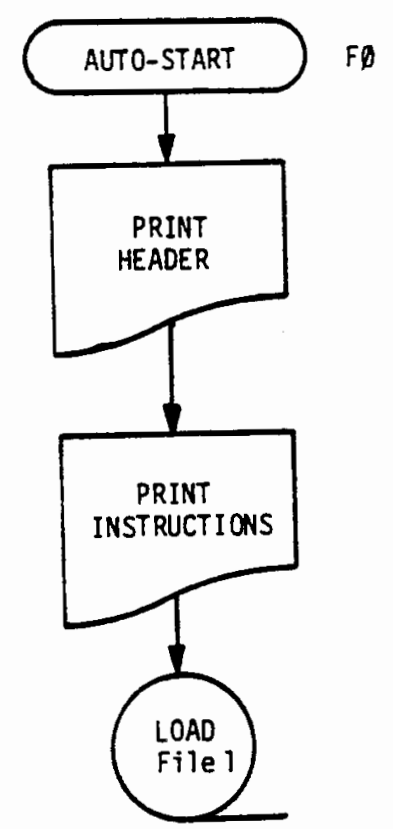

FIGURE 2. File $\emptyset$ - Header (Auto-Start) Program Flow Diagram

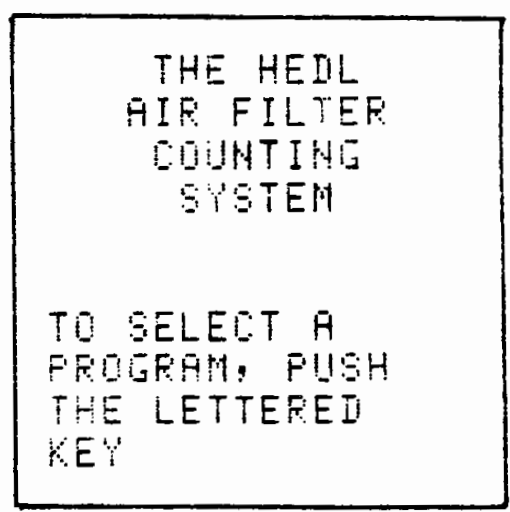

FIGURE 3. Printout of Header (Auto-Start) Program 


\section{FUNCTION SELECT PROGRAM}

The function select program is the return point when any system function is terminated or after the header program runs. This program lists the four system functions available plus "stop" and "instructions" options, assigning each function a lettered key. When the program suspends itself after the listing, any of the six keys listed may be pushed to start a function. (Key 0 turns off the system. The power can be turned off and back on, with the AutoStart option, to restart the system.) For a given function selection, the appropriate file is loaded and executed, thus overlaying the function select program. Once this is done, the lettered keys will have changed functions or have no meaning.

The function select program resides in file 1 of the cassette. It neither generates nor uses any data. See Figure 4 for a flow diagram of the function select program and Figure 5 for the printout. 


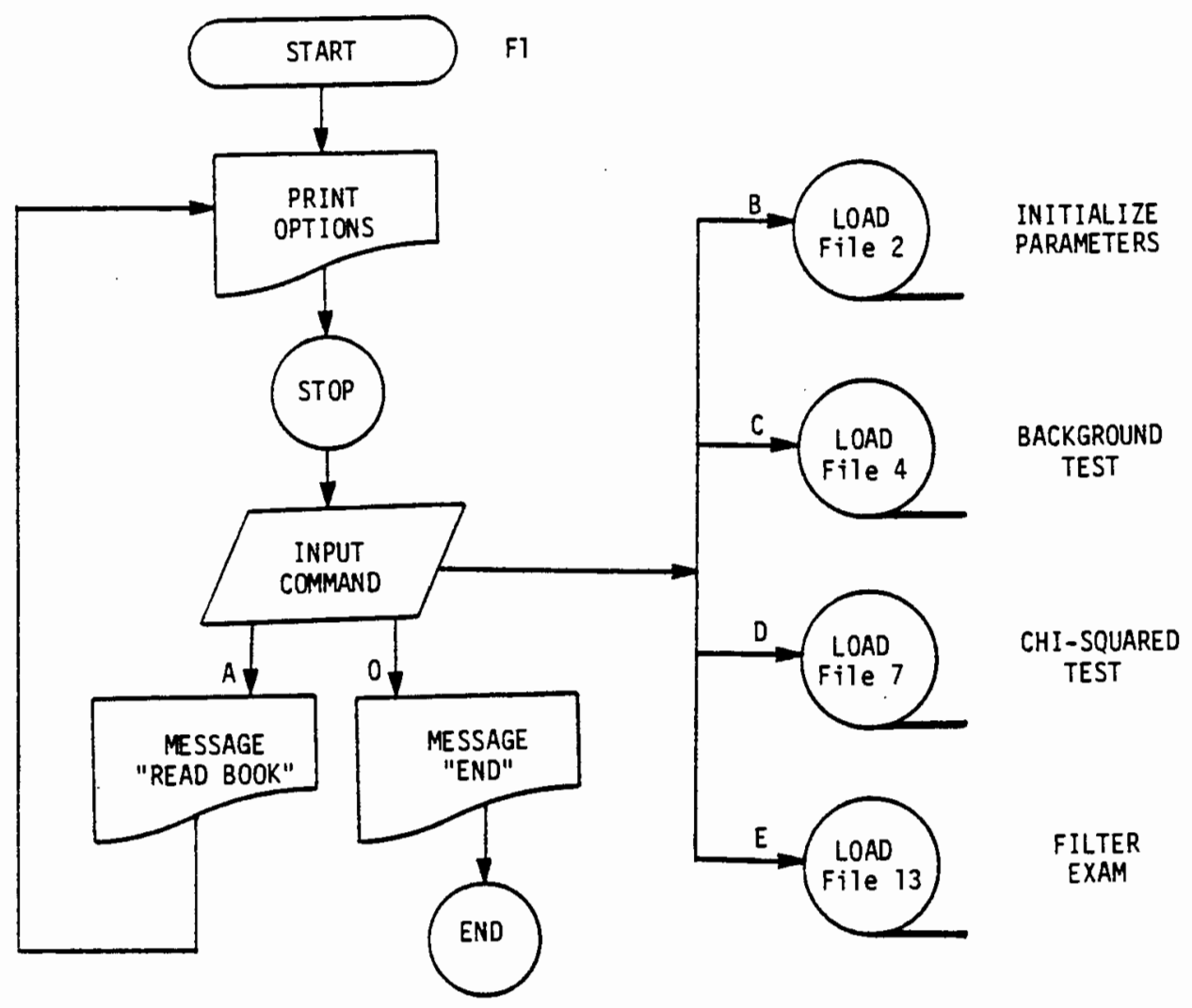

FIGURE 4. File 1 - Function Select Program Flow Diagram

$$
\begin{aligned}
& \text { H - IHETFUTTOHE } \\
& \text { E - IHITIHLIEE } \\
& \text { FHFAMETEF: } \\
& \text { E - EALEGFULHI } \\
& \text { TEST } \\
& \text { I) - CHI SOIAFE } \\
& \text { TEST } \\
& \text { - FILTEF EMI } \\
& \text { - - STOF } \\
& \text { FFESS } \div \text { EHI : } \\
& \text { THEH LETTEF }
\end{aligned}
$$

FIGURE 5. Printout of Function Select Program 


\section{INITIALIZE PARAMETERS PROGRAM}

This function is selected by pressing key "B" in the function select program. The program is stored in two files (2 and 3 ) on cassette. File 2 is first loaded and prints instructions to either: (1) change any of the eight parameters used by the test routines, (2) list the parameters, or (3) stop (return to function select.) The eight parameters that may be listed or changed are shown in Table 2, with their units and typical values. See Appendix $C$ for further information on the storage of these data and others. File 2 holds the instruction, list and stop options while file 3 is loaded to do the change option. When changes are complete, file 2 is reloaded.

The initialize parameters program does not use data, but does access data for storage and listing on cassette files $-\emptyset$ and -2 . Buttons $A$ through $H$ and 0 are used to select parameters for change in the change option and registers R0 through R9 are used as temporary data storage when reading and writing the cassette files. See Figure 6 for a flow diagram of the initialize parameters program and Figure 7 for a sample printout.

TABLE 2. Constants Accessible by the "Initialize Parameters" Program

\begin{tabular}{|c|c|c|c|}
\hline Key & Parameter & Typical Value & Units \\
\hline A & Background Test Count Time & 10.00 & minutes \\
\hline B & Beta Alert Level & $1 \times 10^{-11}$ & $\mu \mathrm{Ci} / \mathrm{cC}$ \\
\hline C & Al pha Alert Level & $3 \times 10^{-13}$ & $\mu \mathrm{Ci} / \mathrm{CC}$ \\
\hline$D$ & ${ }^{239} \mathrm{Pu}$ Alert Level & $3 \times 10^{-13}$ & $\mu_{\mathrm{Ci} / \mathrm{CC}}$ \\
\hline$E$ & Sample Monitor Volume & 1440 & CFD \\
\hline $\mathrm{F}$ & Sample Exposure Period & $1-7$ & Days \\
\hline G & Standard Beta Source & 23000 & $d / m$ \\
\hline$H$ & Standard Alpha Source & 5190 & $d / m$ \\
\hline
\end{tabular}



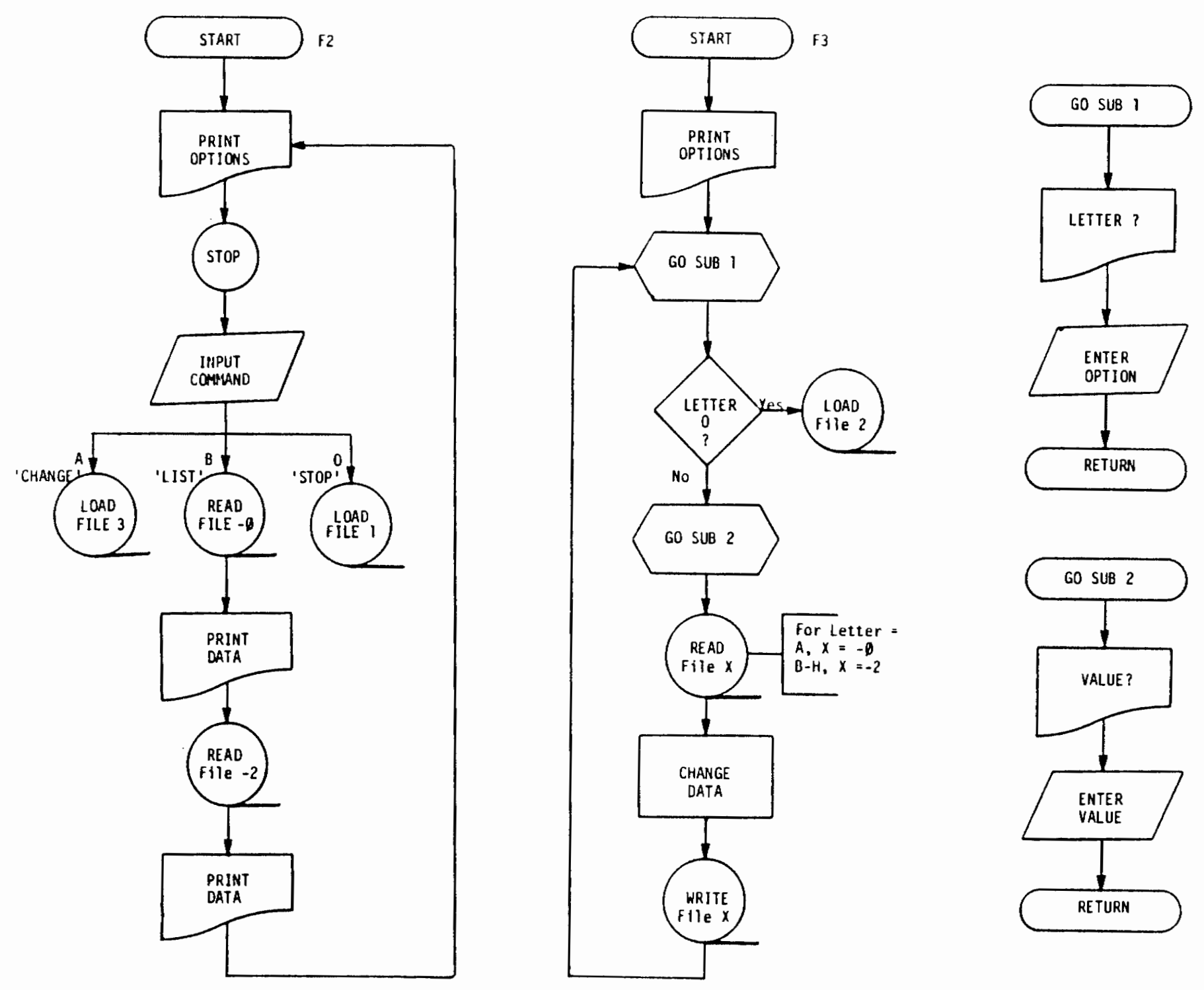

GO SUB 2

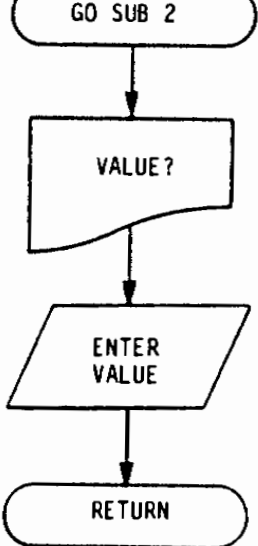

FIGURE 6. Files 2 and 3 - Initialize Parameters Program Flow Diagrams 


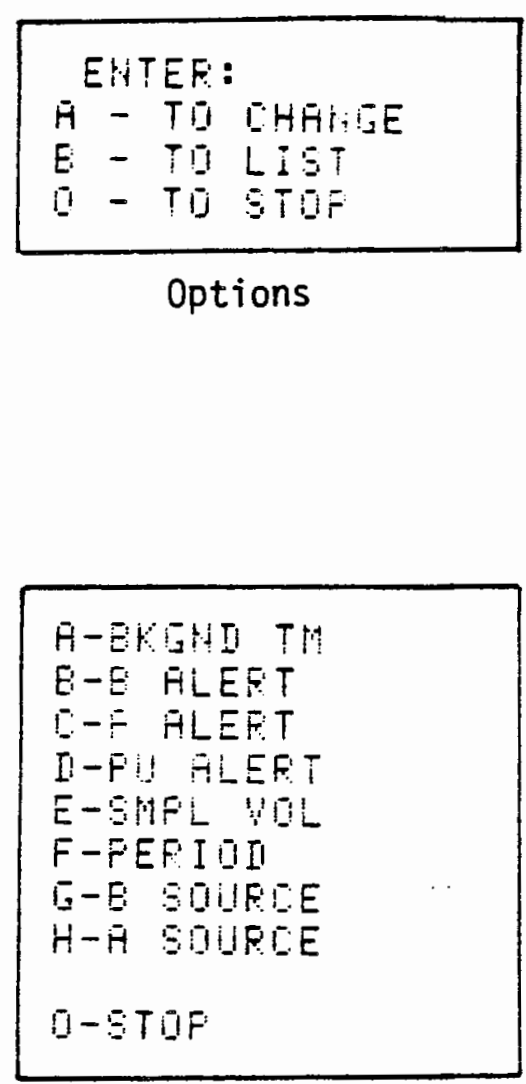

Change Options

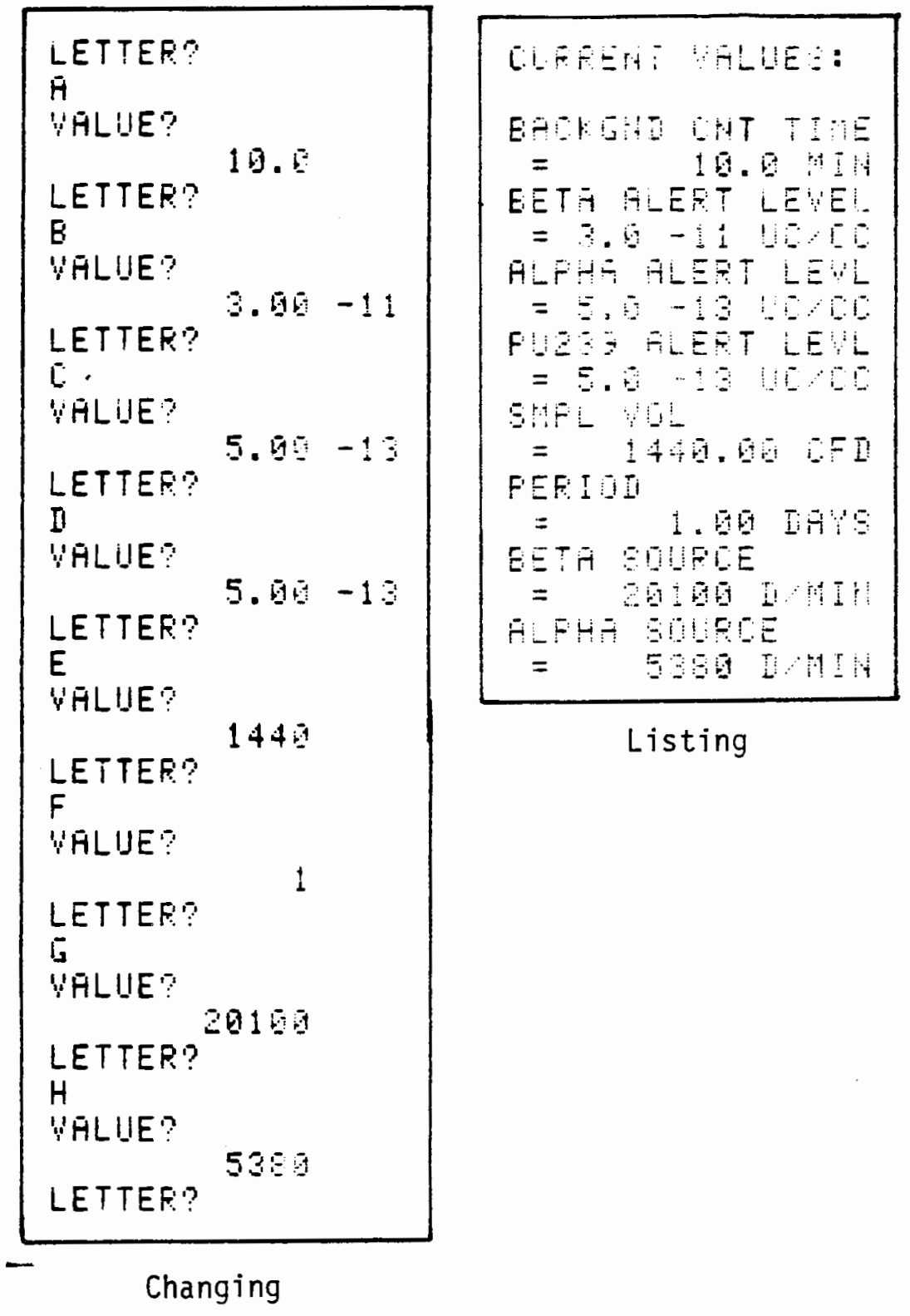

FIGURE 7. Sample Printouts from Initialize Parameters Program 


\section{BACKGROUND TEST PROGRAM}

The background test program is stored in three files (4,5 and 6) on the cassette. The first file loaded (4) performs the test and then calls the second and third files (5 and 6 ) which print the test results.

This program examines an empty filter holder for a specified period of time (typically ten minutes) and calculates the average beta, alpha, ${ }^{239} \mathrm{Pu}$, and radon counts per minute. These averages are then stored on cassette (see Appendix $\mathrm{C}$ ). The chi-squared test and filter examination programs then use these values to adjust their gross counts by these background averages.

The background test program examines the count time stored in memory and displays it to alert the operator to check the timer setting, see figure 8 .

At this point the operator may abort the test and reset the time through the initialize parameters program, set the timer, or continue the test. If the program notes a difference between the expected time and the timer setting when the test is finished, an alert message is printed. However, the data is calculated by the timer setting, thus assuring the quality of the background data. Also, the timer value replaces the time value originally stored. All timer readings are assumed to be in 0.01 minute increments.

Refer to Figure 9 for a flow diagram, and Figure 10 for a completed test result. Note that the chi-square test result prints out on the same page of the external printer, if the chi square is acceptable. 


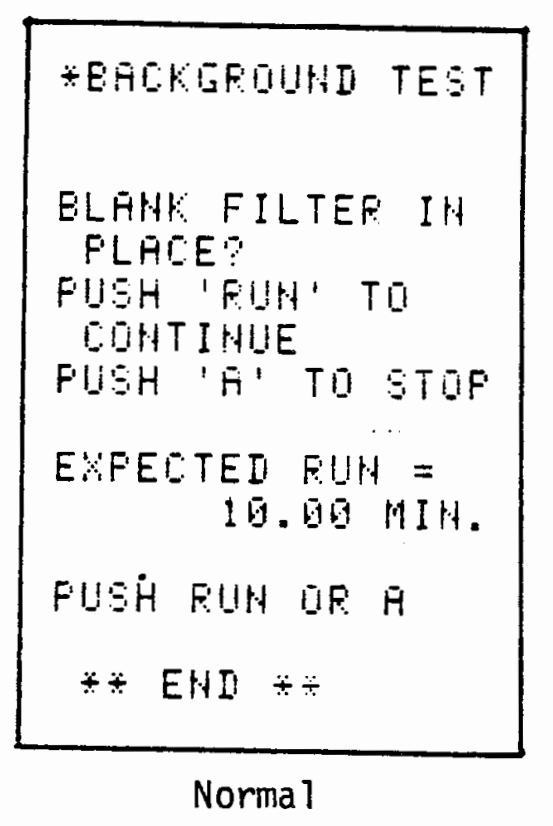

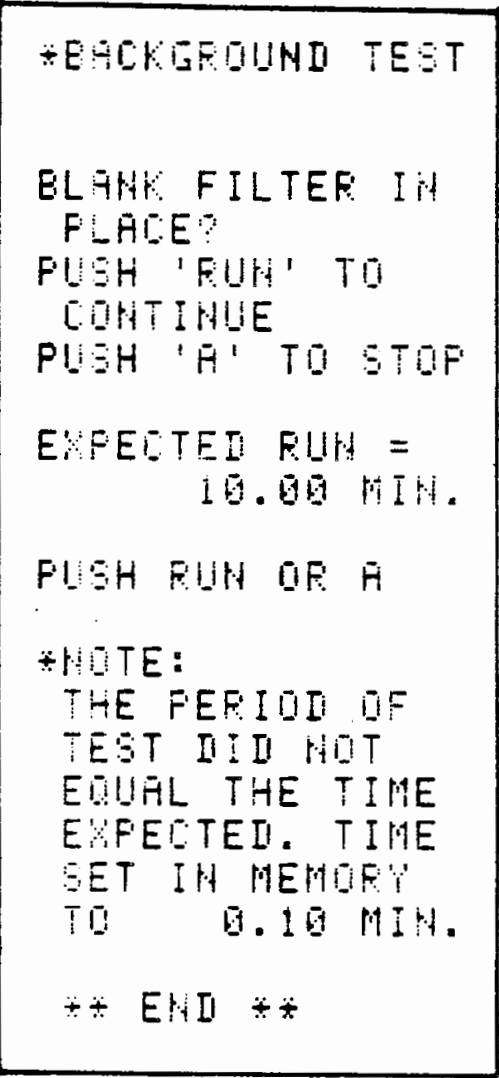

Timer Error

FIGURE 8. Sample Printouts from Background Test 

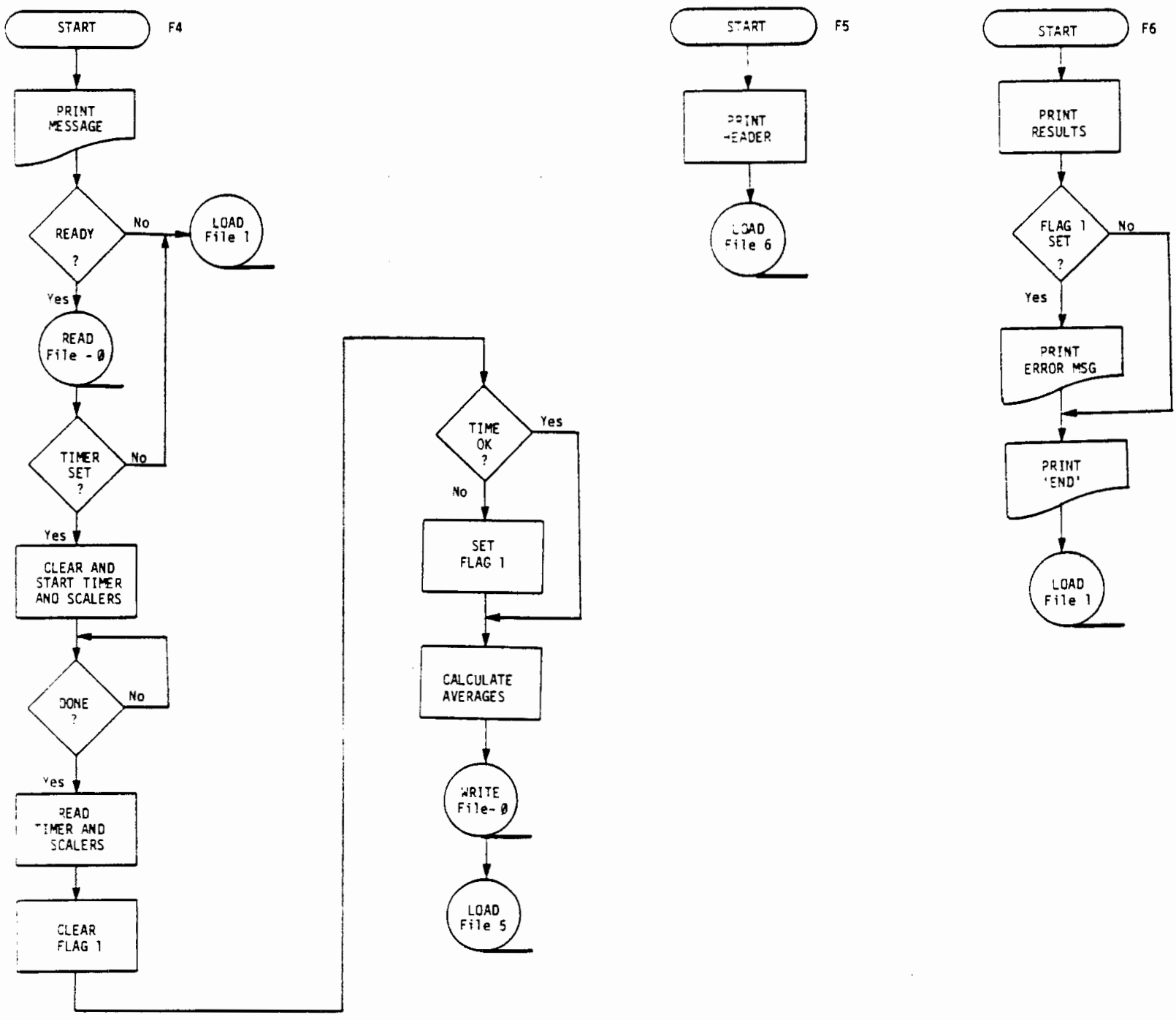

FIGURE 9. Files 4, 5, and 6 - Background Test Program Flow Diagram 
BACKGROUND TEST RESULT

$\begin{array}{cc}\text { AVERAGE BACKGROUND } & \text { (COUNTS/MINUTE) } \\ \text { BETA }= & 10.70 \\ \text { ALPHA }= & 0.00 \\ \text { 23YPU }= & 0.00 \\ \text { RADON }= & 0.00\end{array}$

FIGURE 10. Printout of Background Test Results 


\section{CHI-SQUARED TEST PROGRAM}

The chi-squared test program is stored in six files ( 7 through 12) on the cassette. The first file loaded (7) prompts the operator to ensure proper setup. The threshold dial and window on the radon channel must be lowered to accept the ${ }^{239} \mathrm{Pu}$ pulses for this test. The second file (8) performs the test, checks for correct time, and prints out the raw data for each scaler after each count cycle.

The third file (9) completes the chi-squared and efficiency calculations and prints the results on the thermal printer. The fourth file (10) evaluates each counters performance for acceptability. The results are printed on the thermal printer and, if the counters are found acceptable or conditionally acceptable, the next two files (11 and 12) are loaded, which formats and prints the results below the background data on the external printer.

This program examines a known source of radioactive material for twenty periods of any value (typically one minute). By calculating the chi-squared values of a standard source, the probability of the data comprising a normal set can be determined. Deviations indicate that hardware recalibration is necessary.

The chi-squared values are determined for beta, alpha, ${ }^{239} \mathrm{pu}$ and radon by the equation:

$$
\operatorname{Chi}{ }^{2}=\frac{\sum_{i=1}^{n}(x i-\bar{x})^{2}}{\bar{x}}
$$

where: $x i=$ individual count

$$
\begin{aligned}
& \bar{x}=\text { mean count } \\
& n=\text { number of counts }
\end{aligned}
$$


Since a limited number of registers are available in the HP9815A calculator (23 through 26 for this program) the following form of the chisquared equation was actually used.

$$
C n i^{2}=\frac{\sum_{i=1}^{n} x i^{2}-\frac{\left(\sum_{i=1}^{n} x i\right)^{2}}{n}}{\bar{x}}
$$

The mean, or average, count and the detector efficiencies for each channel are also calculated. For the mean count:

$$
\bar{x}=\frac{\sum_{i=1}^{n} x_{i}}{n}
$$

The detector efficiency is then calculated by:

$$
\% E=\frac{\left(\bar{X}-X_{B}\right)}{S} * 100 \%
$$

where: $X_{B}=$ background count rate

$$
S=\text { source strength. }
$$

The background count rates and standard sample source strengths are retrieved from the cassette data files when the counting process concludes. The efficiency is expressed as a percentage and reflects the ratio of the number of radiation particles which were detected with respect to the number of radiation particles generated by the source. Since a plane detector mounted above the source is used, the detector efficiency must be less than $50 \%$. The beta, alpha and ${ }^{239} \mathrm{Pu}$ detector efficiencies are saved for later use in 
calculating radiation particle concentration in the filter examination program. The radon data is printed out but not saved since only the net counts/ min is used by the filter examination program. Registers 10, 11,12 are used to pass the radon data between files.

The activity of the radioactive sources used for this test are entered into memory via the initialize parameters program prior to running the chisquared test. The data is entered as the number of disintegrations per minute. At this time, the alpha, ${ }^{239} \mathrm{Pu}$, and radon source are considered to be the same, thus only the alpha source can be initialized. A typical mixture for the source is ${ }^{90} \mathrm{Sr}$ and ${ }^{239} \mathrm{Pu}$ with activities of 16,100 beta decays and 4900 alpha decays per minute. The calculator's range will not limit the maximum source strengths to be used.

Please refer to Figures 11 through 13 for flow diagrams of the chi-squared test, Figure 14 for a sample printout during the test, and Figure 15 for a printout of the test results.

The acceptance test is stored in file 10 on the cassette and is used to evaluate the chi-squared results for acceptability.

The criteria for accepting or rejecting a counter's performance is based on the probability of exceeding given limits as shown below:

$\begin{array}{lllll}\text { Probability } & 99 \% & 90 \% & 10 \% & 1 \% \\ \text { Chi }^{2} & 7.63 & 11.65 & 27.20 & 36.19\end{array}$

Depending on the value of $\mathrm{Chi}^{2}$, each counter's performance will be acceptable, conditionally acceptable or unacceptable.

To be acceptable: $10 \% \leq \mathrm{Chi}^{2} \leq 90 \%$

To be conditionally acceptable: $1 \% \leq \mathrm{Chi}^{2}<10 \%$ or $90 \%<\mathrm{Chi}^{2} \leq 99 \%$

To be unacceptable: $\mathrm{Chi}^{2}<1 \%$ or $\mathrm{Chi}^{2}>99 \%$.

If a counter is found unacceptable, the data is not sent to the external printer and the system returns to the wait mode. 

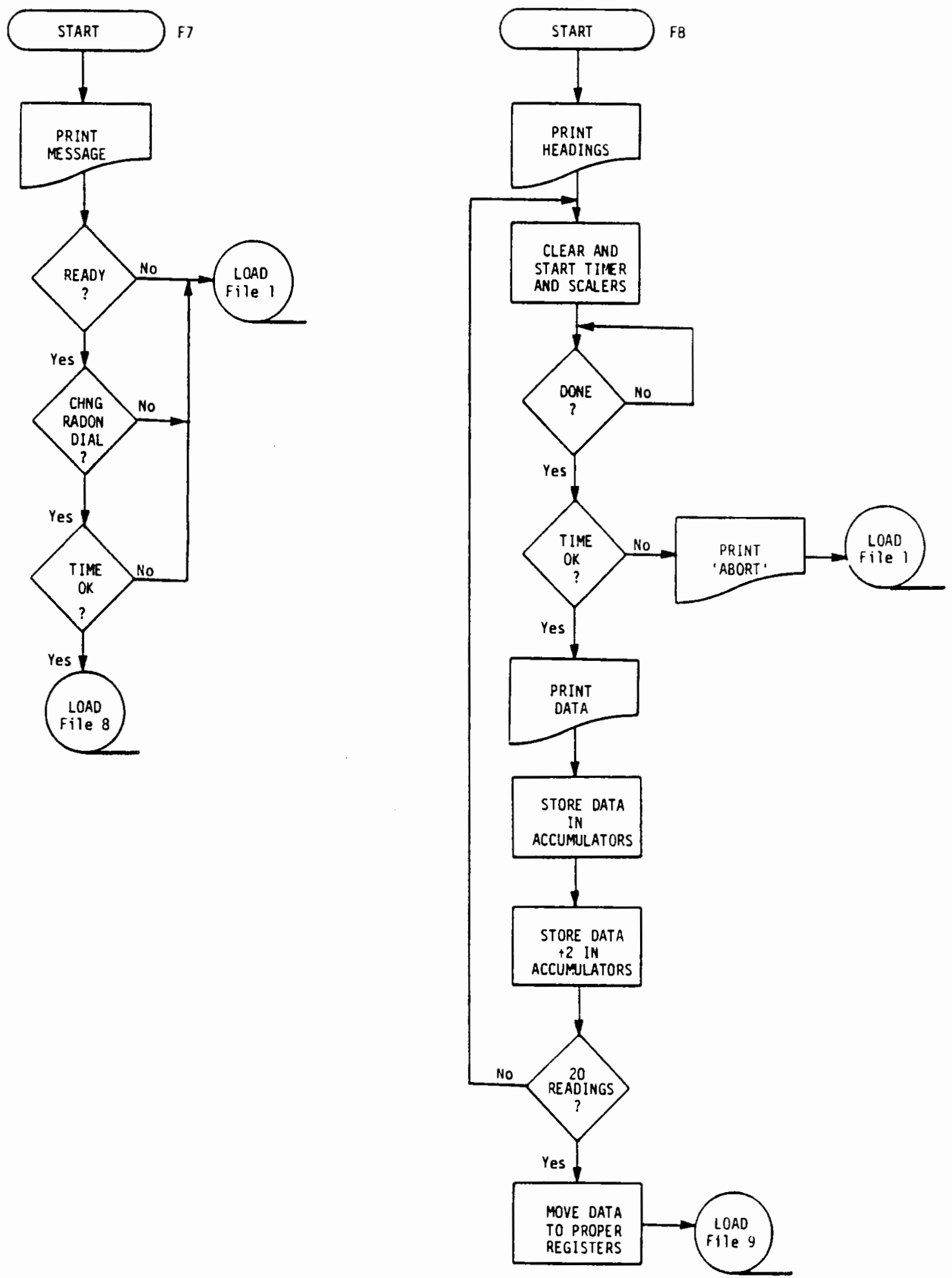

FIGURE 11. Files 7 and 8 - Chi-Squared Test Program Flow Diagrams 

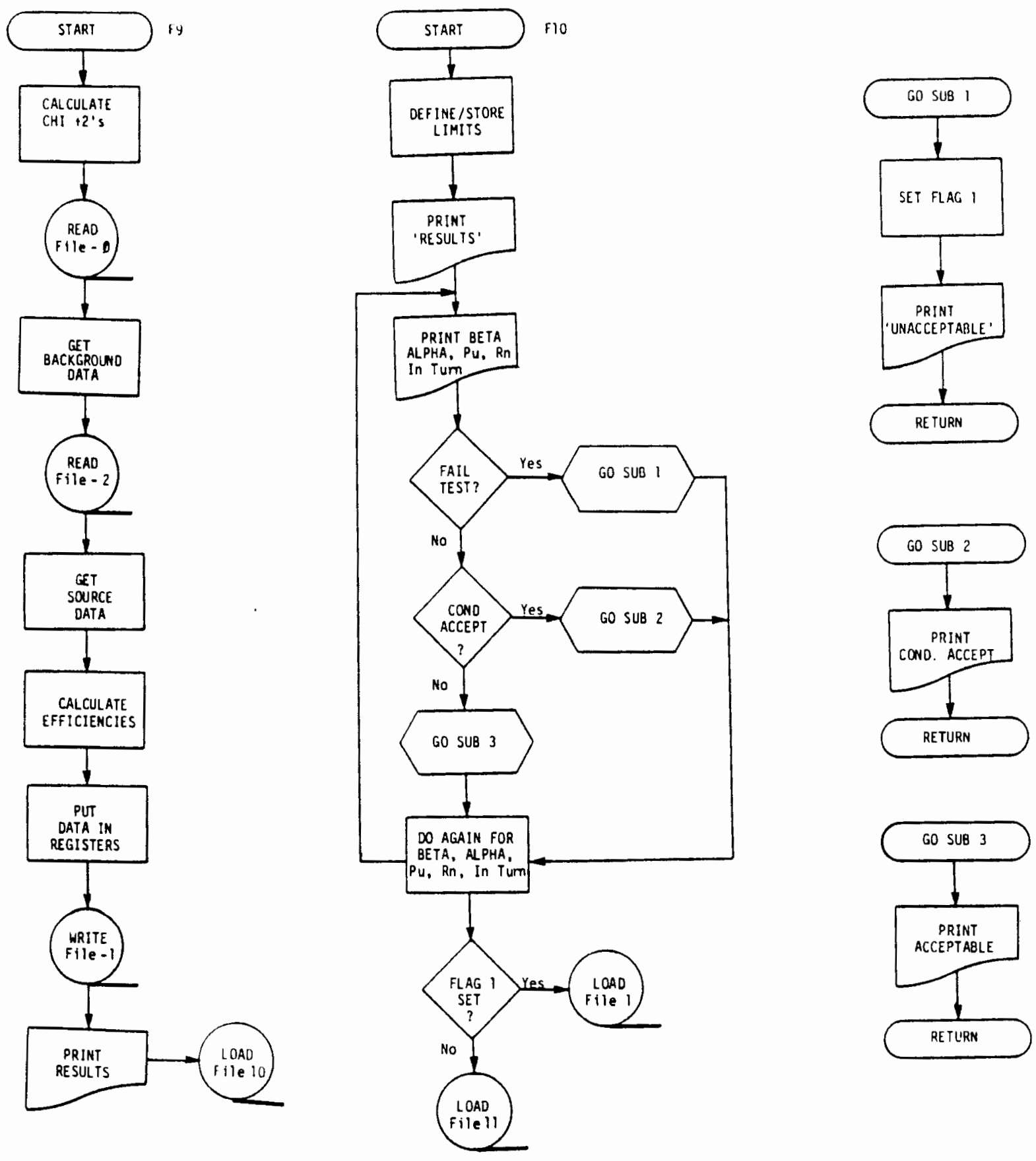

FIGURE 12. Files 9 and 10 - Chi-Squared Test Program Flow Diagrams 

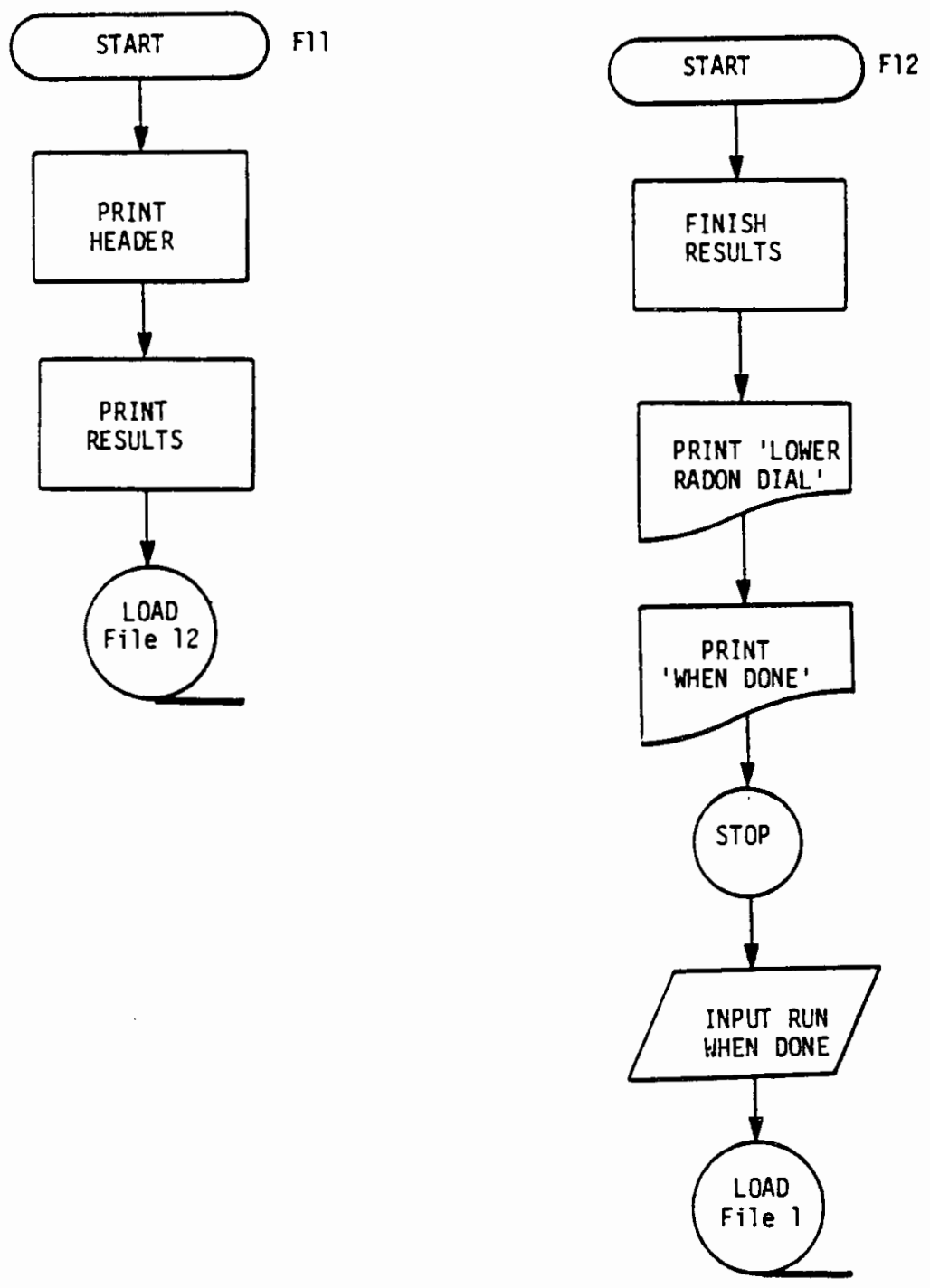

FIGURE 13. Files 11 and 12 - Chi-Squared Test Program Flow Diagrams 

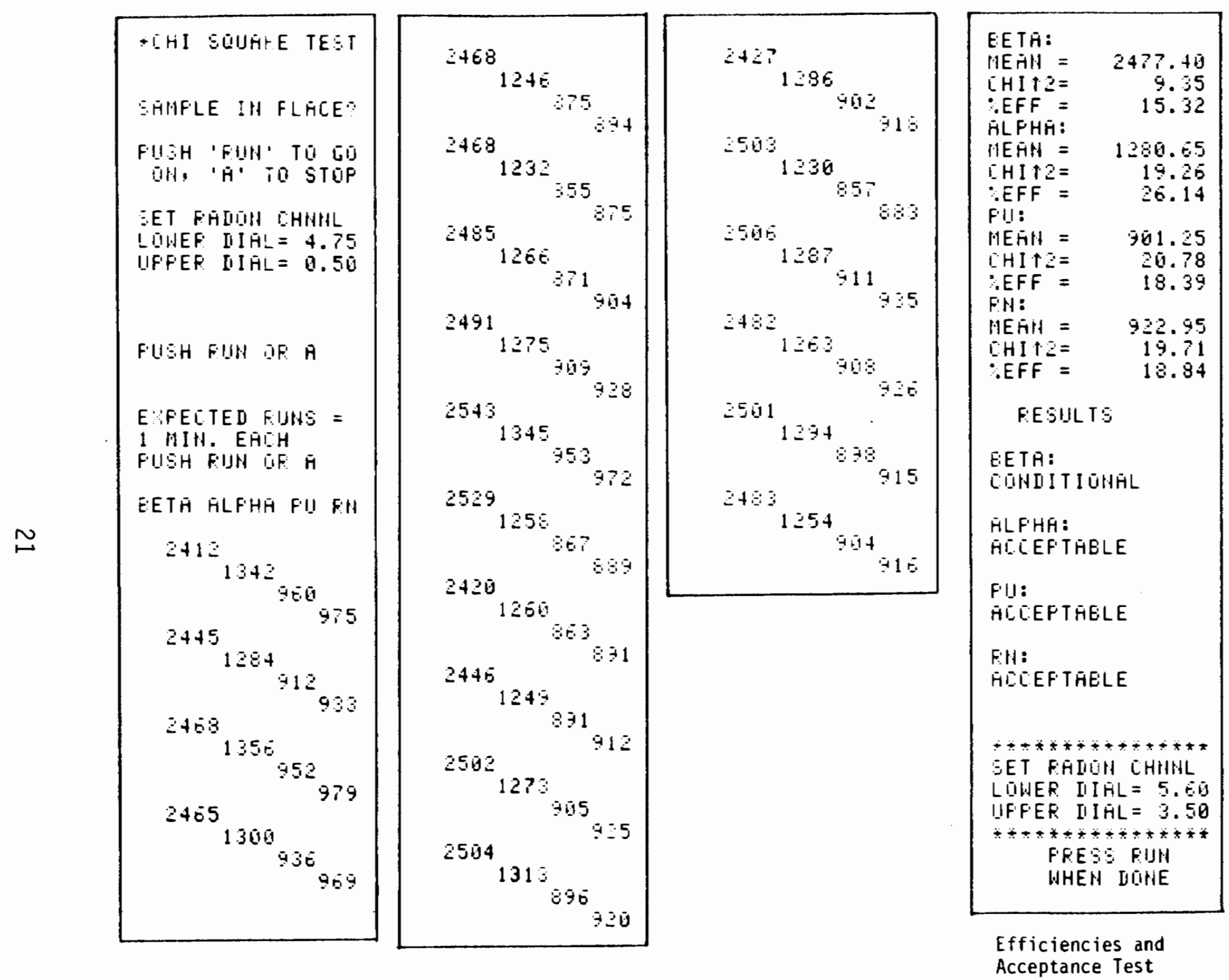

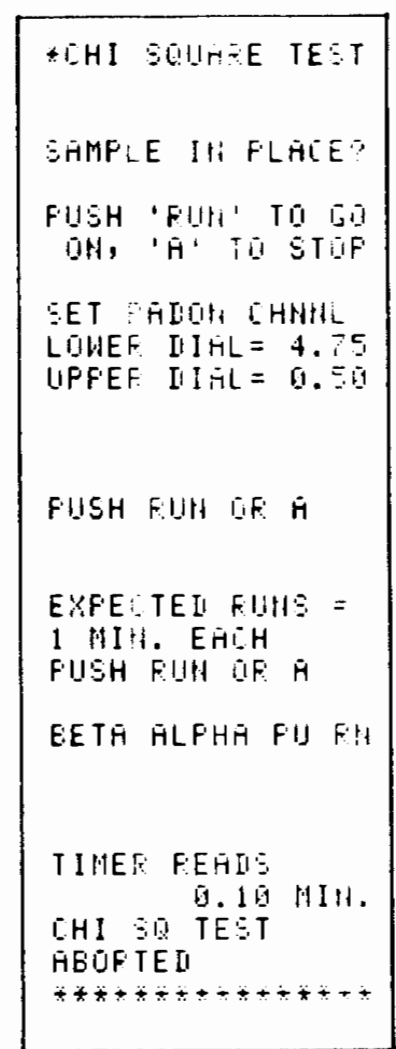

Timer Error

FIGURE 14. Sample Printout from Chi-Squared Test Program 
DATE

SHIFT

AUTO-MANUAL

RM INITIALS

BACKGROUND TEST RESUIT

AVERAGE BACKGROUND (COUNTS/MINUTE)

\begin{tabular}{|c|c|c|}
\hline BETA & $=$ & 10.70 \\
\hline ALPHA & & 0.0 \\
\hline $239 \mathrm{PU}$ & & 0.00 \\
\hline RADON & $=$ & 0.0 \\
\hline
\end{tabular}

CHI SQUARE TEST RESUIT

$\begin{array}{lr}\text { BETA SOURCE } & =16100 \mathrm{D} / \mathrm{M} \\ \text { ALPHA SOURCE } & =4900 \mathrm{D} / \mathrm{M}\end{array}$

CHANNE L

MEAN C/M

CHI SQ.

* EEE

BETA

2477.40

9.35

15.32

AL PHA

1280.65

19.26

26.14

${ }^{231} \mathrm{PU}$

901.25

20.78

13. 39

RADON

922.95

19.71

18.84

FIGURE 15. Printout of Chi-Squared Test Results 


\section{FILTER EXAMINATION PROGRAM}

The filter examination program is stored on eight cassette files (13 through 20). The first file (13) is loaded and is used to initialize the data registers prior to running tests on the samples. The second, third and fourth files $(14,15$ and 16) are used to print the header information on the external printer. The fifth file (17) is called to examine the sample presently in place, forward the changer when finished (auto system), determine if the timer was correct, and then either load the next file (18) or abort the examination if the timer reading was incorrect. Two versions of file 17 exist, one for an automatic system (17A) and one for the manual system (17M).

File 18 prints the net counts/minute on the external printer, then subtracts the radon counts from the gross beta, gross alpha and ${ }^{239} \mathrm{Pu}$ channels prior to calculating the $\mu \mathrm{Ci} / \mathrm{cc}$ levels. Extensive testing has shown that if 100 counts are detected in the radon channel, 120 counts is an acceptable number to be subtracted from the gross beta, 100 counts from the gross alpha, and 10 counts from the ${ }^{239} \mathrm{Pu}$. File 18 then looks for alert conditions, and flags the external printout if over limit conditions exist.

The seventh file (19) checks to see if an alert condition was previously detected. If no alert condition existed, and it was not the last sample, file 17 is again loaded and the next sample examined. If an alert condition was detected, the sample percentage over-limits is calculated and recorded. The last file (20) is loaded after all samples have been read and one or more samples were found to be over-limit. This file prints out a summary of the samples which exceeded the alert levels on the thermal printer.

This program examines a series of samples (up to 100 per run) for two minutes each. It then divides the gross counts of each channel by 2 , subtracts the background and prints the net counts-per-minute for each channel on the external printer. By using the efficiency data collected earlier and the present net radon, it determines the concentrations of beta, alpha, and ${ }^{239} \mathrm{Pu}$ radiation for the air filtered by each sample filter. The known air flow rate and period of exposure must be entered into memory via the "initialize parameters" routine prior to running the filter examination program. For each sample examined, the data are compared against alert level limits (also entered 
via "initialize parameters") to help the operator recognize high radiation levels. For each sample with an over-limit value, the concentration in the report is followed by "*" to help point to it. In addition, the next program will calculate the percentage of over-limit, and record it onto the cassette data files (-3 to -102). Finally, when all samples have been examined and if there were any over-limit readings, "Alert List" is called to print a summary of the over-limit samples on the thermal printer.

The concentrations are calculated by the equation:

$$
C=Q^{\star} A C(\mu C i / C C)
$$

where: $C=$ concentration

$A C=$ adjusted counts $/$ minute

$=$ gross counts - background counts - radon counts (alpha and ${ }^{239} \mathrm{Pu}$ )

The factor $Q$ is precalculated to save time and is evaluated as:

$$
Q=\frac{1.59 * 10^{-11 * 100}}{A * \text { Sample Vol * No. Days *\%E }}
$$

where: sample volume is previously entered ( $\mathrm{ft}^{3} /$ day)

No. days is the exposure time (days)

$\% E=\%$ efficiency for each channel

$A=$ absorption factor

$=0.8$ for beta

$=0.7$ for alpha and $239 \mathrm{pu}$ given: there are $2.2 \times 10^{6} \mathrm{~d} / \mathrm{m} / \mu \mathrm{Ci}$ or $\frac{4.505 \times 10^{-7} \mu \mathrm{Ci}}{\mathrm{d} / \mathrm{m}}$
there are $3.53 \times 10^{-5} \mathrm{ft}^{3} / \mathrm{cc}$ 
The information passed between the filter examination files is stored in the data registers as defined in Table 3. Many of these registers experience multiple use (e.g., the over-limit data to be recorded will temporarily replace data in registers $\emptyset-3)$.

The program checks the timer reading after every sample. If the timer does not equal 200 (assumed 0.01 min increments) the program prints an error message and aborts. Please refer to Figures 16 through 19 for flow diagrams of the filter examination program, Figures 20 and 21 for sample printouts from the exam.

In Figure 21, sample no. 4 has been flagged as over-limit beta, and sample no. 7 for both alpha and ${ }^{239} \mathrm{Pu}$. These also are printed out on the alert list after all counting has been completed.

Using the alert levels and the calculated concentrations for each, the percent over-limit values are calculated:

$$
\% O L=\frac{\text { concentration }}{\text { alert level }}-1 * 100 \%
$$

The current sample number and the three values for beta, alpha, and ${ }^{239} \mathrm{Pu}$ are then stored in the data registers $\emptyset$ through 3 to be recorded onto a cassette file.

One hundred files which hold four data items each (files -3 through -102) are used to store over-limit data as it becomes known by the filter examination program. A file counter, kept in register 7 , points to the next available file to store data. When data are stored, the pointer is decremented by 1 . The filter examination program always sets the pointer to -3 to start a new run. When the filter examination program is done, a message is printed and the alert list program is called to list a summary of the alerted data on the thermal printer. 
TABLE 3. Register Use for Data Passage in Filter Examination

\begin{tabular}{cll} 
Register & & \multicolumn{1}{c}{ Use } \\
\cline { 1 - 1 } A & & Current sample counter \\
B & & Internal control loop \\
C & & Internal control loop \\
D & & Internal control loop \\
E & Temporary data \\
F & Total no. of samples in \\
& run \\
G & Internal control loop \\
H & Internal control loop \\
I & Temporary data \\
J & Temporary data
\end{tabular}

\begin{tabular}{|c|c|}
\hline Register & Use \\
\hline$\emptyset$ & Unused \\
\hline 1 & Raw data sample no. \\
\hline 2 & Raw data timer count \\
\hline 3 & $\begin{array}{l}\text { Raw data Radon count, } \\
\text { net radon }\end{array}$ \\
\hline 4 & $\begin{array}{l}\text { Raw data }{ }^{239} \mathrm{Pu} \text { count, } \\
\text { net } 239_{\mathrm{Pu}}\end{array}$ \\
\hline 5 & $\begin{array}{l}\text { Raw data alpha count, } \\
\text { net alpha }\end{array}$ \\
\hline 6 & $\begin{array}{l}\text { Raw data beta count, } \\
\text { net beta }\end{array}$ \\
\hline 7 & $\begin{array}{l}\text { File counter for over- } \\
\text { limit samples }\end{array}$ \\
\hline 8 & $Q$ for beta \\
\hline 9 & Q for alpha \\
\hline 10 & $Q$ for ${ }^{239} p_{u}$ \\
\hline 11 & Sample volume in CFD \\
\hline 12 & Period \\
\hline 13 & Alert level for beta \\
\hline 14 & Alert level for alpha \\
\hline 15 & Alert level for ${ }^{239} \mathrm{Pu}$ \\
\hline 16 & Background for beta \\
\hline 17 & Background for alpha \\
\hline 18 & Background for ${ }^{239} \mathrm{Pu}$ \\
\hline 19 & Background for radon \\
\hline
\end{tabular}




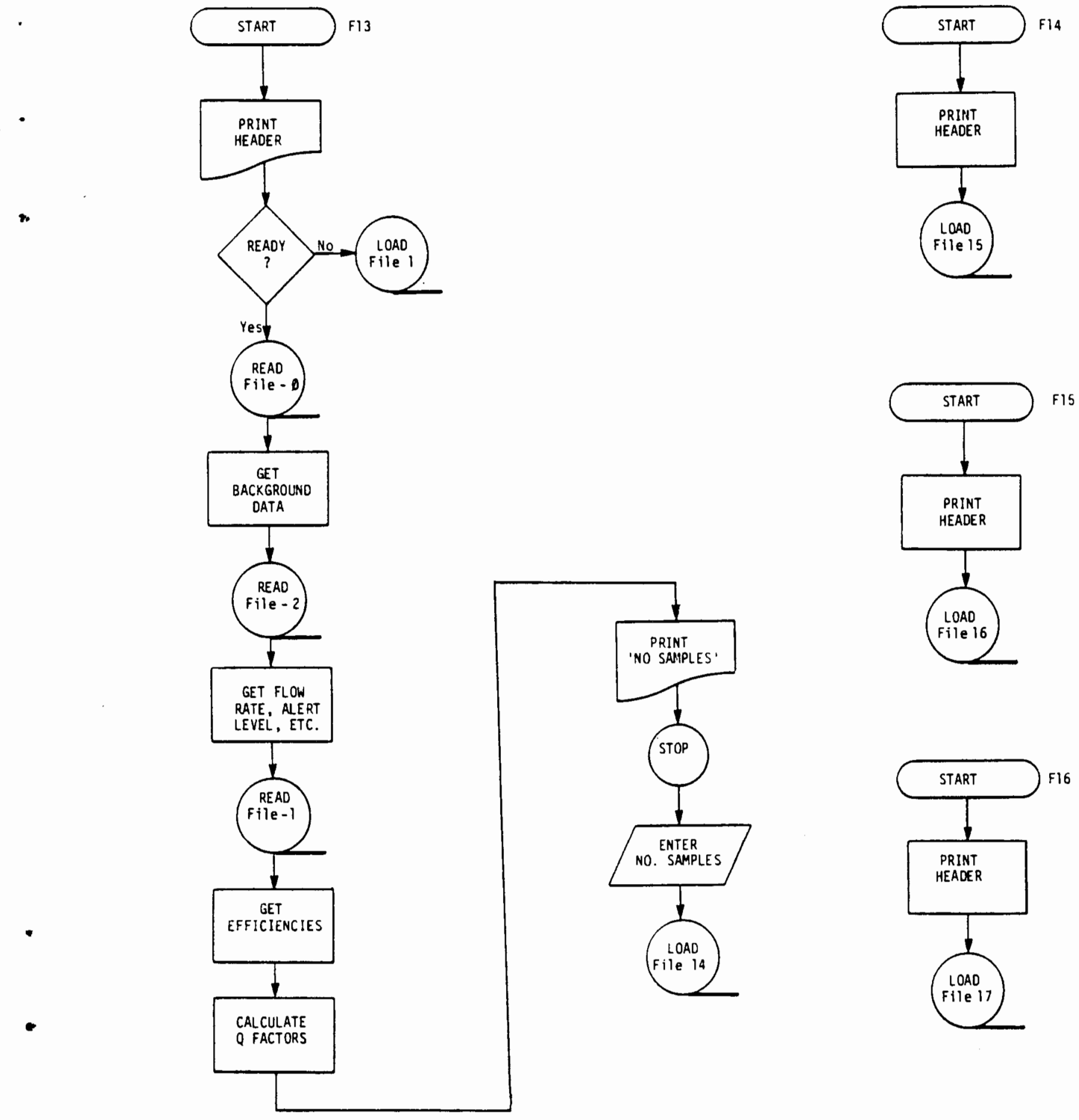

FIGURE 16. Files 13 through 16 - Filter Examination Program Flow Diagrams 

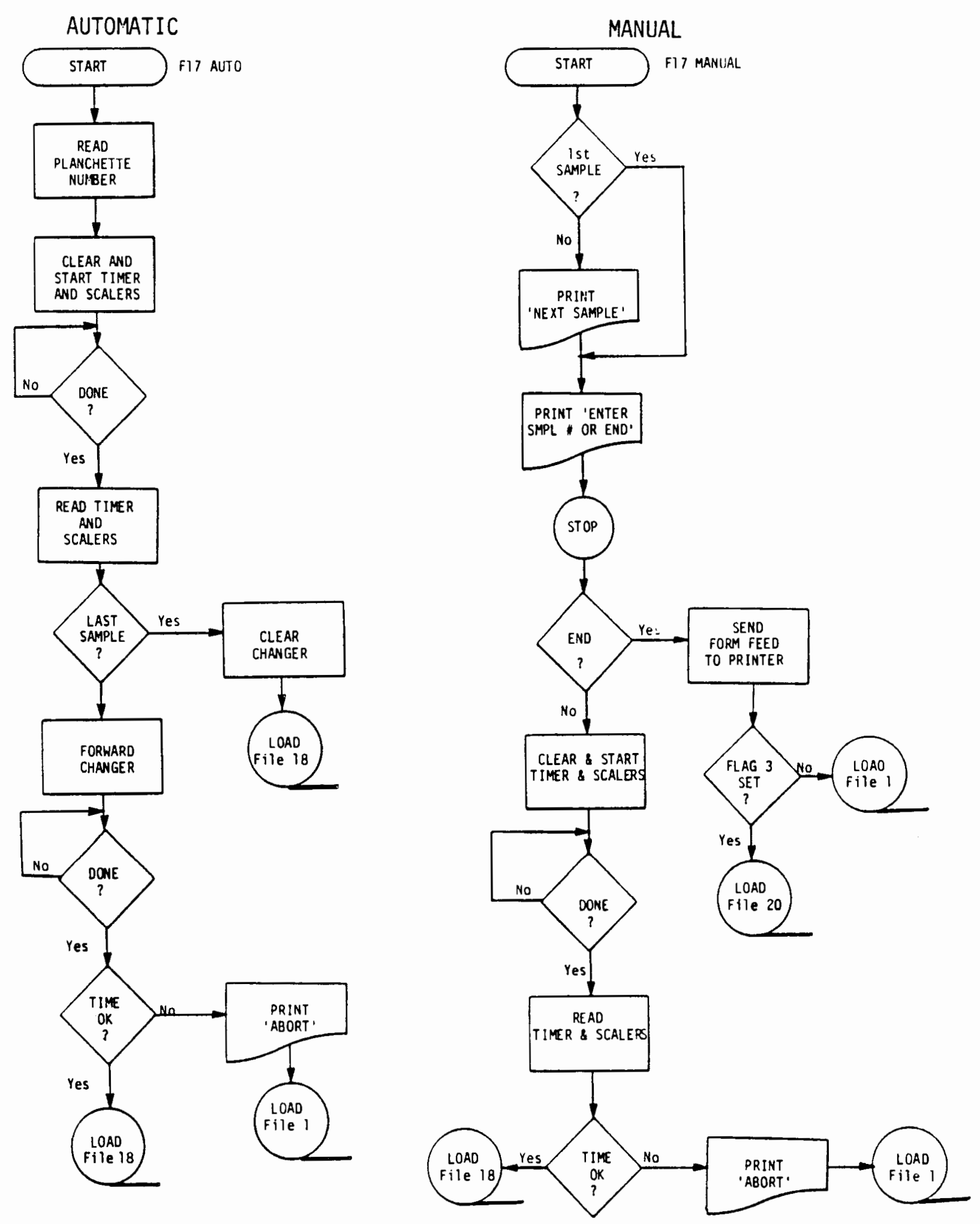

FIGURE 17. File 17 - Filter Examination Program Flow Diagram 

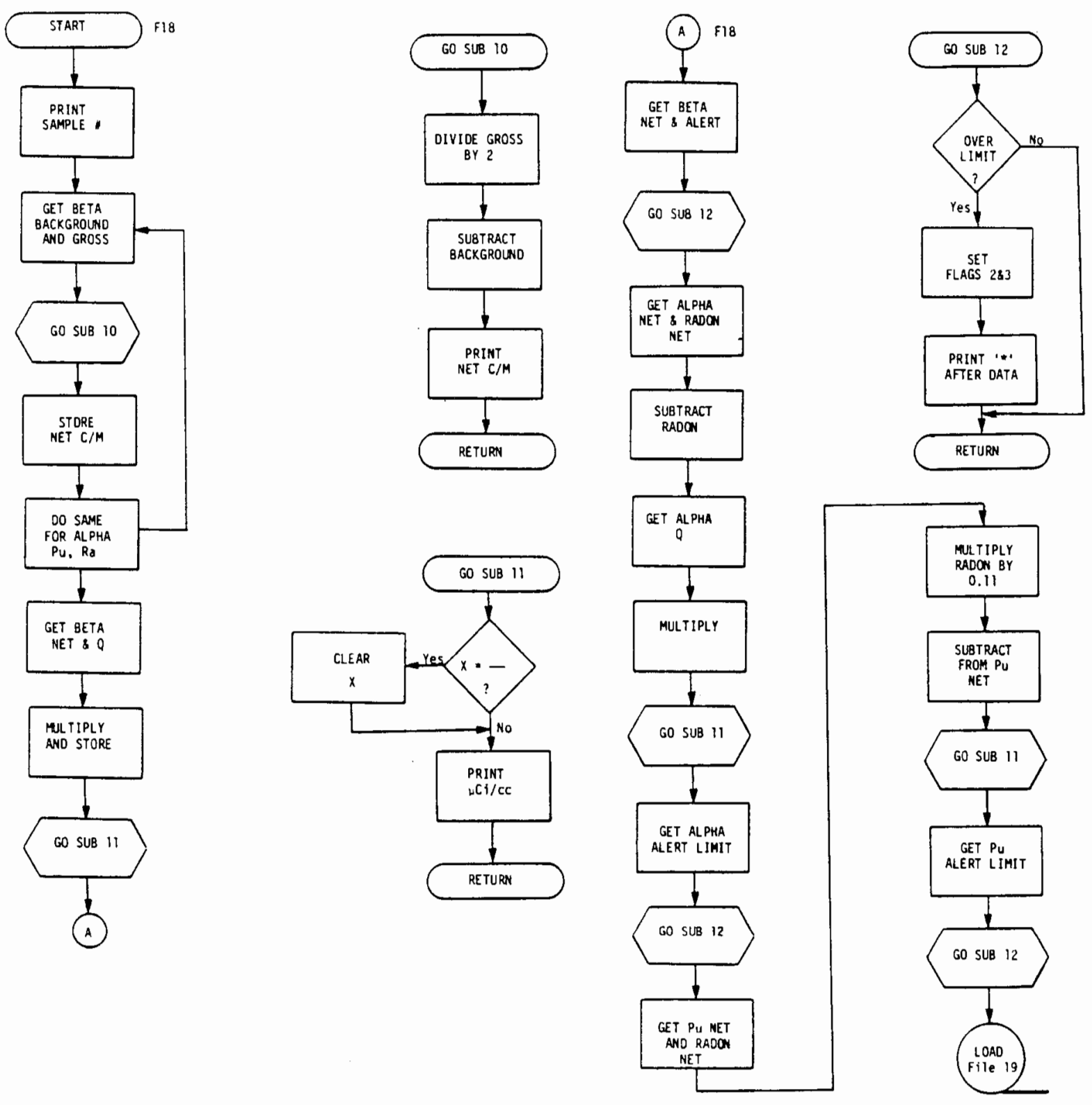

FIGURE 18. File 18 - Filter Examination Program Flow Diagram 


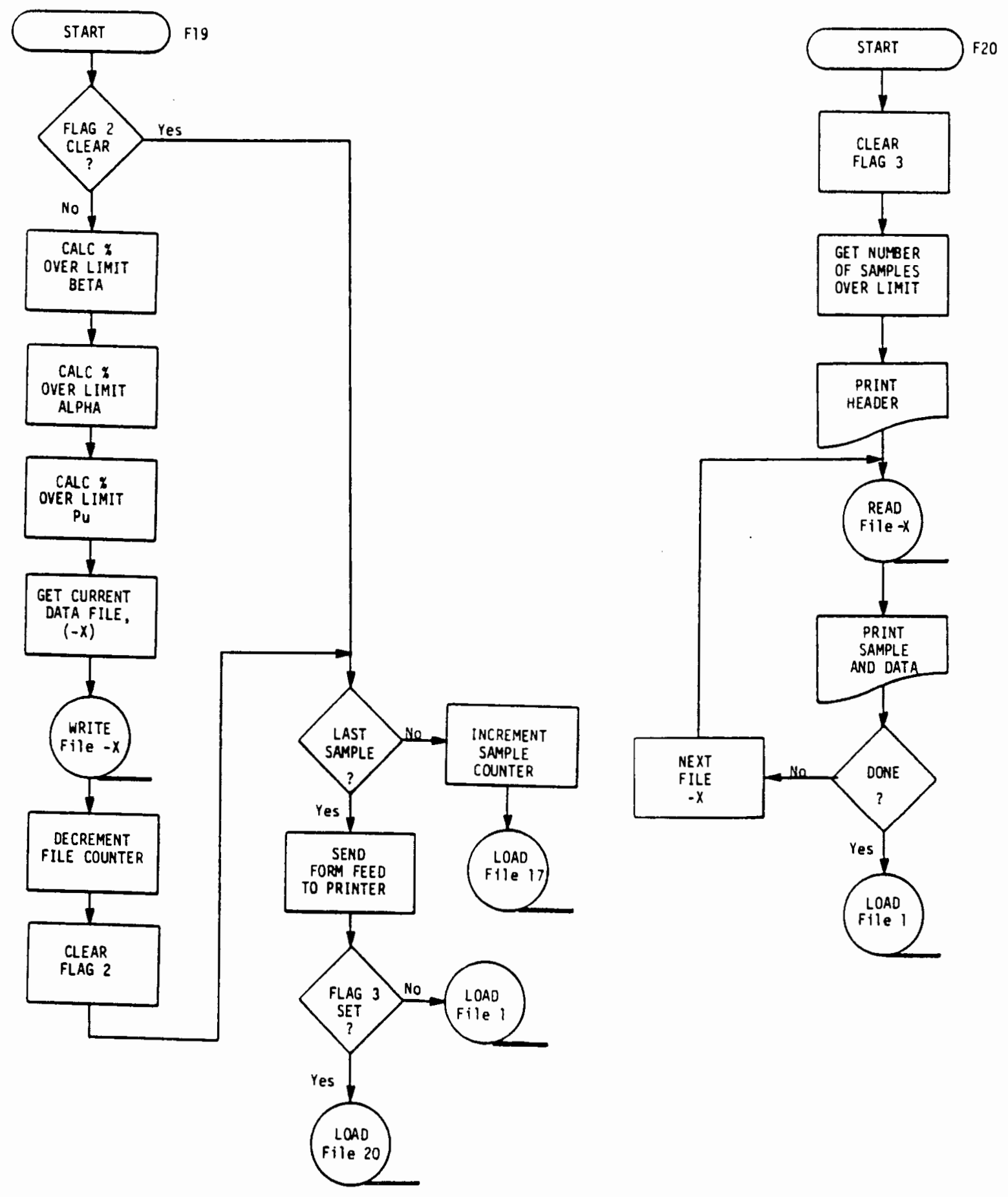

FIGURE 19. Files 19 and 20 - Filter Examination Program Flow Diagram 


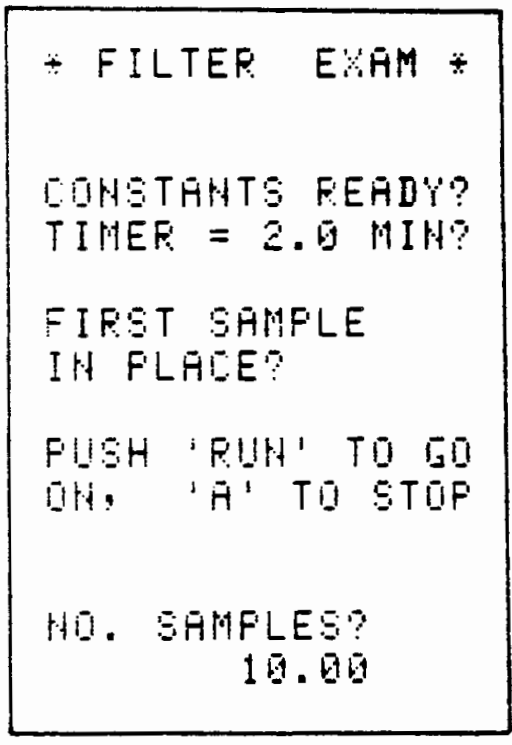

Printout from Either Auto or Manual Systems

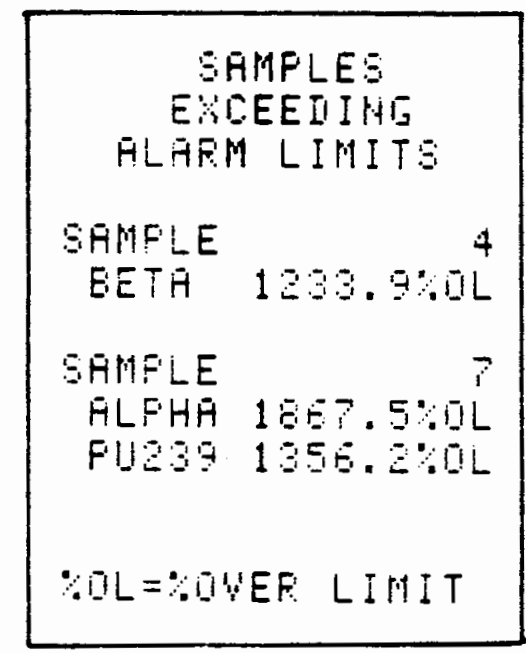

Alert List Auto/Manual

$$
\begin{aligned}
& \text { EHTEF SAHFLE\# } \\
& \text { DF } \because F \div \text { TO EHIJ } \\
& \text { FIIT HEAT BAIFLE } \\
& \text { IA HOLIEF } \\
& \text { EHTEF SAHFL \# } \\
& \text { GE: } \because F \div \text { TO EHI } \\
& 1: \\
& \text { Normal Printout from } \\
& \text { Manual System }
\end{aligned}
$$

TINEF: FEAIS

FILTEF EYAH FEORTED

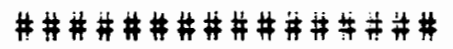

Timer Error

Auto/Manual

FIGURE 20. Sample Printouts from Filter Examination Program 
DATE

SHIET

AUTO-MANUAL

RM INITIALS

COMMENTS

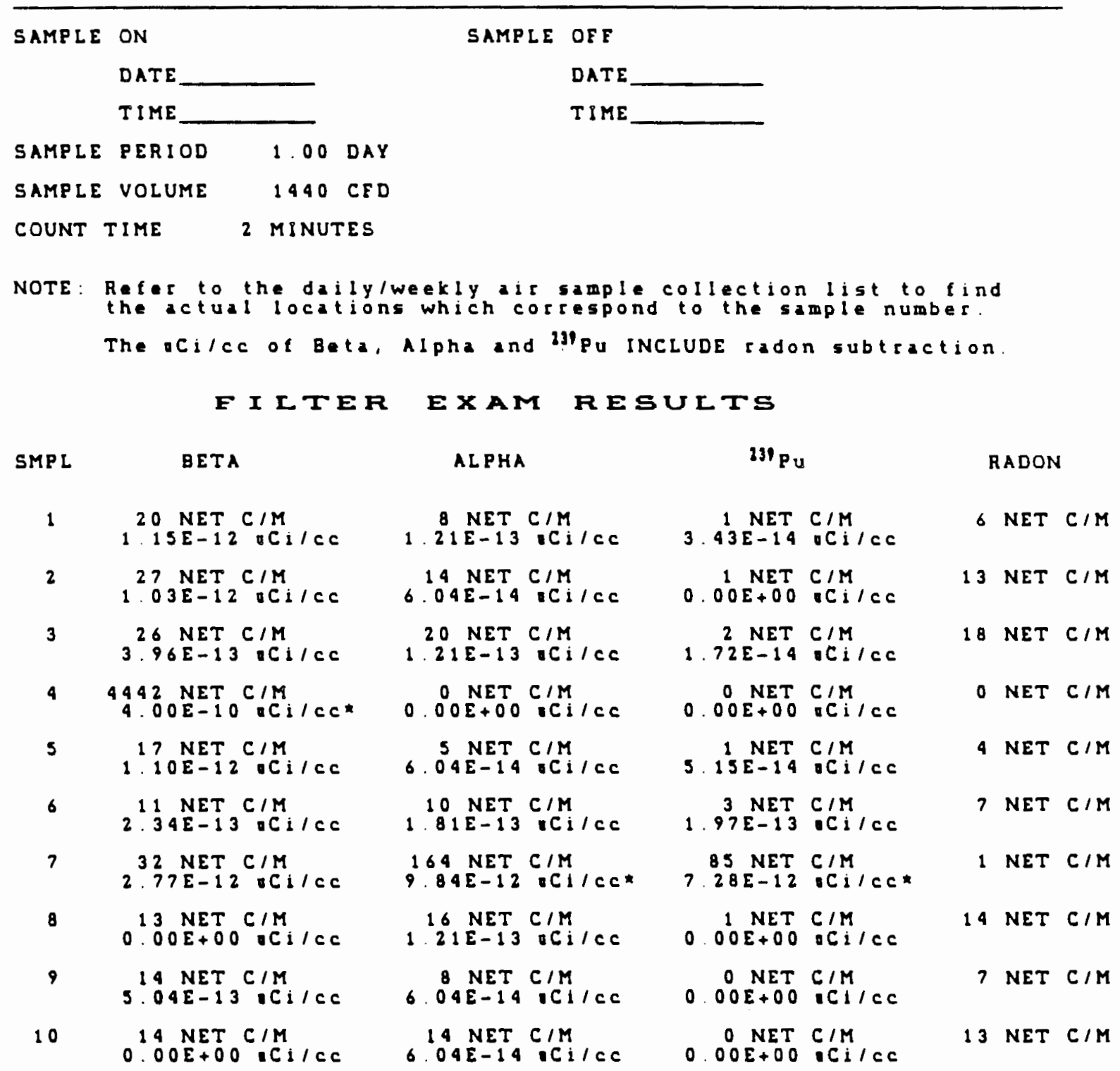

FIGURE 21. Printout of Filter Examination Program Results 


\section{ALERT LIST PROGRAM}

The alert list program resides on cassette file 20 and is loaded to run by the filter examination program. This program reads the data stored in cassette files and prints a summary of the samples which exceeded the alert levels.

When called, the last file minus one is left in data register 7 . This is used to set up a loop to read the cassette files ( -3 through $27-1)$ and 1 ist the over-limit data. The sample no. and the percent over-limit data is printed. See Figure 20, alert 1ist. Non-over-limit data is not printed. When the program finishes, the function select program is loaded. Note: once the filter examination is restarted, the data stored in the cassette files is over-written. 


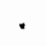




\section{OPERATING PROCEDURES}

Although the functions of this system may be selected in any order, the normal procedure is to (1) run the background test program, (2) the chi-squared test program, and (3) the filter examination test program.

GENERAL

A few conventions should be explained prior to starting any tests. Most of these will concern the calculator itself. This document does not discuss the settings for the single-channel analyzers or the power supply for the detector. However, other hardware settings are discussed briefly. Further information may be found in the manufacturer's literature referenced in Appendix A.

The four scalers and the timer, TC 547P, can be set. Once initially set, only the timer and the radon-channel single-channel analyzer should ever need to be changed. All four scalers are set identically. Use Table 4 to get the proper switch settings.

\section{TABLE 4. Scaler and Timer Switch Settings}

\begin{tabular}{llll}
\multicolumn{1}{c}{ Switch } & \multicolumn{1}{c}{ Scaler } & & \multicolumn{1}{c}{ Timer } \\
\cline { 1 - 1 } $\begin{array}{l}\text { Count/Stop } \\
\text { Mode }\end{array}$ & Count & & Count \\
Gate & Slave & & Master \\
Scaler/Timer & Scaler & Timer \\
0.01 min/0.1 sec & (either) & & 0.01 min \\
PRESET (upper) & OFF & & (to be set later) \\
PRESET (lower) & (not used) & (to be set later)
\end{tabular}

The planchette sample changer, PSC-1, is set to the "single-cycle" position on the front rotary switch. While running, the "START" switch will cause the changer to move blank planchettes until a numbered planchette is under the detector. The "RESET" switch is used to move all of the sample holders to the 
right stack and reposition holder no. 1 under the detector. A manual advance switch is provided on the interface unit in the electronics rack.

The HP9815A calculator (or desktop computer if you prefer) uses a cassette to store all of this system's programs and some data which is used by several programs. Since this requires that data will be written to the cassette, the RECORD switch on the cassette itself must be enabled (right position). This makes the cassette vulnerable to being over-written if the calculator is carelessly used. Although a backup cassette will probably exist, it is extremely important to either remove the cassette (and store properly) when running the calculator by itself, or to not use any of the cassette function keys (five keys at the upper lefthand side of the keyboard).

The thermal sensitive paper used in the printer can be replaced easily by following the diagram exposed when the cover immediately behind the printer is lifted.

When running the system programs, you will be asked to select lettered keys or enter numbers. The lettered keys are the lower left group of pale lettered keys on the calculator. When selecting an option by these, depress only one key one time. If an undefined key is pushed, an error message is printed. When entering numbers, the RUN KEY MUST BE DEPRESSED TO RESTART THE PROGRAM. The decimal may or may not be entered as needed. Very large or very small values may be entered using the scientific notation. Five examples are shown. For each, the display format must be changed to see the value properly:

1.) Enter 23000
a) to reformat: (gold key) (+-) (0)
b) to enter: (2) (3) (0) (0) (0) (RUN/STOP)

2.) Enter -42
b) to enter:
(4)
(2) $(+-)$
(RUN/STOP)

3.) Enter 61.092
a) to reformat: (gold key) (t-) (3)
b) to enter:
(6)
(1) $($.
(0) $(9)$
(9) (2) (RUN/STOP) 
4.) Enter $3 \times 10^{13}$
a) to reformat: (gold key) (E EX) (2)
b) to enter: (3) (E EX) (1) (3) (RUN/STOP)

5.) Enter $4.5 \times 10^{-11}$
b) to enter:
(4) (.) (5) (E EX) (+-)
(1) (1) (RUN/STOP)

While running the programs, you normally do not need to change the display format before entering the value, but the changes are shown here to help you become familiar with the calculator.

START-UP PROCEDURE

When this system is new to the operator or if the power has been off to the hardware (other than the calculator), consult the "general" section of this chapter.

When the air filter examination system is to be started, the power will normally be applied to the calculator last (i.e., start the other hardware, check switches, and load filters first.) To activate the programs, the RUN/AUTO-START/PRGM switch at the lower right of the calculator key should be set to AUTO START. Then, the power is turned on (the rocker switch at the front-right position to the "1" position.) When this is done, the calculator begins by running the header (auto-start) program and then the function select program. At this point the function select program will have printed a list of options.

\section{FUNCTION SELECT PROGRAM}

The function select program is run automatically when start-up is done via the auto-start. It is also the return point from any function whether it completed or found an error. The options that may be selected by this program are:

$$
\text { A - instructions ( a brief note referring to this document) }
$$


$B$ - initialize parameters (a routine used to enter data to be used in the calibration routines and filter examinations)

C - background test (for background radiation calibration)

D - chi-squared test (for calibration and detector quality analysis)

$E$ - filter examination (to examine a set of sample filters)

Each of these options may be selected by pushing the corresponding lettered key of the calculator. The " 0 " function may be used to stop the entire system. To recover from this point, the start-up procedure can be repeated.

\section{INITIALIZE PARAMETERS PROGRAM}

When the initialize parameters option, " $B$ ", is selected, a list of further options is listed:

$$
\begin{aligned}
& \text { A - To change } \\
& \text { B - To list } \\
& \text { O - To stop }
\end{aligned}
$$

Again, pressing one of the identified lettered keys starts the desired sequence. Starting with " 0 ", this option simply terminates this program and returns to the function select program. Option " $B$ " is entered to list the nine parameters as they presently reside in memory (see Figure 7 for examples.) Then, the above three options are repeated. Any of these parameters may be changed or initialized by entering the " $A$ " option. Here, an abbreviated list of the parameters is printed and the lettered keys are reprogrammed to select any of the nine parameters (key " 0 " again means stop but here it will only return to the above three options.) To enter a value, first press the corresponding lettered key. When asked to enter the value, enter it and press (RUN) to resume the program (see "general" section). The parameters may be entered in any order or re-entered as often as desired. 
BACKGROUND TEST PROGRAM

When this test is called as option " $C$ " the operator will be given two chances to see that: first, the proper filter (blank) is in place, and second, the time value matches the timer setting on the TC547P Timer. In both events, the RUN/STOP key may be pushed to proceed, or the A key may be pushed to abort this test and return to the function select program.

Setting the TC547P timer is done as follows: (1) be sure the $0.01 \mathrm{~min} / 0.1 \mathrm{sec}$ toggle switch is in the 0.01 -min position, (2) use the PRESET switches to set the time. (For example: 10 minutes $=1 \times 10^{3}$ hundredths thus the upper switch is set to 1 and the lower switch to the $10^{3}$ position.)

If the timer reading at the end of the test does not match the value set in memory, the true timer value is used to calculate the background radiation rates and the time in memory is changed. Thus, the data is still useful.

A summary of the test results is printed, and the data is stored on cassette for later use. The function select program is called when finished.

\section{CHI-SQUARED TEST PROGRAM}

When this program is called via option " $D$ ", the operator is given three chances to abort. First, the operator is asked to check the sample. Second, he is told to change the setting of the single-channel analyzer for the radon channel. Third, he is asked to verify the run time expected against the TC547P timer (see previous section for setting the timer.) In either case, the operator may continue by pressing the RUN/STOP key or he may abort the run by pressing "A".

The program, if allowed to continue, then reads the sample twenty times, printing the raw count data for each reading on the thermal printer. (This is done to keep the operator informed of the progress. All data/information printed on the thermal printer may be discarded.) Next, a summary is printed and the acceptability test is run. If all channels are found acceptable or conditionally acceptable, the final results are printed on the external printer for permanent filing. Resulting data are stored on the cassette for use by the filter examination program. When completed, or a counter is found 
unacceptable, the program returns to function select after the operator is reminded to return the radon channel to its original setting.

\section{FILTER EXAMINATION PROGRAM}

When the filter examination program is called by the "E" option of the function select program, the operator is given one opportunity to abort the test. Then he is asked to enter the number of samples to be processed by this run. For each run, all of the following parameters must be the same: alert levels, sample volume, sample period. The program may be run more than once to process a stack of samples if the parameters need to be changed between known subsets of the stack.

For the filter examination program the TC547P timer must always be set for 2.0 minutes. The program checks the timer after every sample and will abort the remainder of the test if an error is detected (returns to the function select program.) See "Background Test" section for an explanation of setting the timer.

As each sample is examined, a report is printed. First, the sample number (the actual number of the planchette holder for the sample when using the automatic system) is printed. Then the adjusted net (true counts-background) and the concentrations (in micro curies per cubic centimeter) are 1 isted for each channel (only net counts for the radon channel.) See Figure 20 for a sample printout. Each concentration is compared to the alert levels entered. Overlimit values are flagged in the printout.

When the series of samples has been tested and if any over-limit samples were detected, the program calls the alert 1 ist program which summarizes the samples which exceeded the alert levels in memory. This is the conclusion of the test and the program returns to the function select routine. 
APPENDIX A

AIR FILTER EXAMINATION SYSTEM HARDWARE REFERENCES 
APPENDIX A

AIR FILTER EXAMINATION SYSTEM HARDWARE REFERENCES

Hewlett-Packard Co., "HP9815A Calculator Operating and Programming Manual"

Hewlett-Packard Co., "HP9815A Calculator 98134A General I/0 Interface Operating and Service Manual"

Hewlett-Packard Co., "HP9815A Calculator 98136A Serial I/0 Interface Operating and Service Manual"

Nuclear Enterprises Limited, "Westinghouse PSC System Information Manual" 

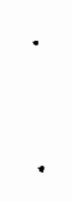

$\checkmark$

$-$

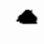


APPENDIX B

PROGRAM LISTINGS OF THE 21 FILES USED BY THE AIR FILTER EXAMINATION SYSTEM 


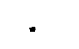


PROGRAM LISTINGS OF THE 21 FILES USED BY THE AIR FILTER EXAMINATION SYSTEM

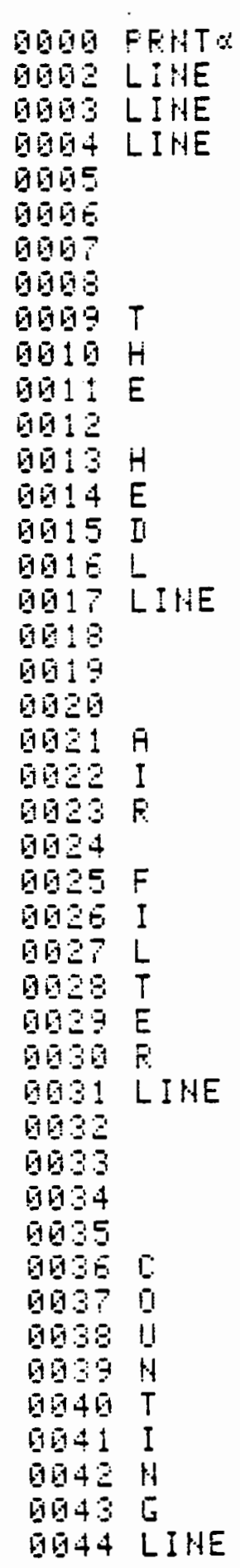

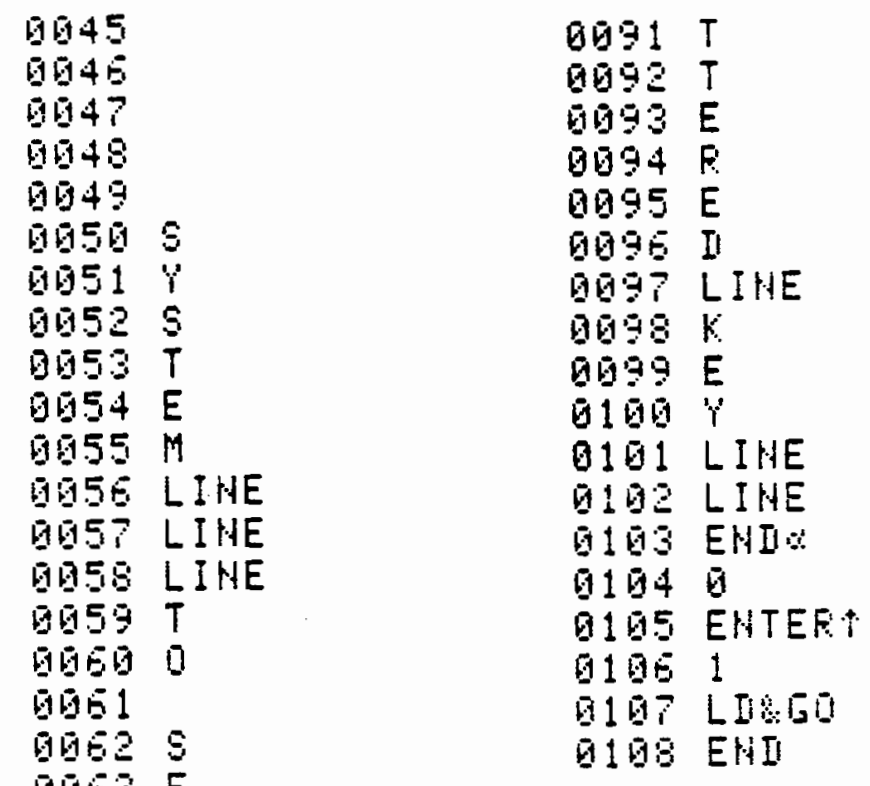

日6)

Q6日E $\mathrm{E}$

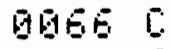

Q1967 T

D日es

6.68 $\mathrm{A}$

Q67G LIHE。

9671 $F$

1972 8

06730

6745

G675

G19 $\mathrm{B}$

6977 क

0678.

6479

西86 F

G6914

015825

$0103 \mathrm{H}$

0084 LIHE

9655 T

g日es $\mathrm{H}$

$0897 \mathrm{E}$

6989

.098 L

G日寸 $E$

File $\emptyset$ Header (Auto-Start) $(1 / 1)$ 


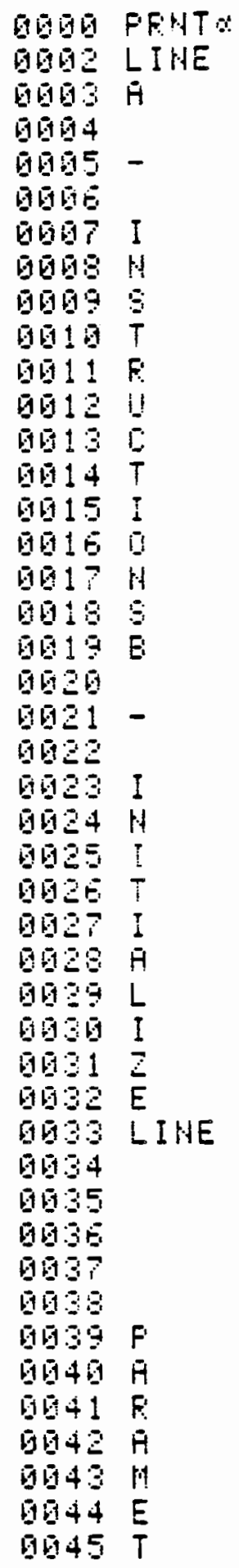

\begin{tabular}{|c|c|c|c|}
\hline 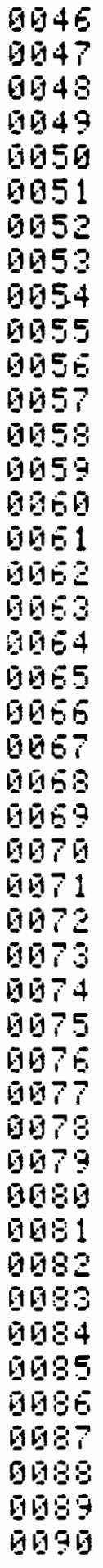 & 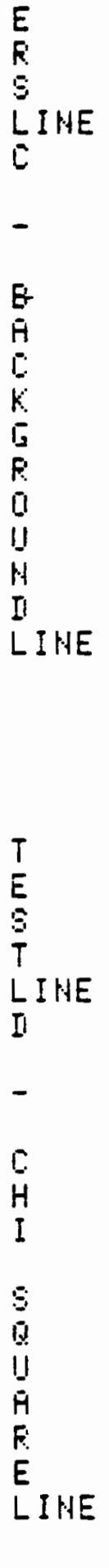 & 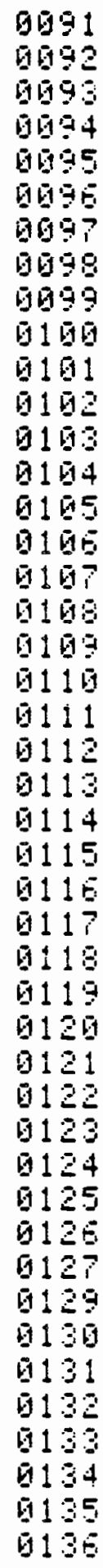 & 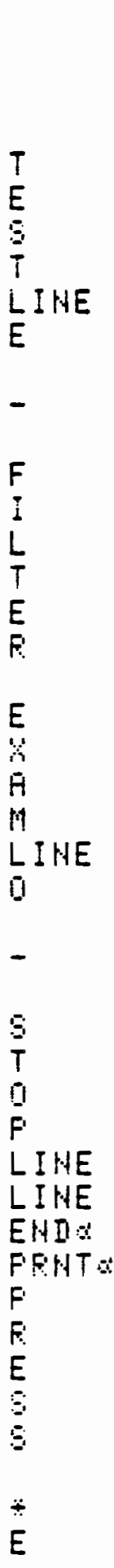 \\
\hline
\end{tabular}

File 1 Function Select (1/2) 

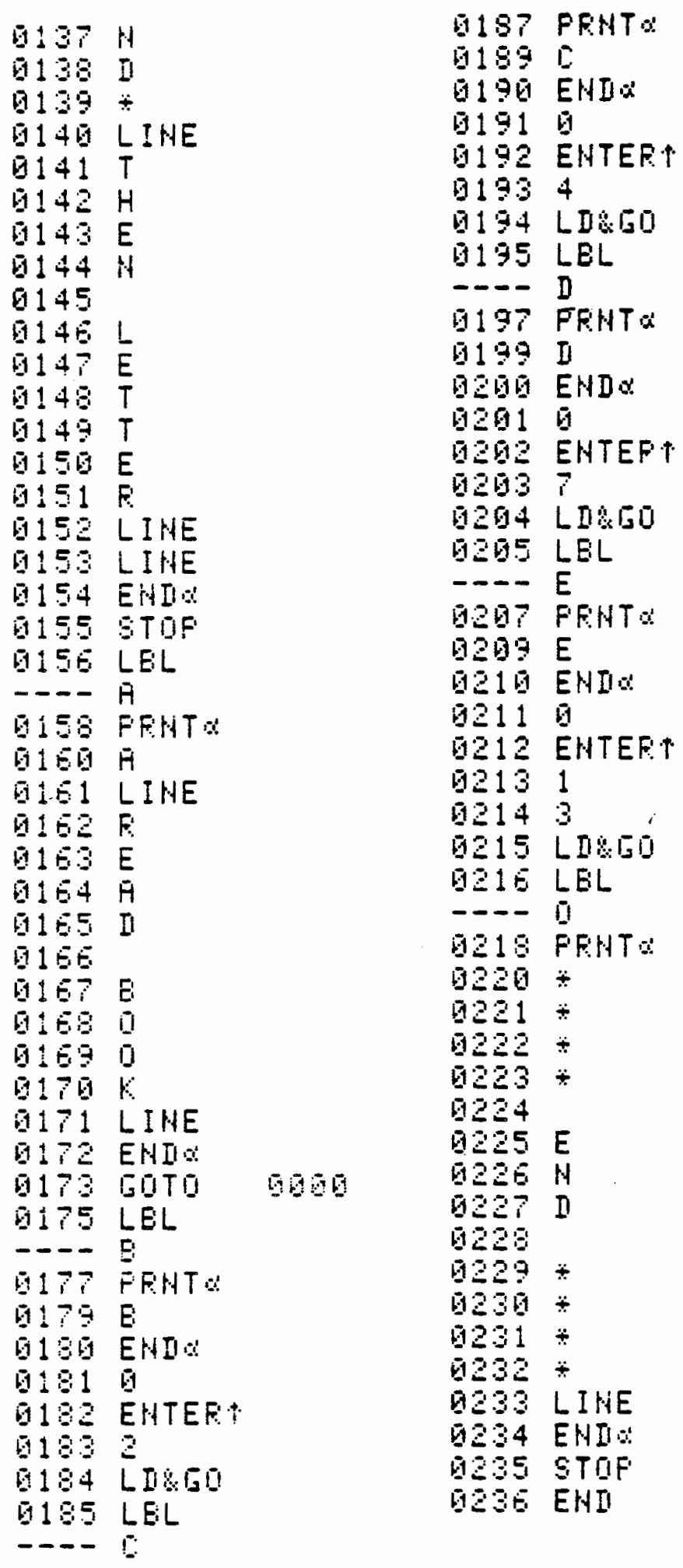

File 1 Function Select (2/2)

B. 3 


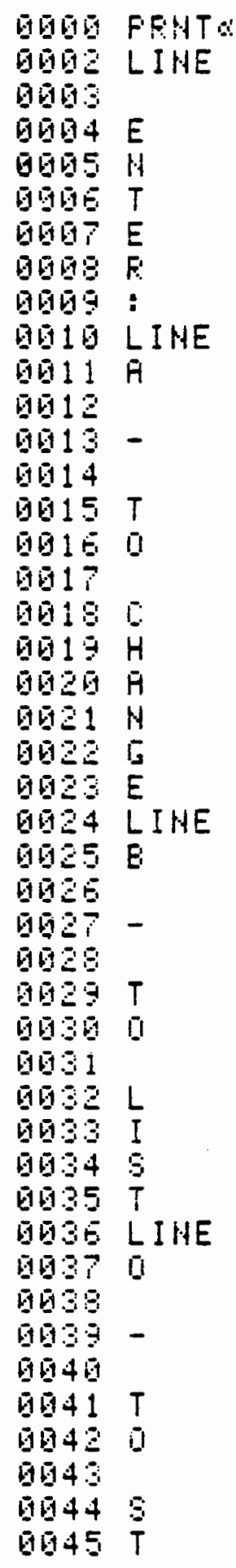

\begin{tabular}{|c|c|c|c|c|}
\hline 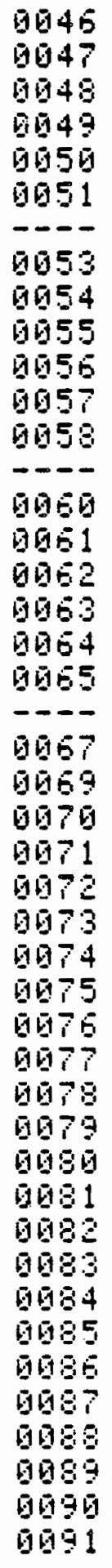 & 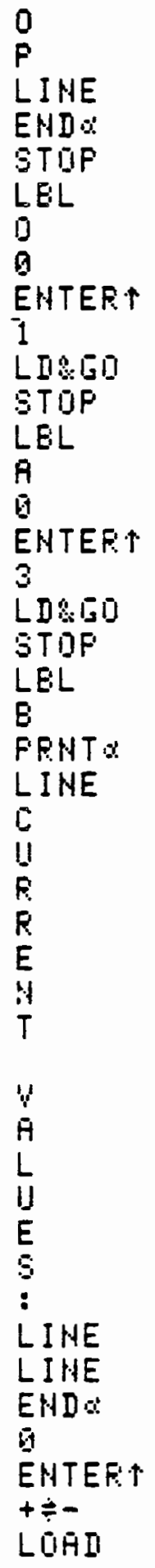 & 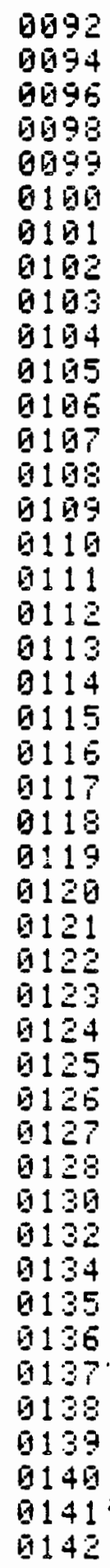 & 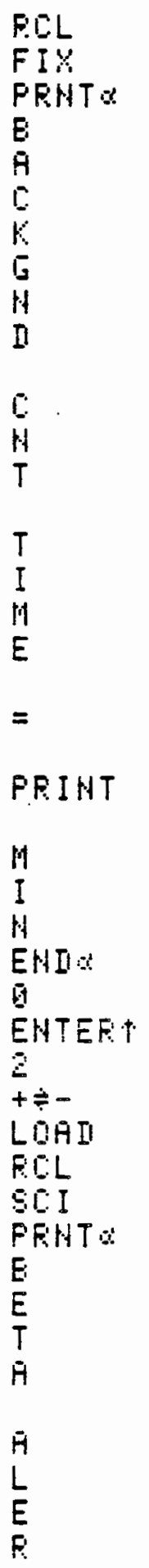 & $\begin{array}{l}\text { FGD } \\
1\end{array}$ \\
\hline
\end{tabular}

File 2 Initialize Parameters (1/3) 


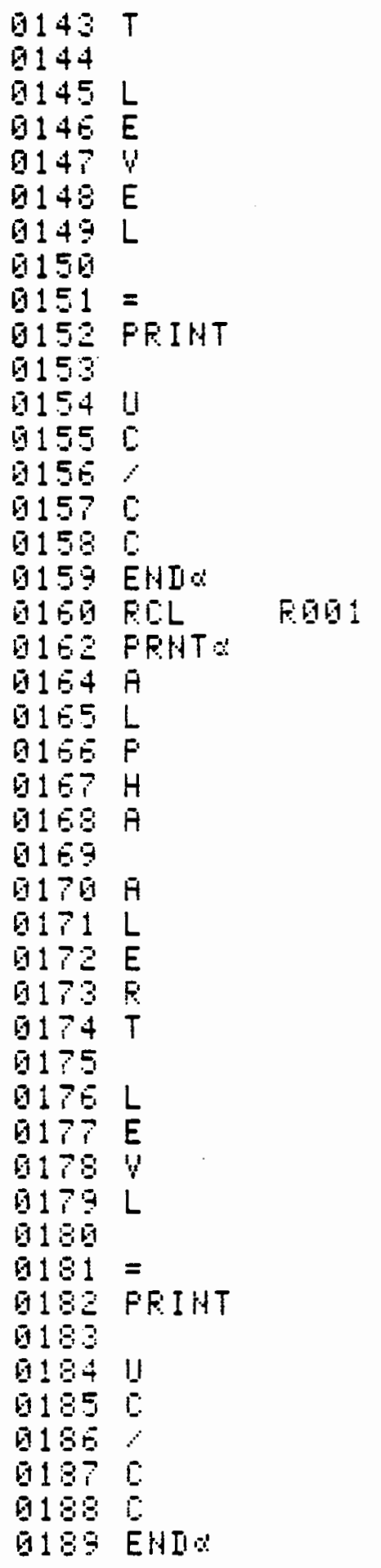

\begin{tabular}{|c|c|c|c|c|c|}
\hline 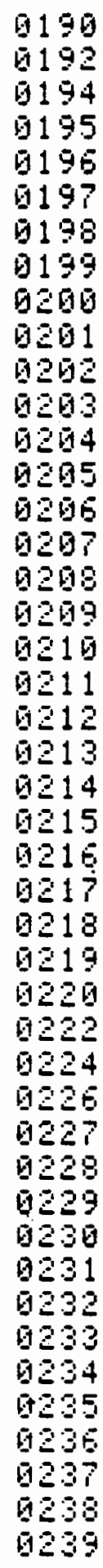 & 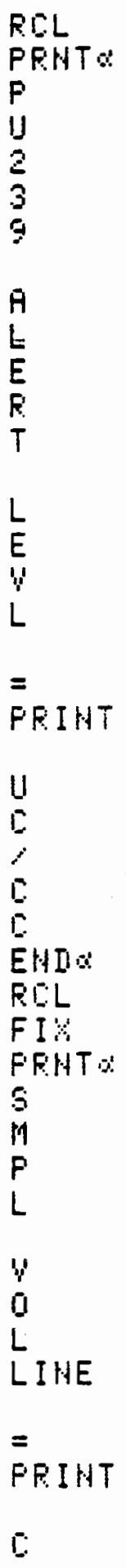 & $\begin{array}{l}\text { F003 } \\
2\end{array}$ & 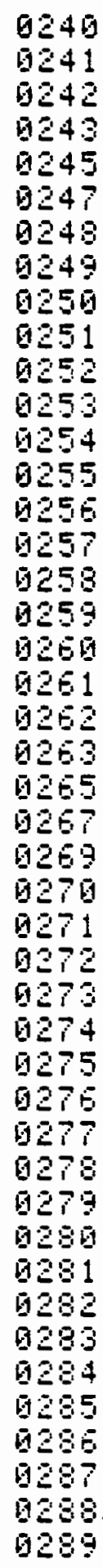 & 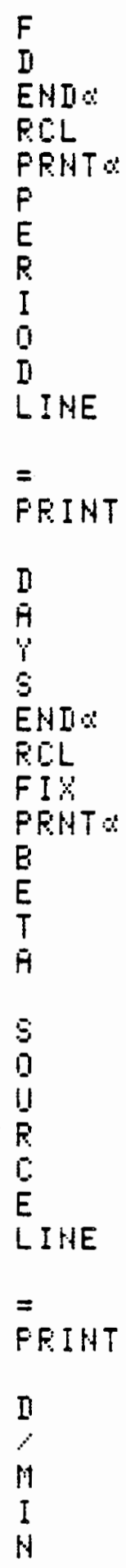 & $\begin{array}{l}\text { FOBS } \\
6\end{array}$ \\
\hline
\end{tabular}

File 2 Initialize Parameters (2/3)

B. 5 


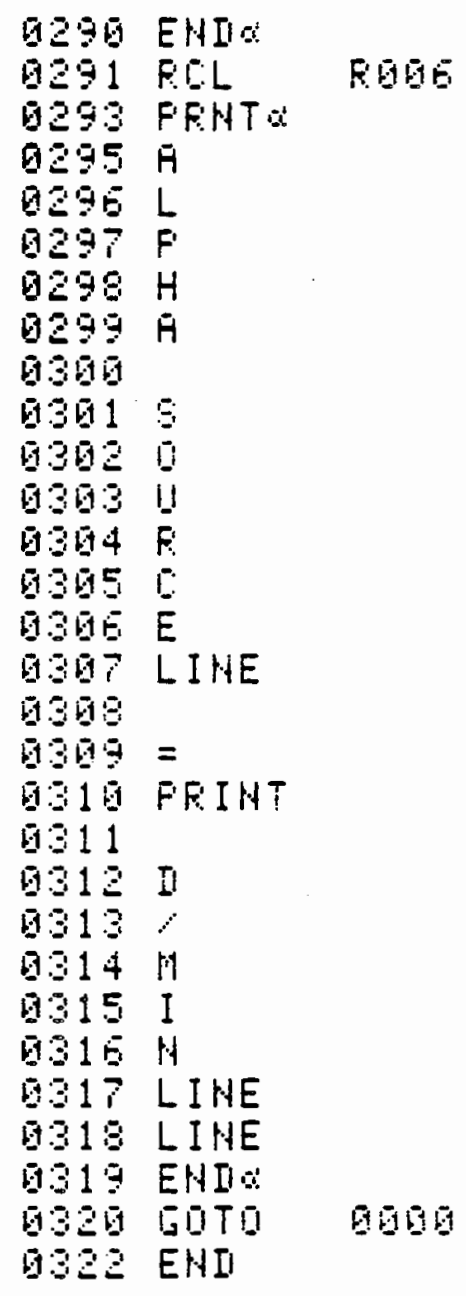

File 2 Initialize Parameters (3/3)

B. 6 


\begin{tabular}{|c|c|c|c|c|c|c|}
\hline 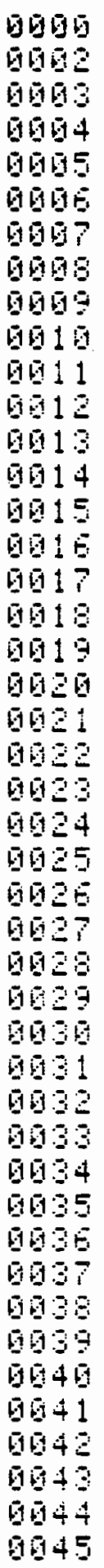 & 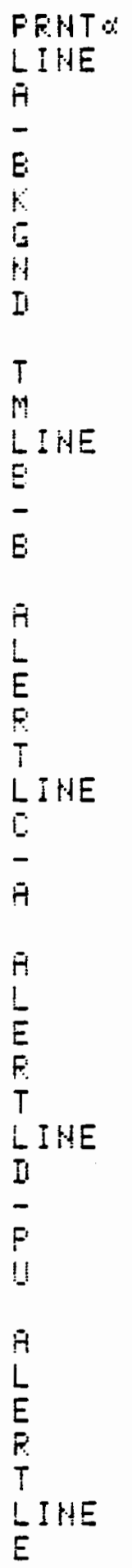 & 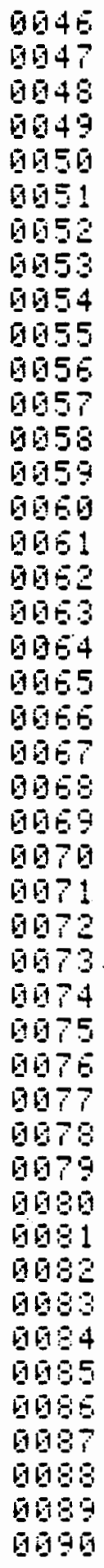 & 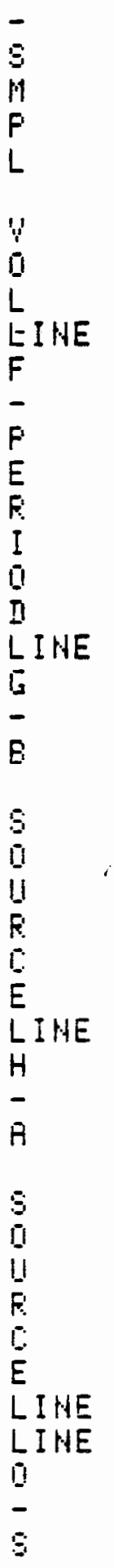 & 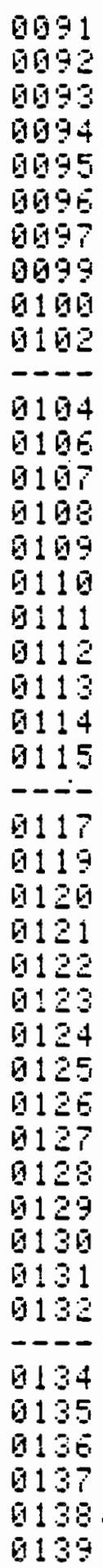 & 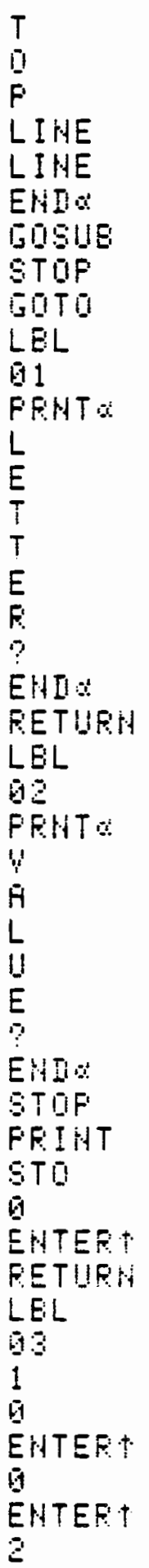 & $\begin{array}{l}451 \\
6599\end{array}$ \\
\hline
\end{tabular}

File 3 Initialize Parameters (1/2) 


\begin{tabular}{|c|c|c|c|c|c|c|c|c|}
\hline 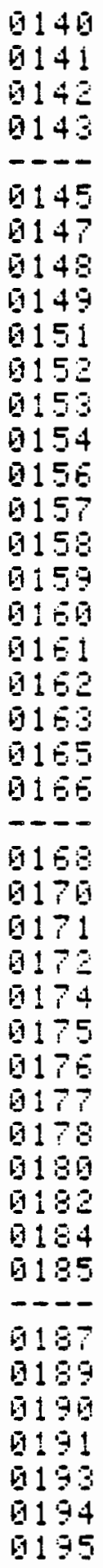 & 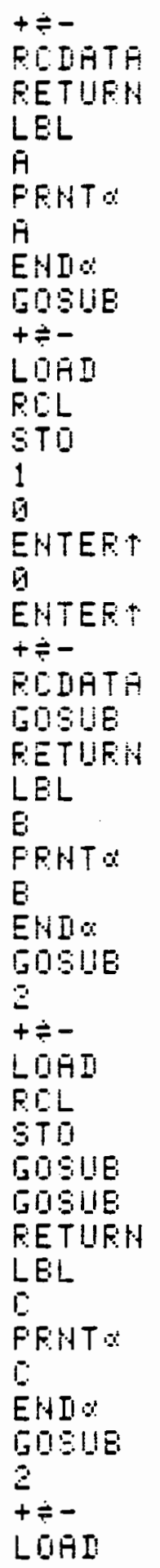 & $\begin{array}{l}8 \\
\text { Fog } \\
L 61\end{array}$ & 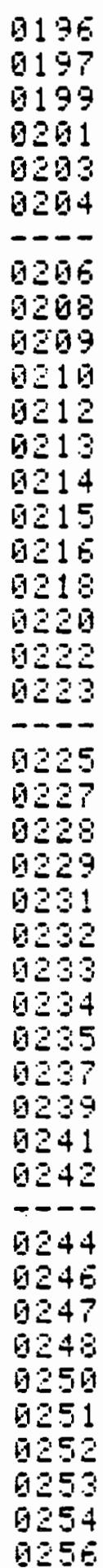 & 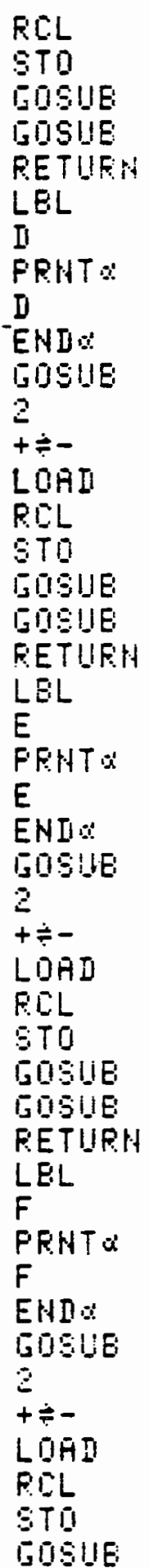 & $\begin{array}{l}1 \\
4632 \\
\text { L01 }\end{array}$ & 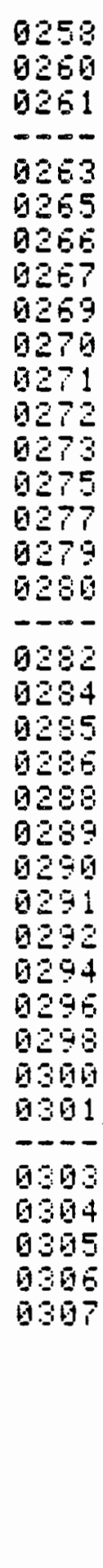 & 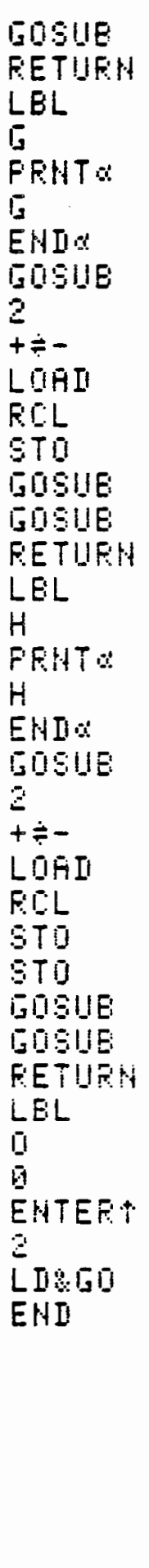 & $\begin{array}{l}1 \\
8000 \\
608 \\
61\end{array}$ \\
\hline
\end{tabular}

File 3 Initialize Parameters (2/2)

B. 8 


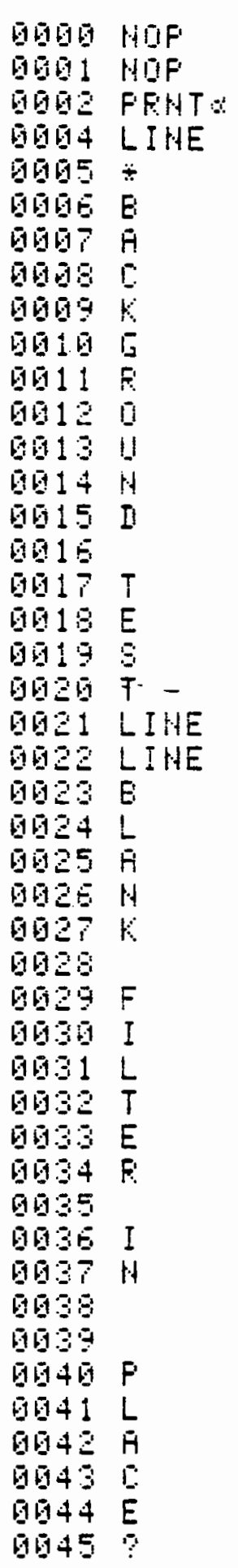

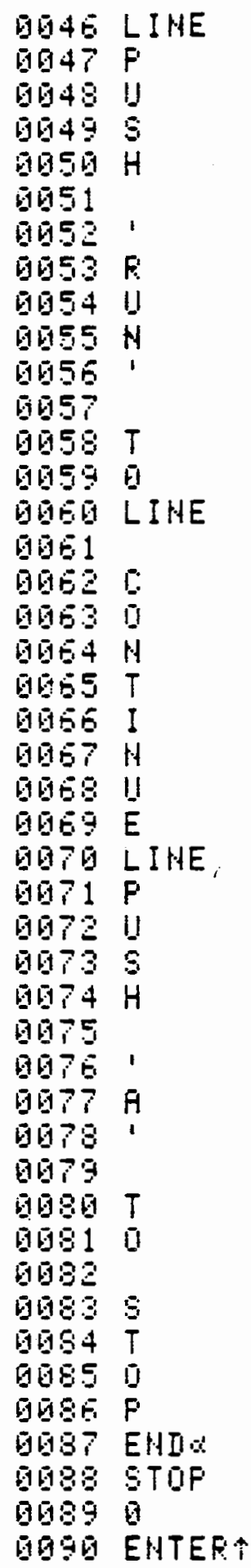

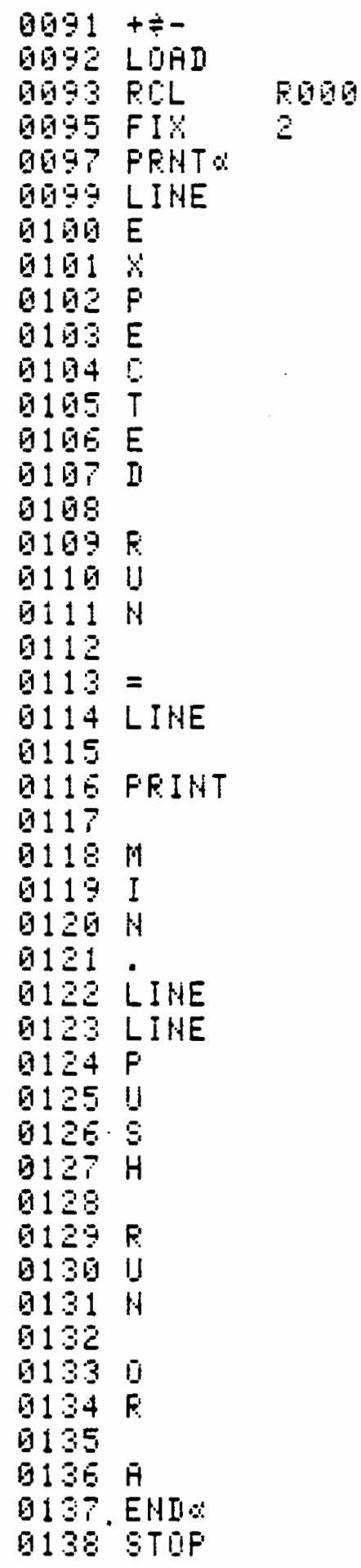

File 4 Background Test (1/2)

B. 9 


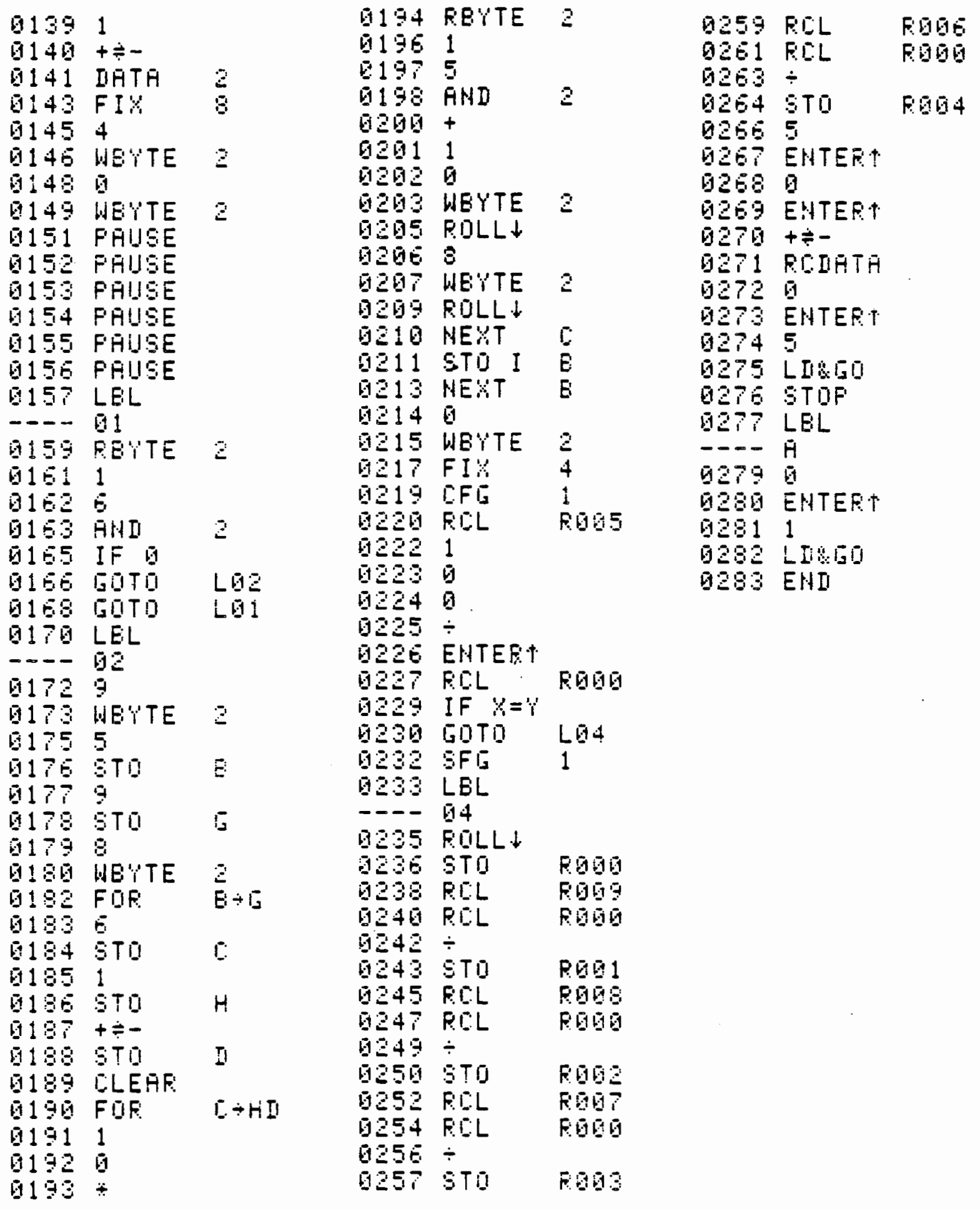

File 4 Background Test (2/2)

B. 10 


\begin{tabular}{|c|c|c|c|c|c|c|c|c|}
\hline 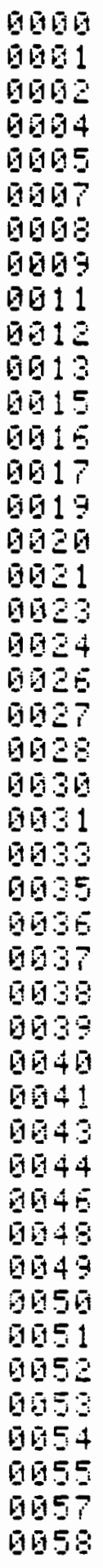 & 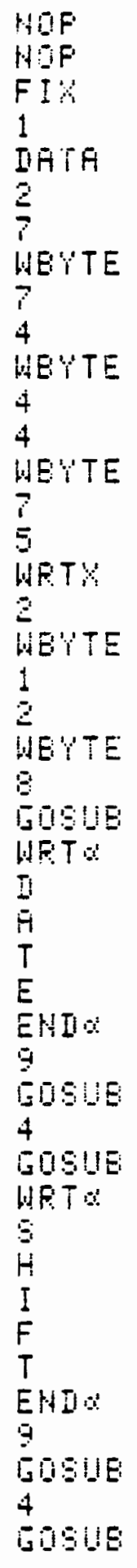 & $\begin{array}{l}3 \\
3 \\
3 \\
3 \\
3 \\
3 \\
481\end{array}$ & 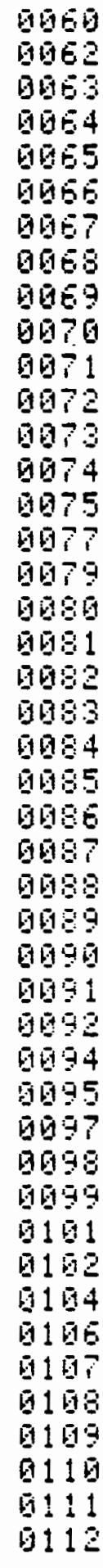 & 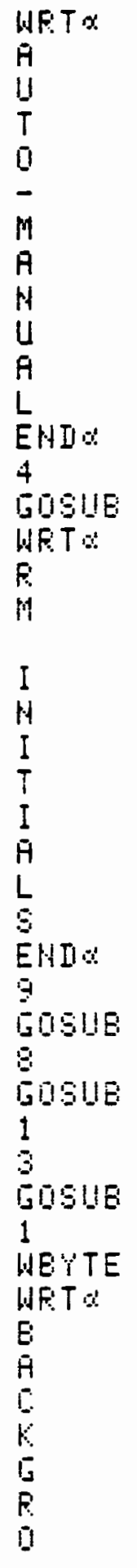 & $\begin{array}{l}\text { LE: } \\
48 t\end{array}$ & 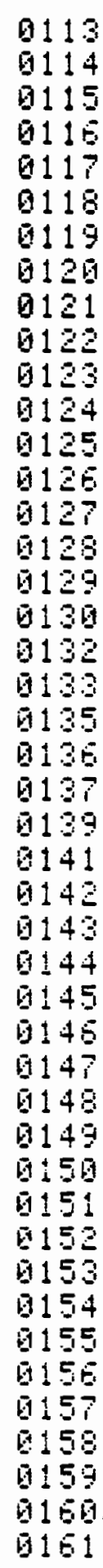 & 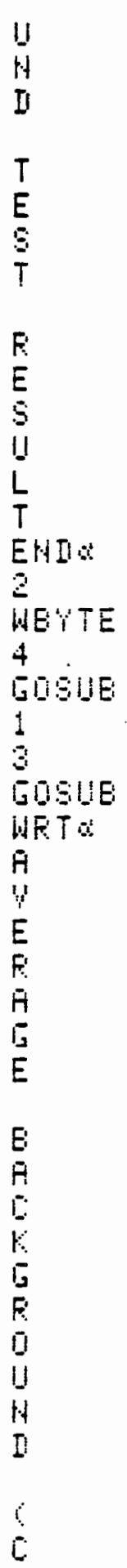 & $\begin{array}{l}3 \\
-91 \\
-62 \\
3\end{array}$ \\
\hline
\end{tabular}

File 5 Background Test (1/2) 


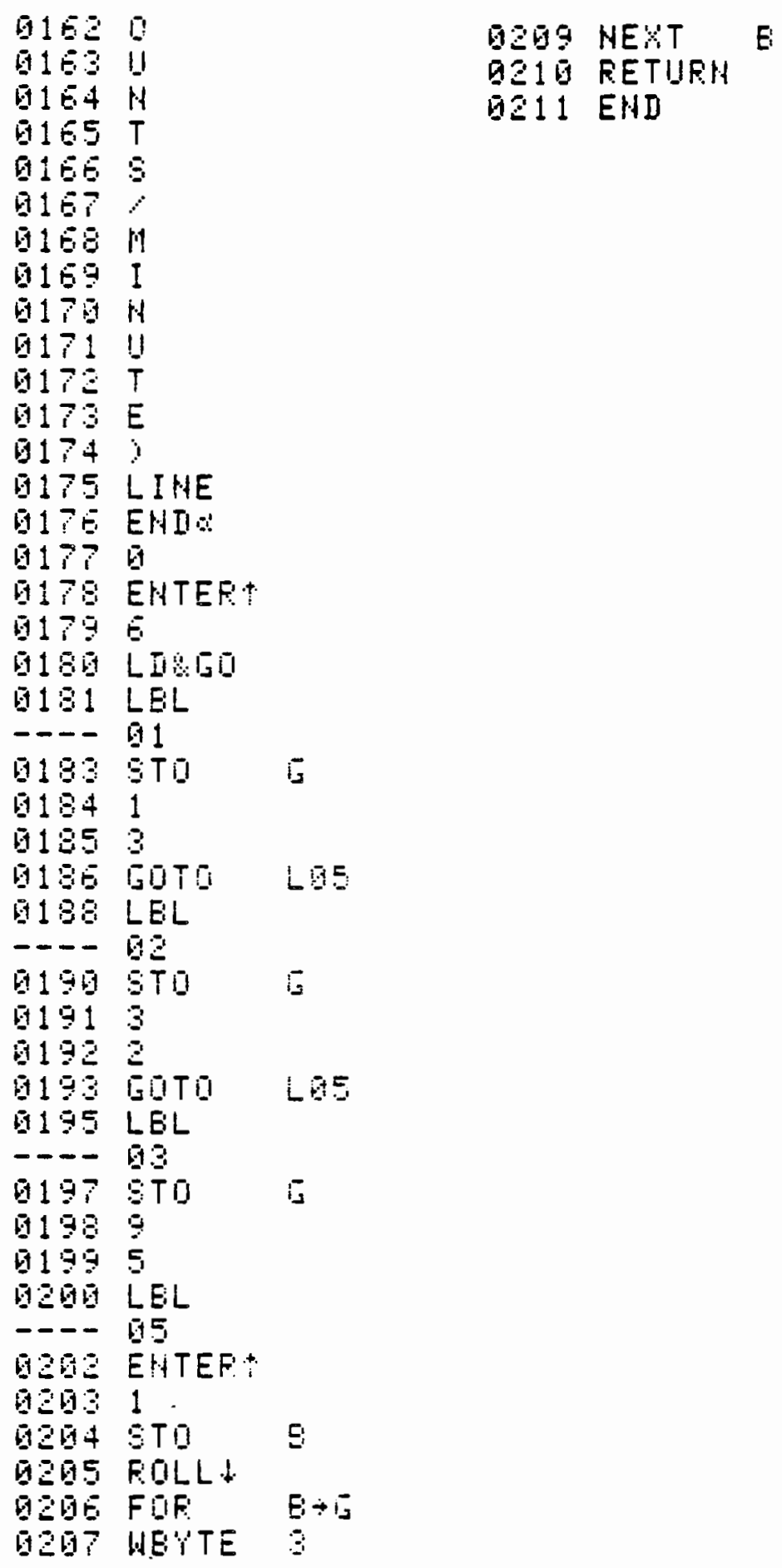

File 5 Background Test (2/2)

B. 12 


\begin{tabular}{|c|c|c|c|c|c|c|c|c|}
\hline 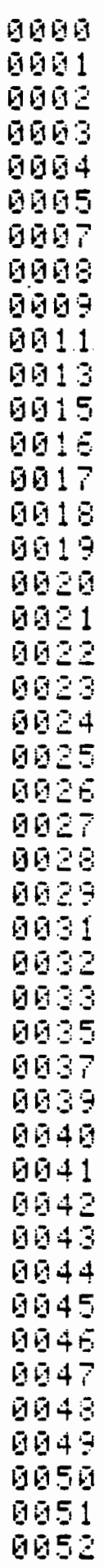 & $\begin{array}{l}\text { MOF } \\
\text { HOF } \\
\text { HUF } \\
1 \\
6 \\
F I E L I \\
1 \\
4 \\
G O S U E \\
\text { FUL } \\
\text { HFT }\end{array}$ & $\begin{array}{l}401 \\
402 \\
3\end{array}$ & 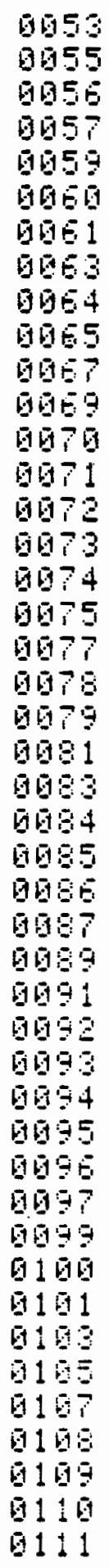 & 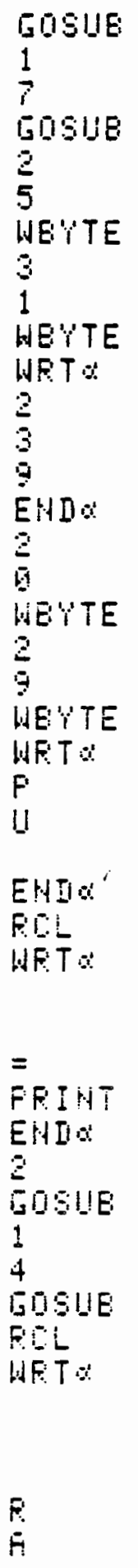 & $\begin{array}{l}162 \\
3 \\
3 \\
3\end{array}$ & 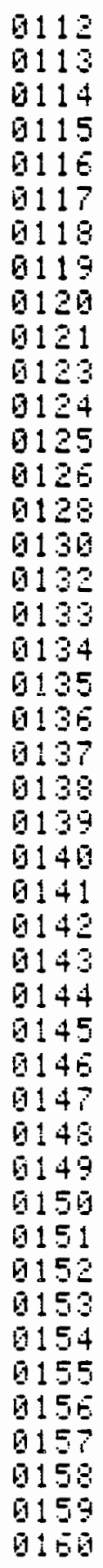 & 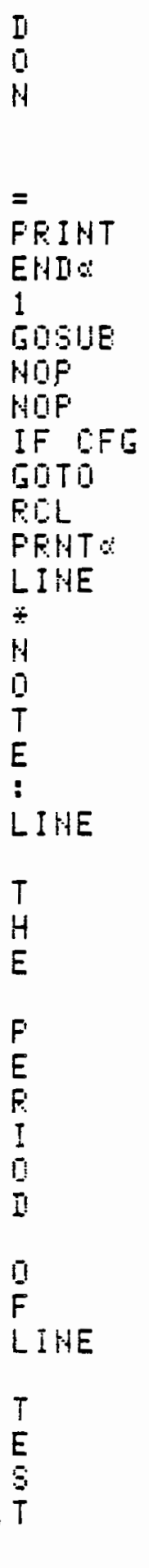 & $\begin{array}{l}\text { Lit } \\
1 \\
\text { Log }\end{array}$ \\
\hline
\end{tabular}

File 6 Background Test (1/2)

B. 13 

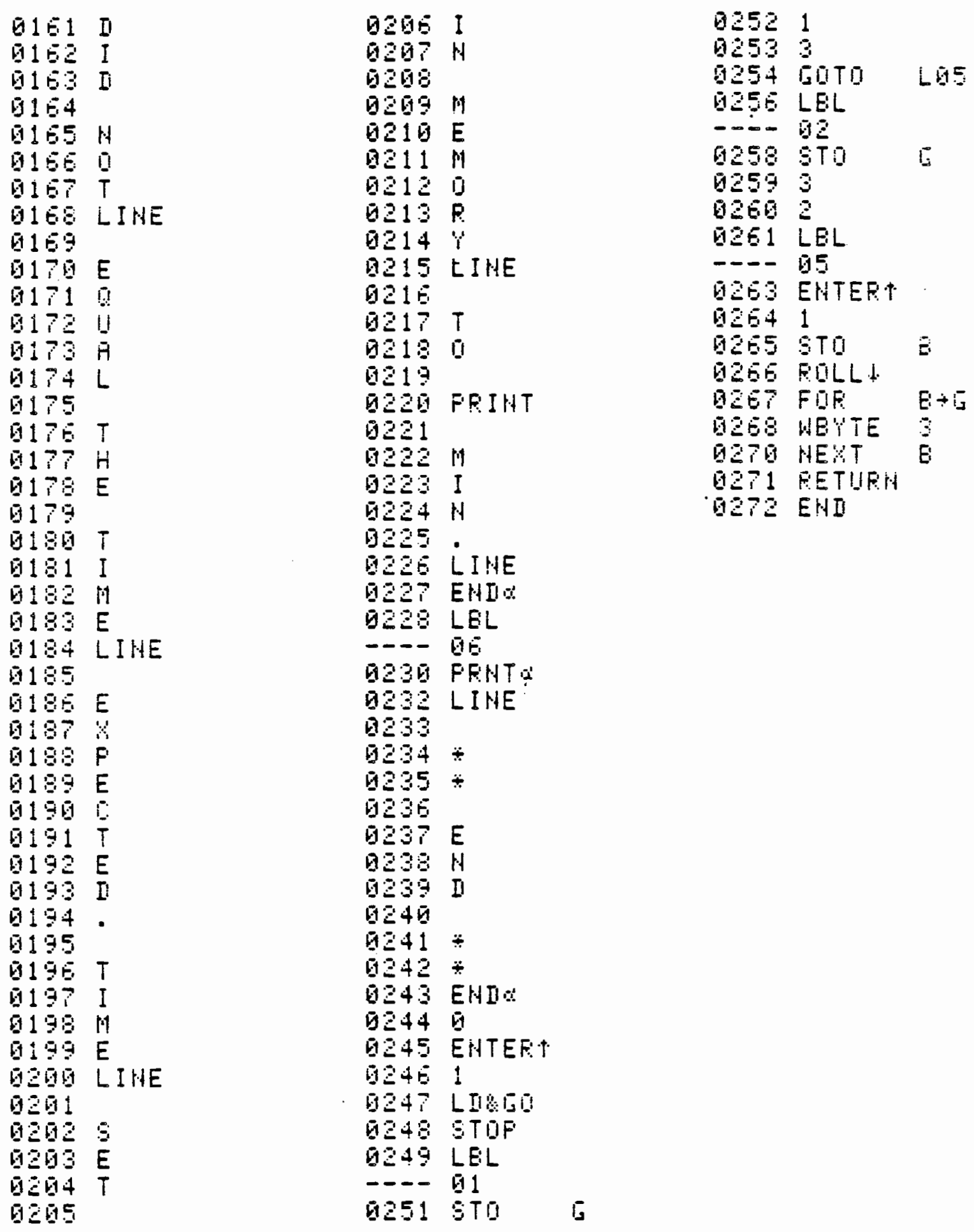

File 6 Background Test (2/2)

B. 14 


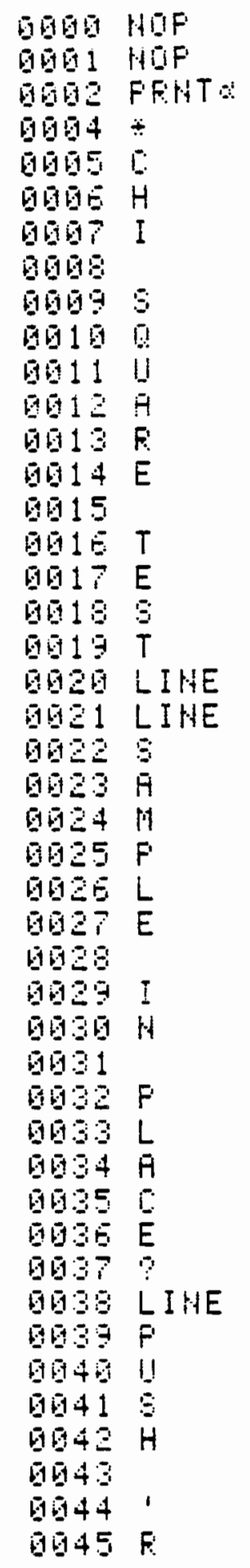

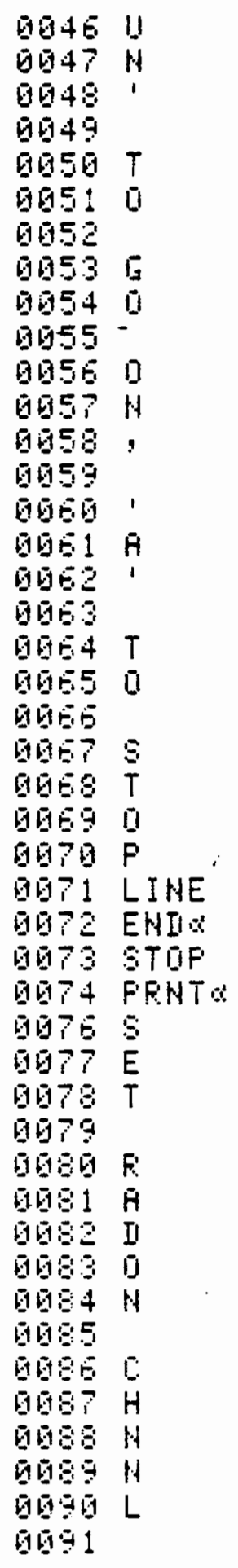

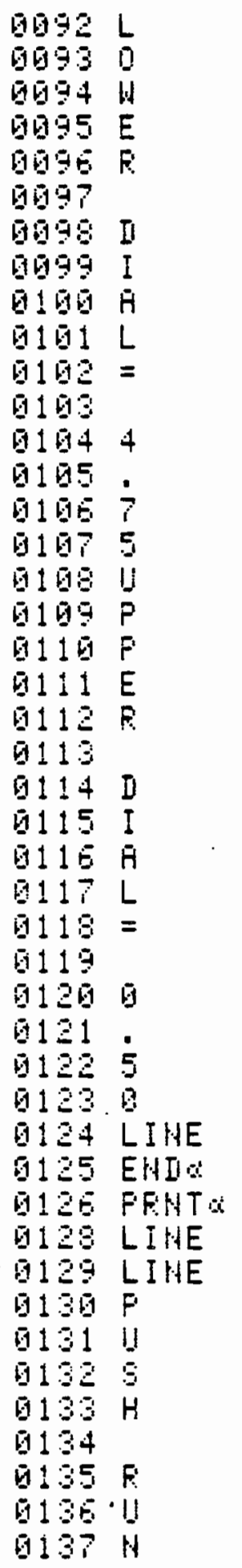

File 7 Chi-Squared Test (1/2)

B. 15 


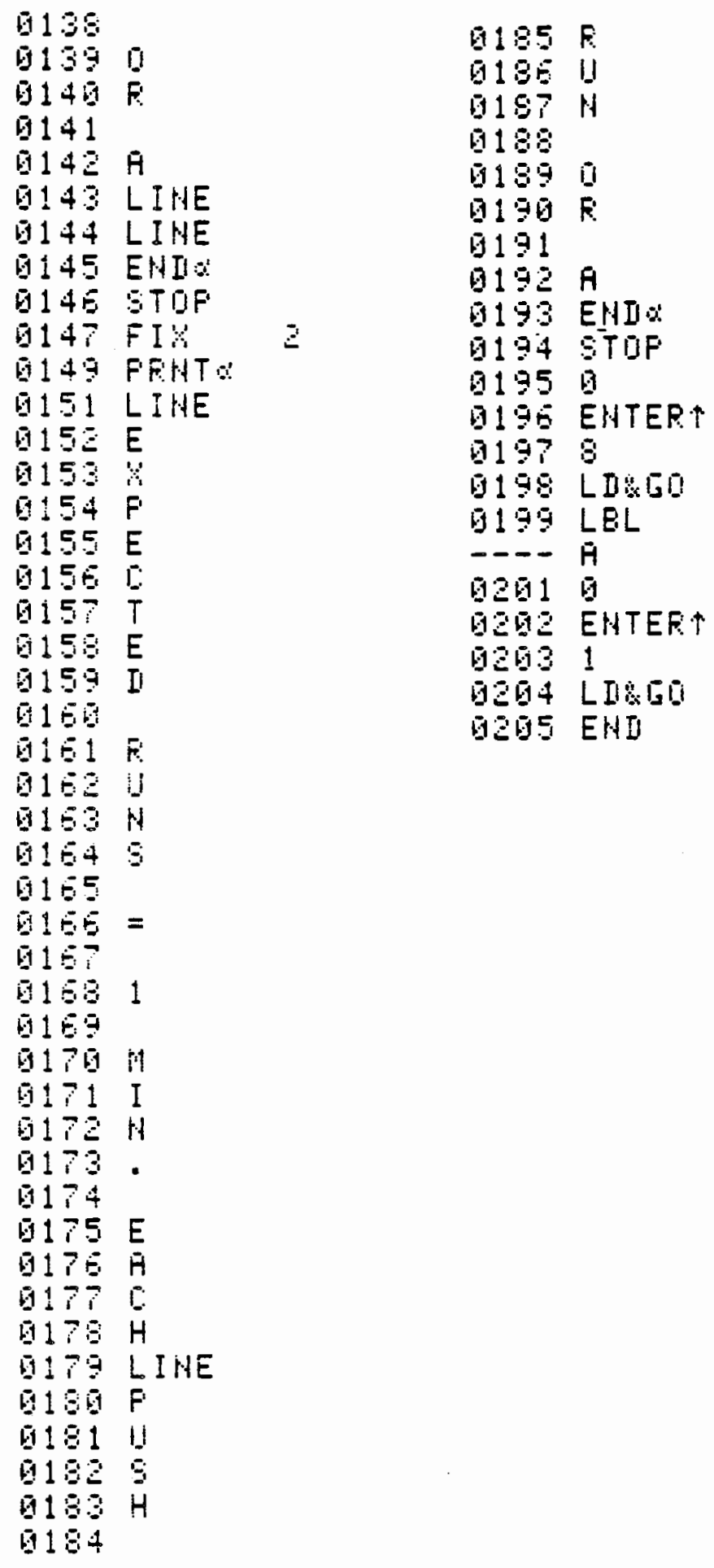

File 7 Chi-Squared Test (2/2)

B. 16 


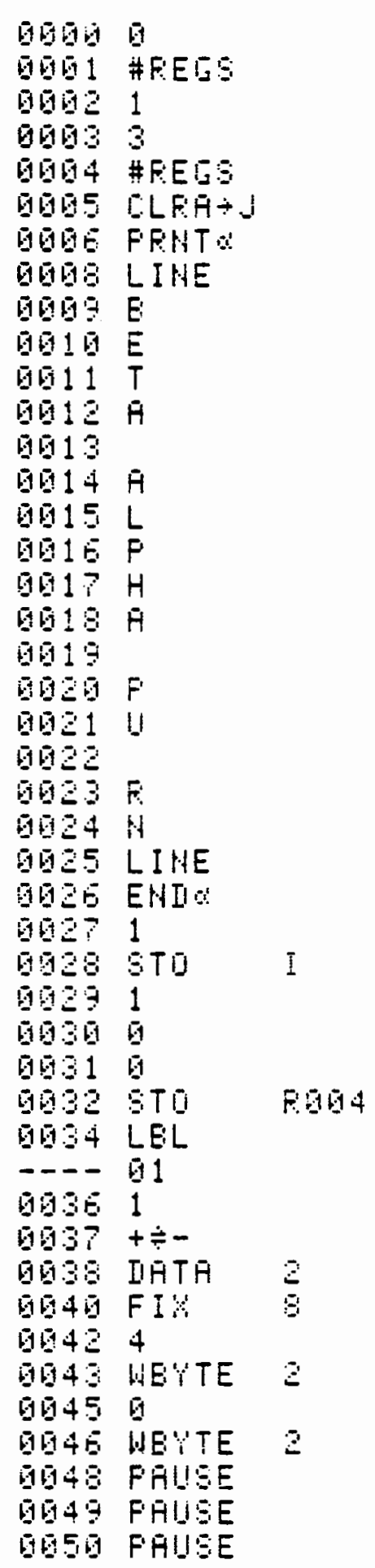

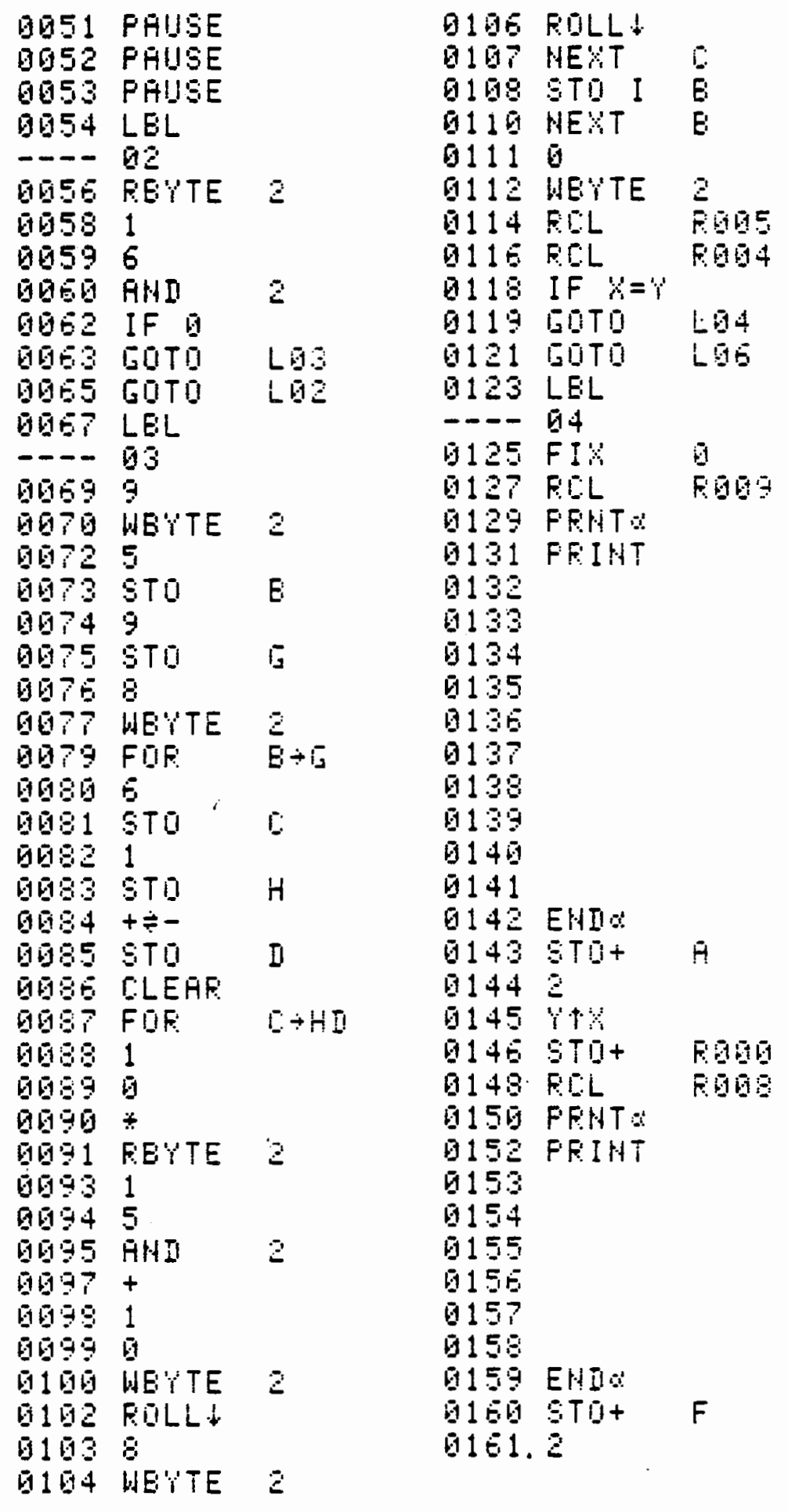

File 8 Chi-Squared Test (1/3) 


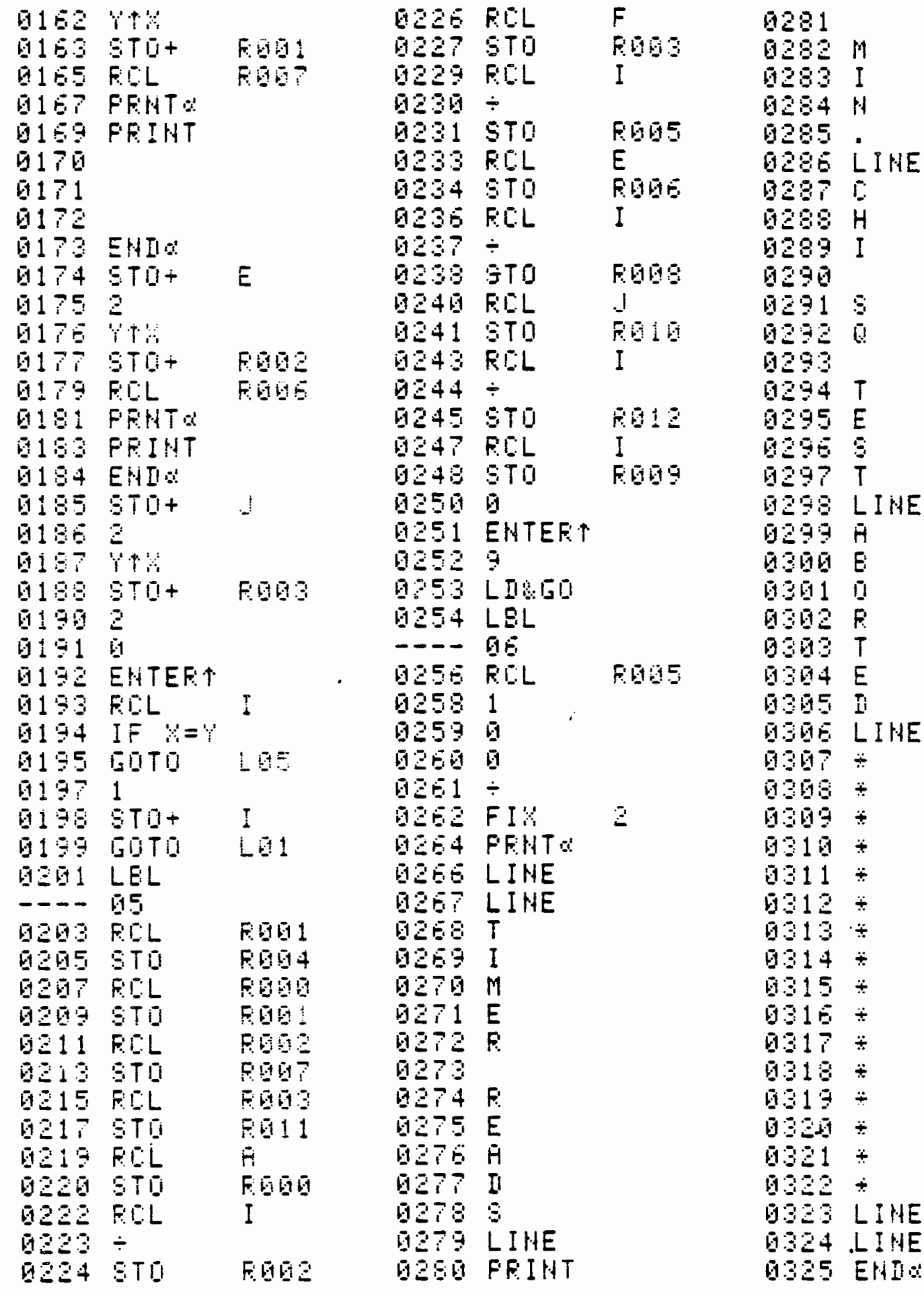

File 8 Chi-Squared Test (2/3) 


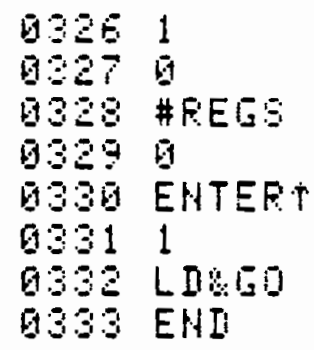

File 8 Chi-Squared Test $3 / 3$

B. 19 


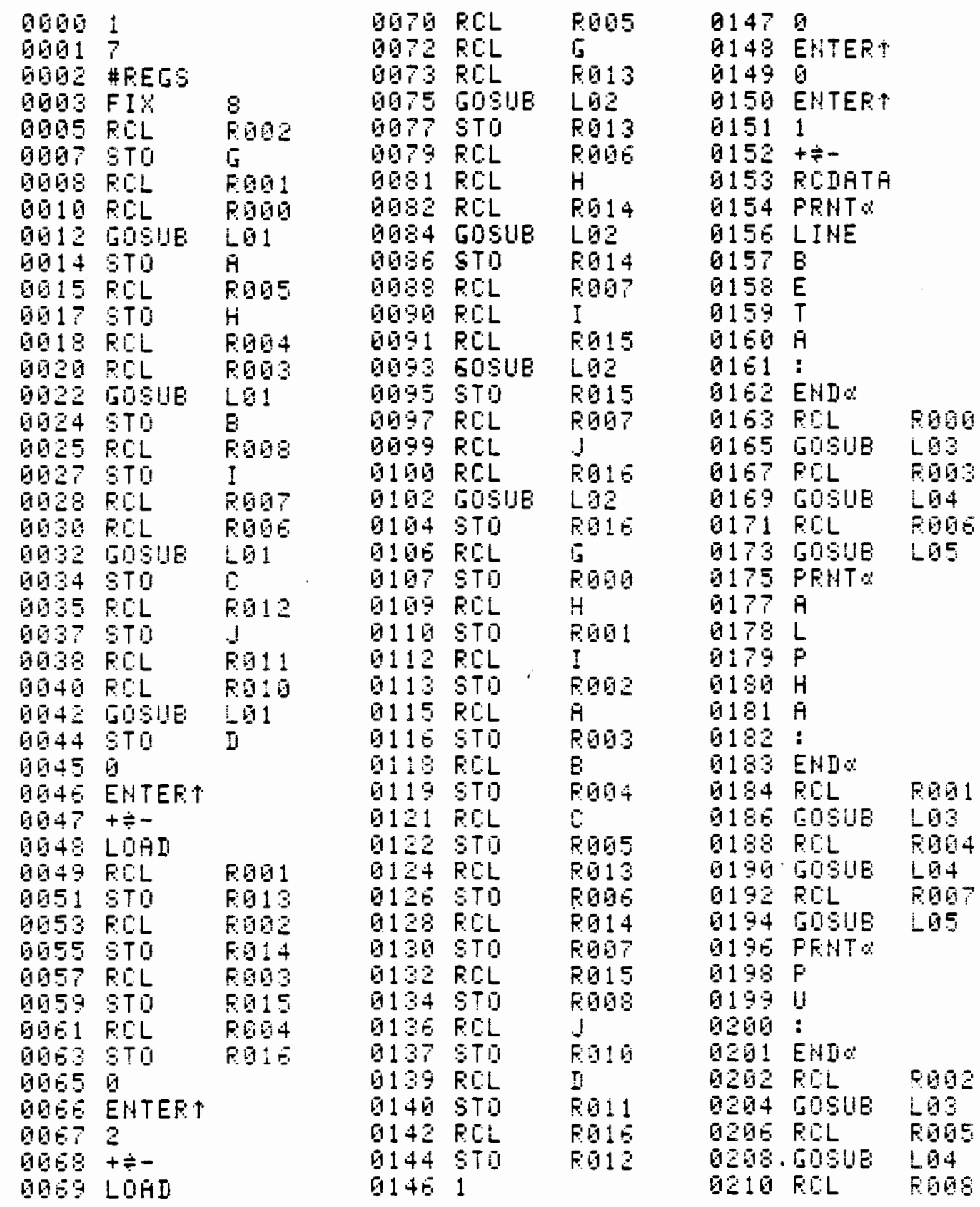

File 9 Chi-Squared Test (1/2) 


\begin{tabular}{|c|c|c|c|c|}
\hline 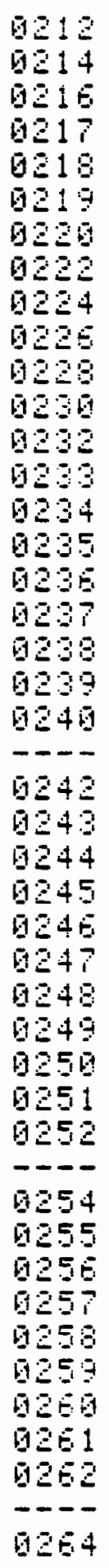 & 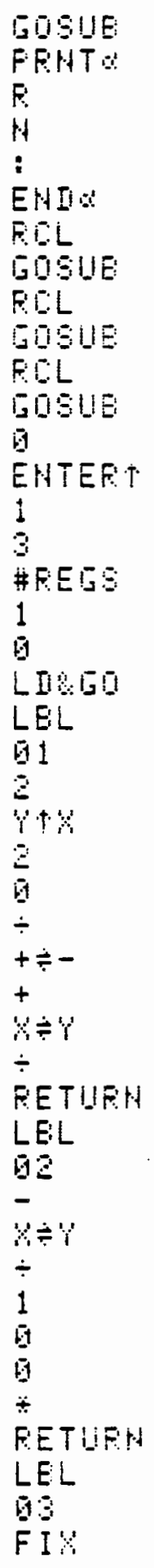 & $\begin{array}{l}6010 \\
-30 \\
6011 \\
6412 \\
60=\end{array}$ & 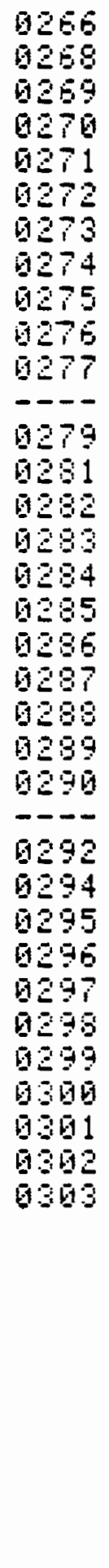 & 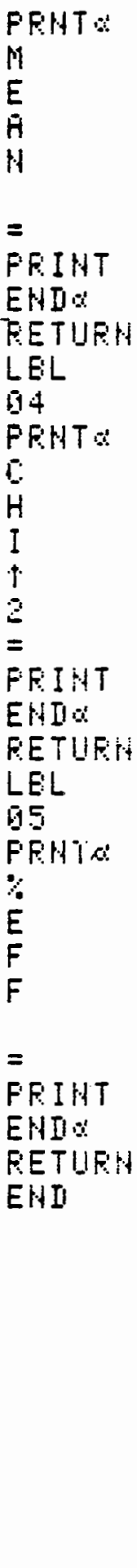 \\
\hline
\end{tabular}

File 9 Chi-Squared Test (2/2)

B. 21 


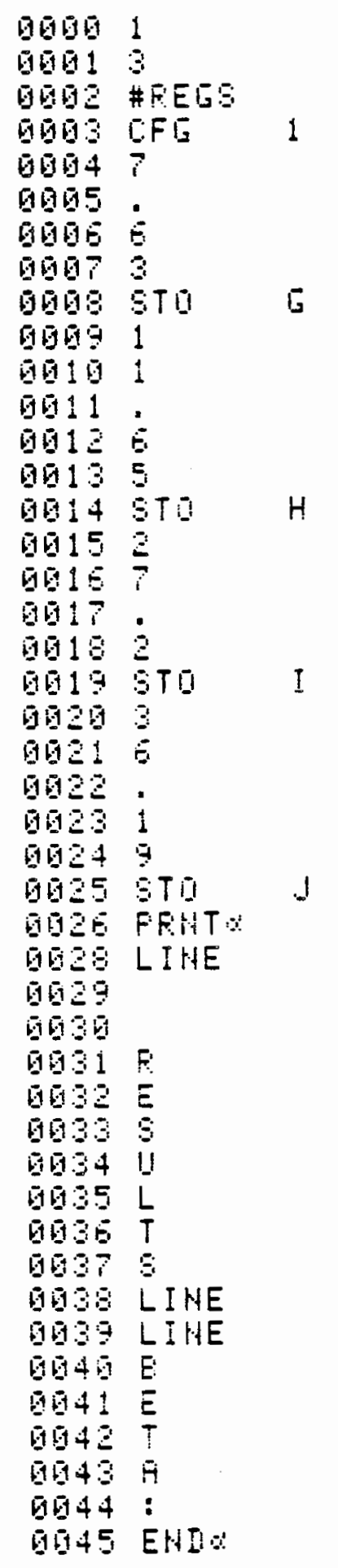

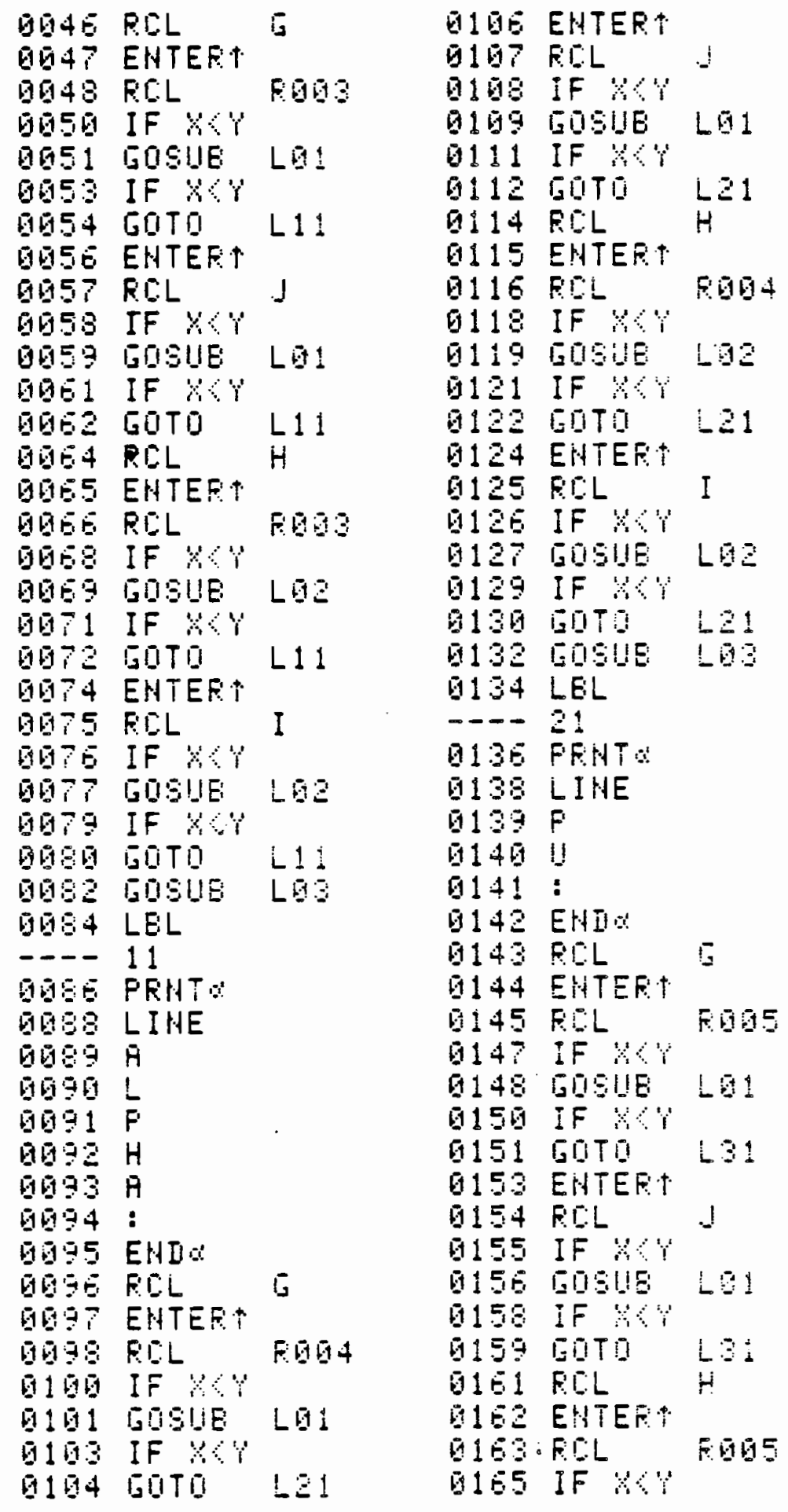

File 10 Chi-Squared Test (1/2) 


\begin{tabular}{|c|c|c|c|c|c|c|c|}
\hline 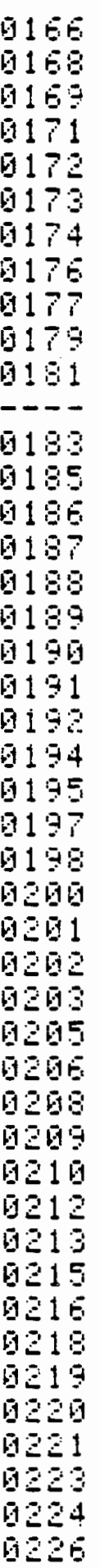 & 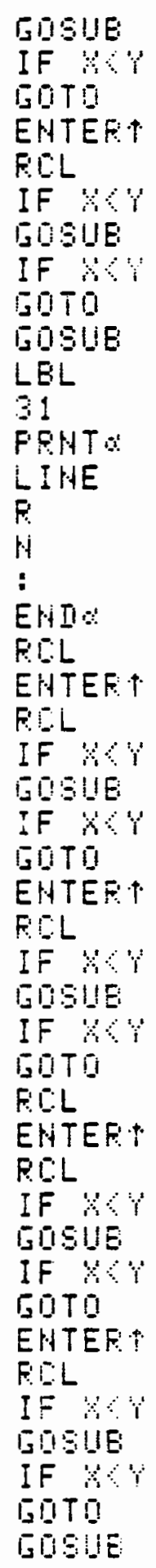 & 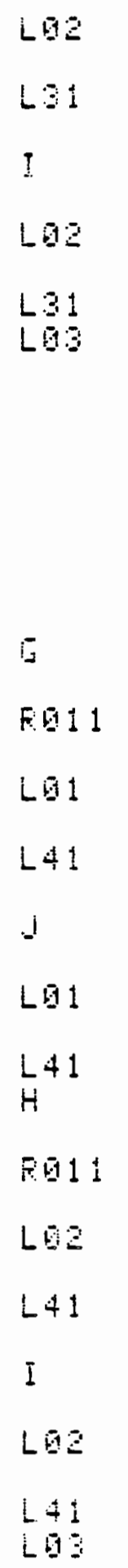 & 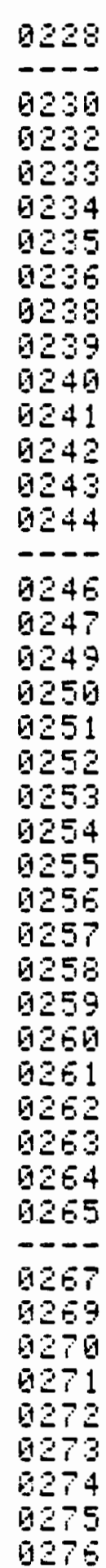 & 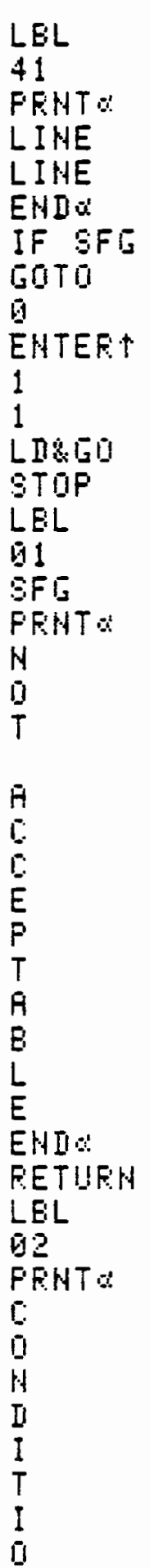 & L 1 & 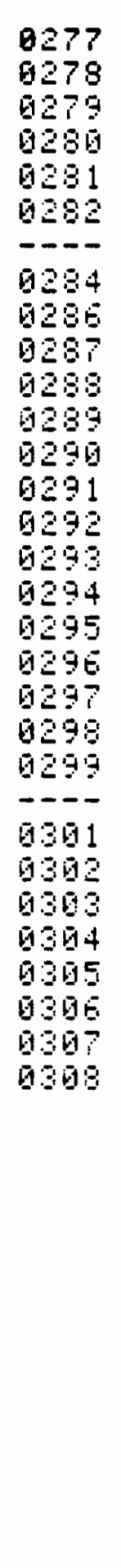 & 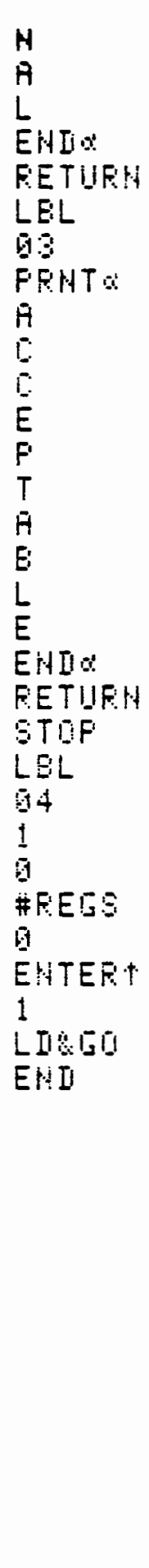 \\
\hline
\end{tabular}

File 10 Chi-Squared Test (2/2) 


\begin{tabular}{|c|c|c|c|c|c|c|c|}
\hline \multicolumn{2}{|l|}{ 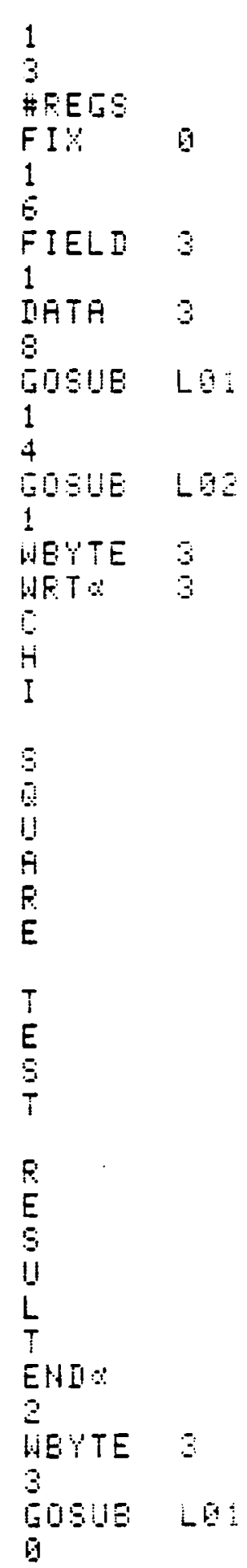 } & 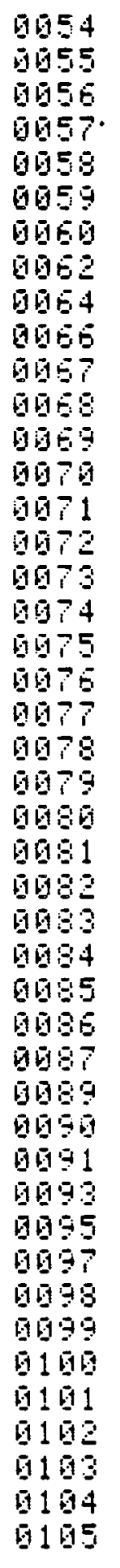 & \multicolumn{2}{|c|}{ 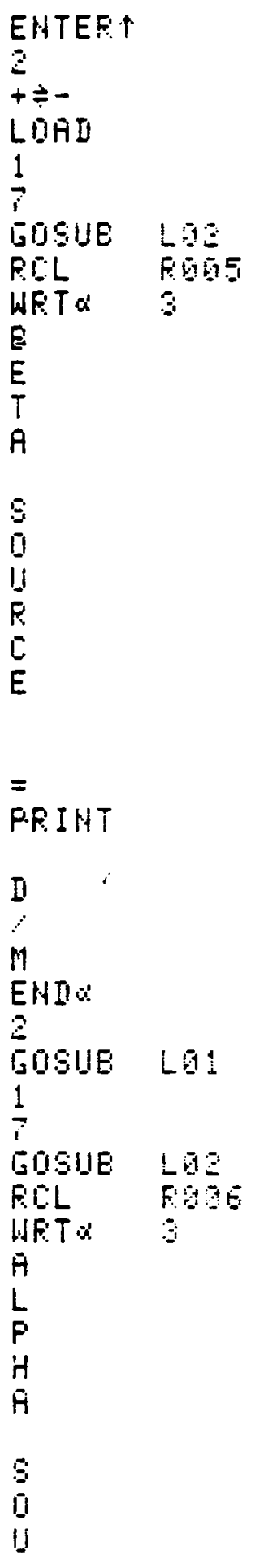 } & 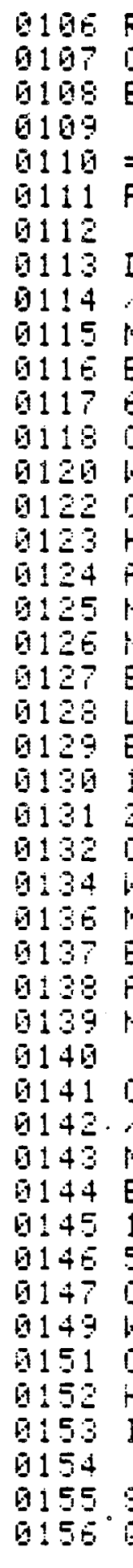 & 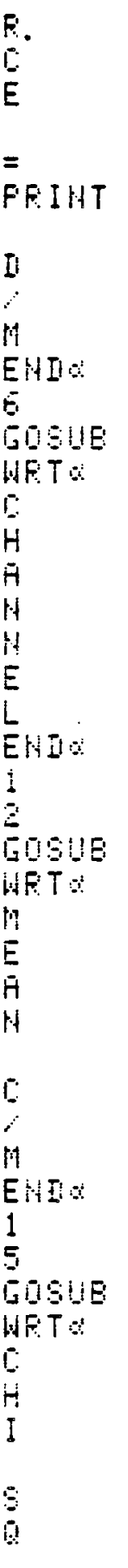 & \\
\hline
\end{tabular}

File 11 Chi-Squared Test (1/2) 


\begin{tabular}{|c|c|c|c|c|c|}
\hline $\begin{array}{l}8 \\
6 \\
6 \\
6\end{array}$ & 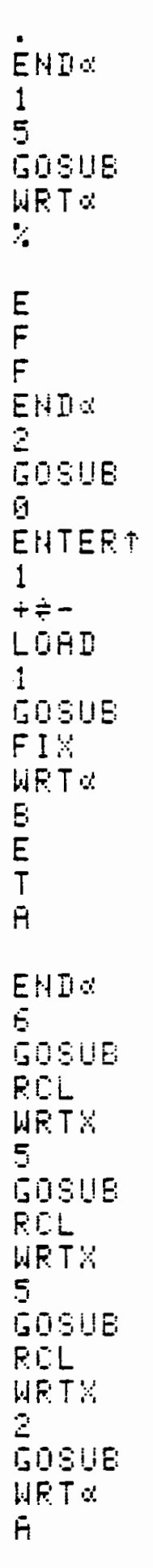 & 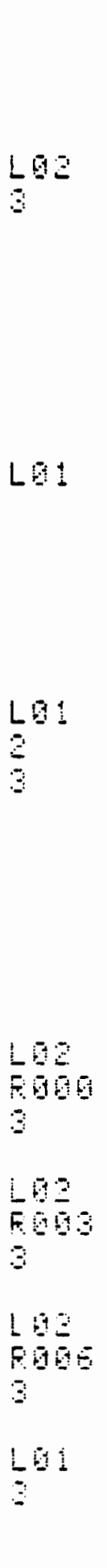 & 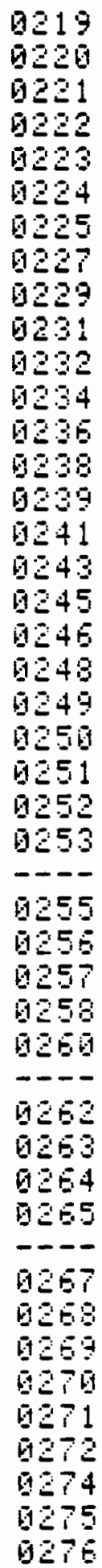 & 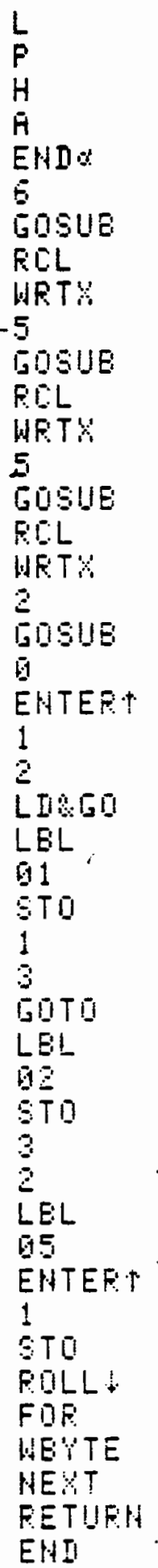 & 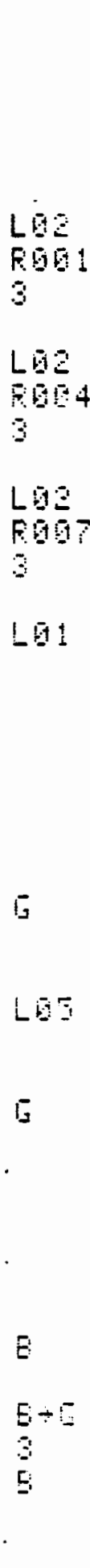 \\
\hline
\end{tabular}

File 11 Chi-Squared Test (2/2) 


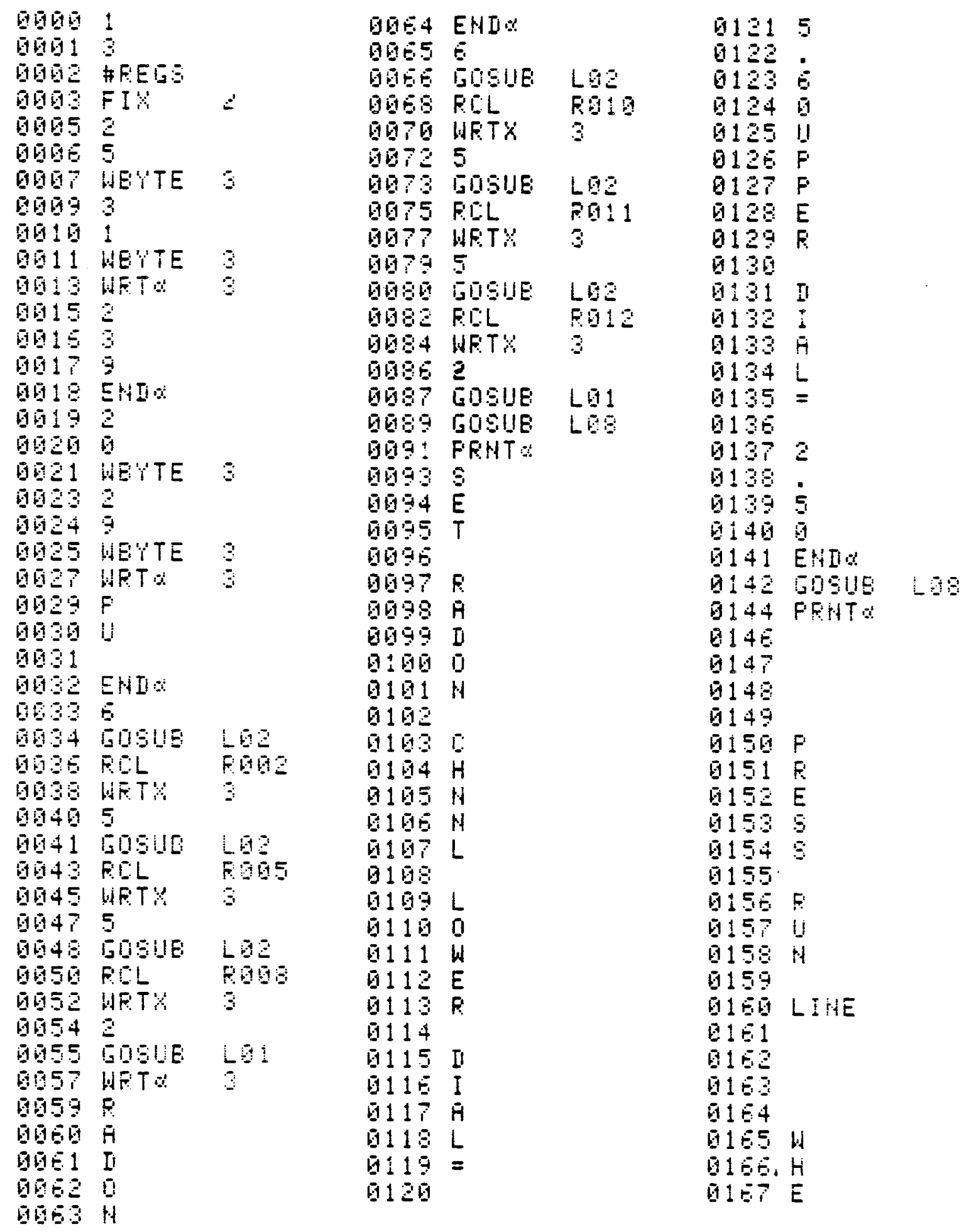

File 12 Chi-Squared Test (1/2) 


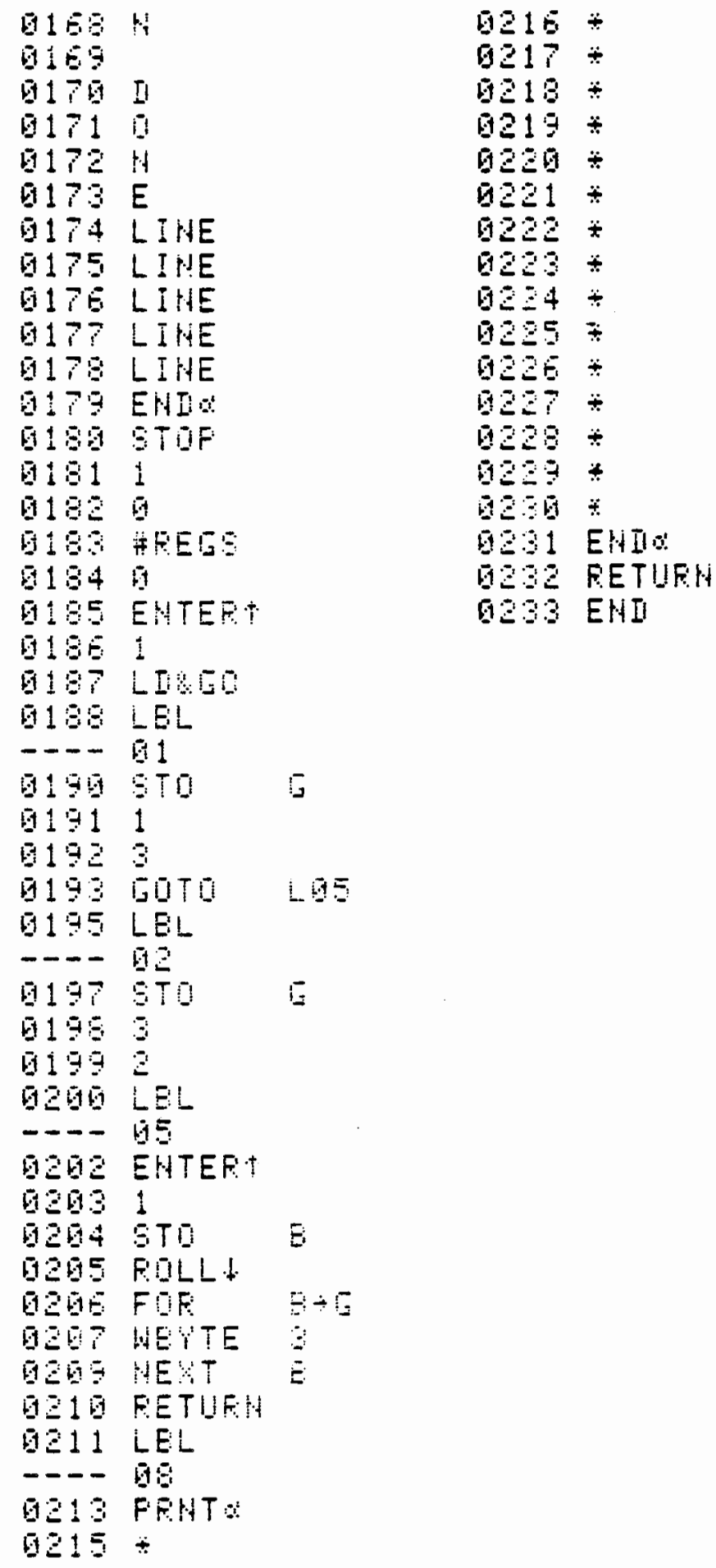

File 12 Chi-Squared Test (2/2) 

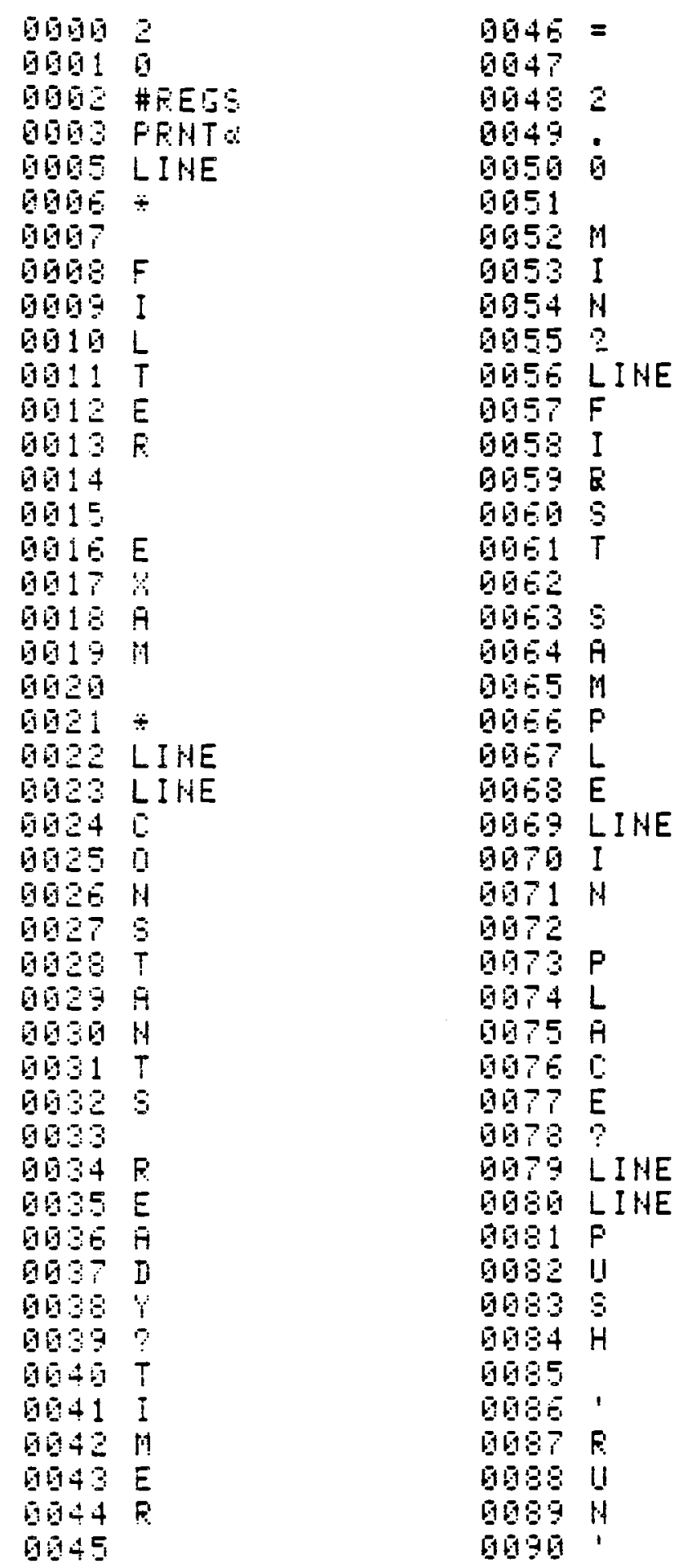

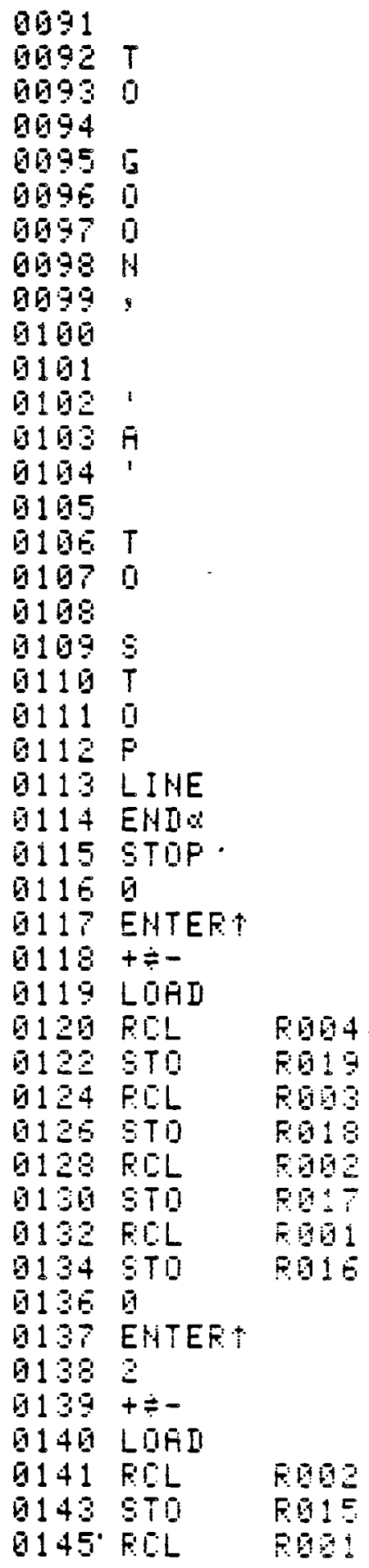

File 13 Filter Exam (1/2) 


\begin{tabular}{|c|c|c|c|c|c|}
\hline 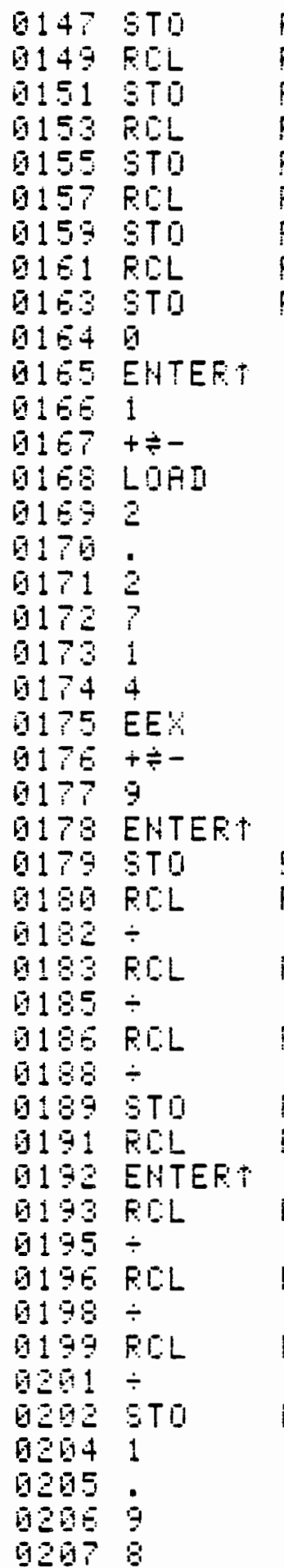 & 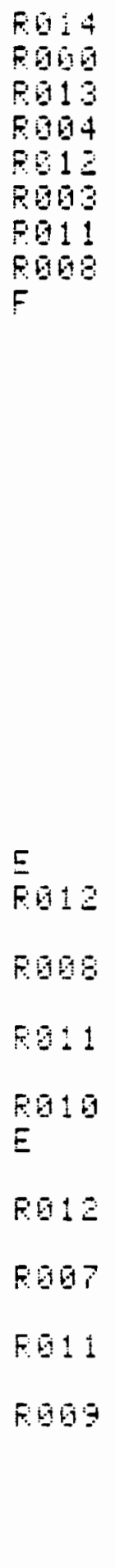 & 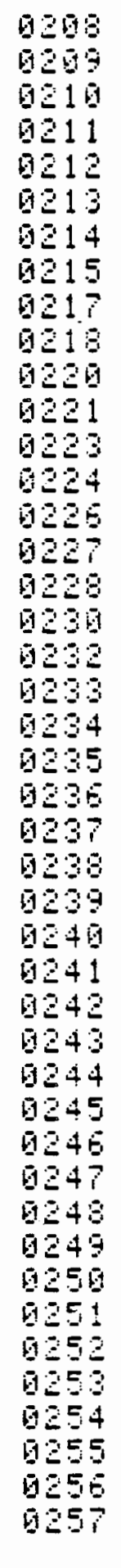 & 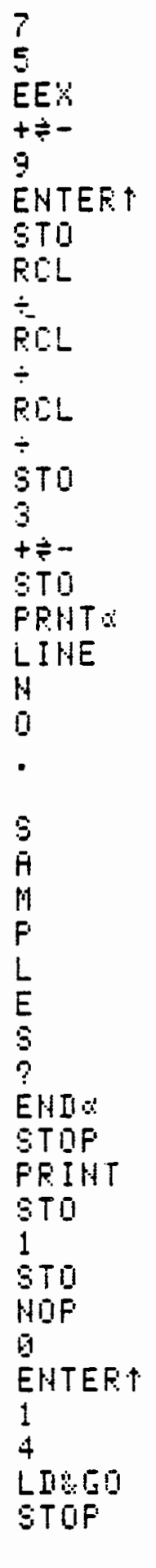 & 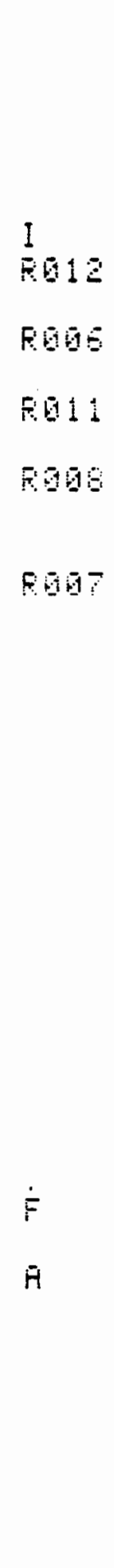 & 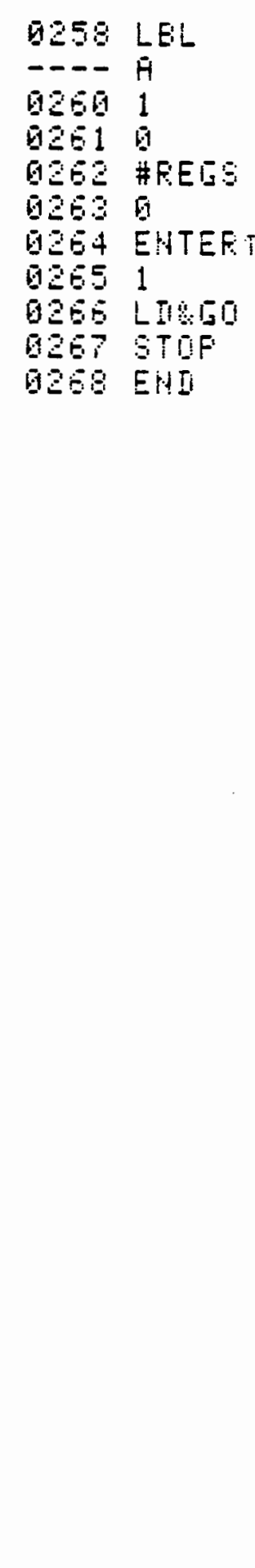 \\
\hline
\end{tabular}

File 13 Filter Exam (2/2) 


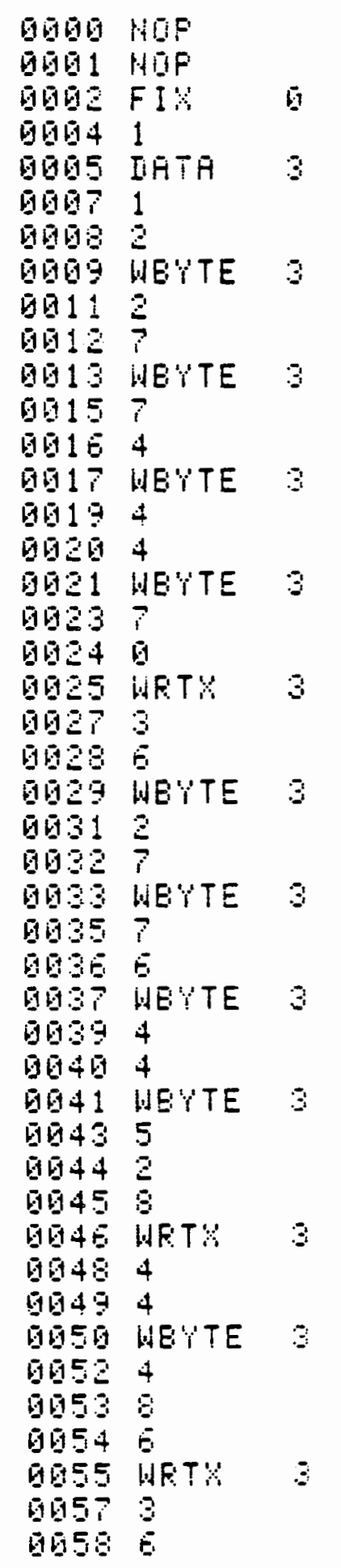

\begin{tabular}{|c|c|c|c|c|c|}
\hline 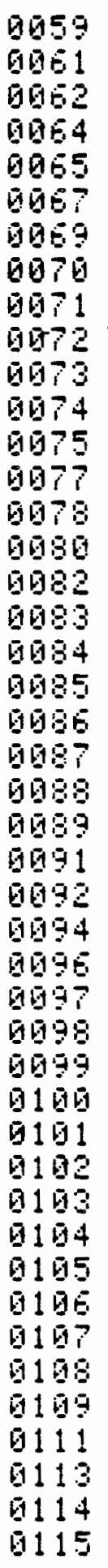 & 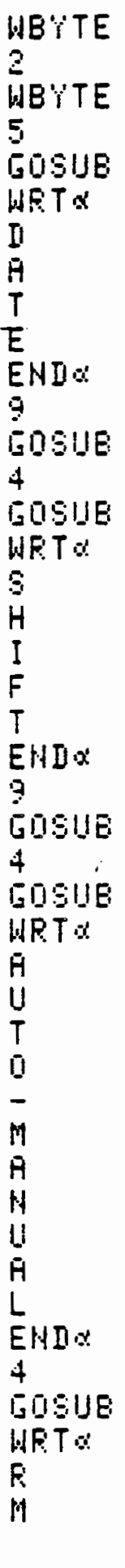 & $\begin{array}{l}3 \\
3 \\
\operatorname{LQ1}^{9}\end{array}$ & 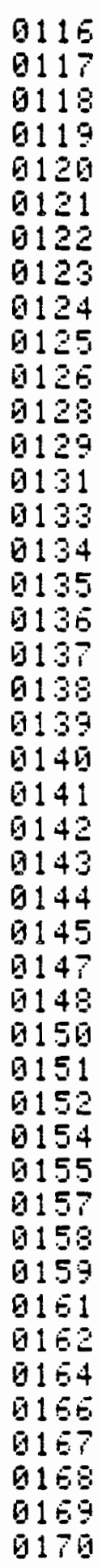 & 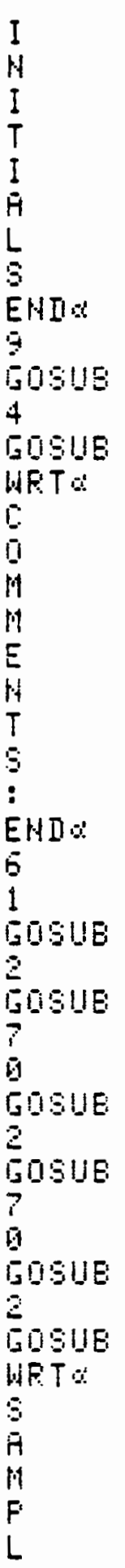 & $\begin{array}{l}403 \\
401 \\
3\end{array}$ \\
\hline
\end{tabular}

File 14 Filter Exam (1/2) 


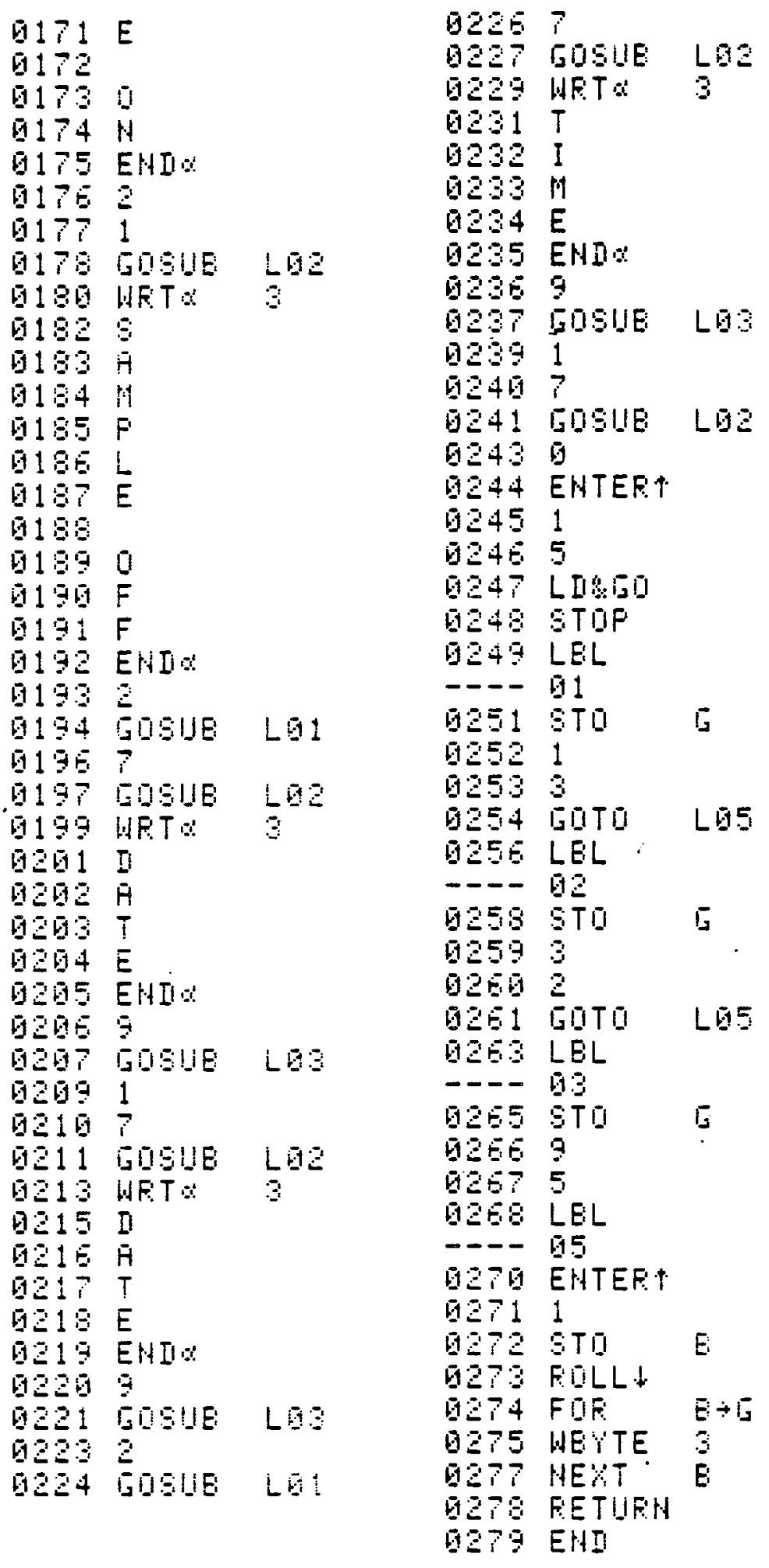

File 14 Filter Exam (2/2) 


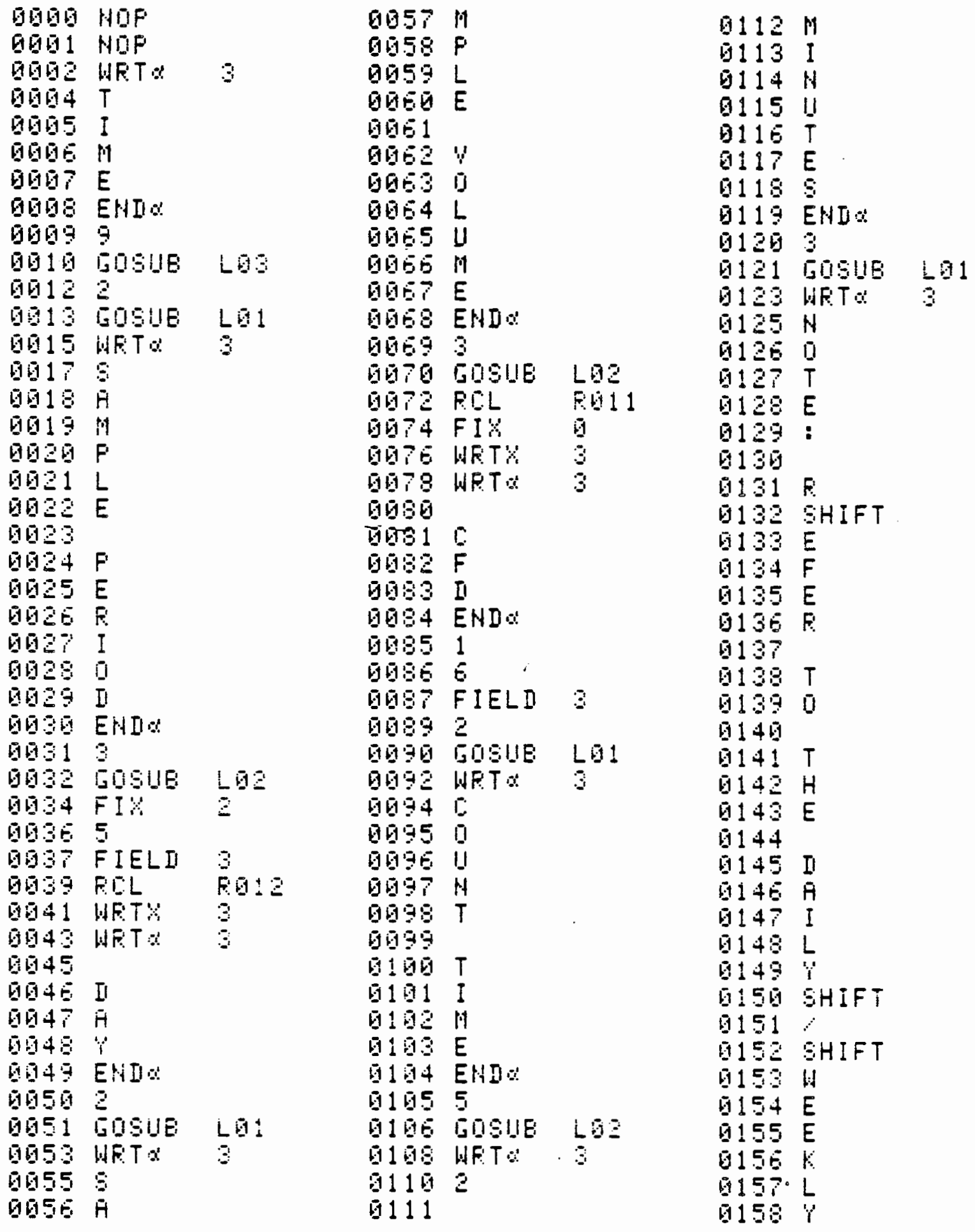

File 15 Filter Exam (1/2) 


\begin{tabular}{|c|c|c|c|c|c|c|c|}
\hline 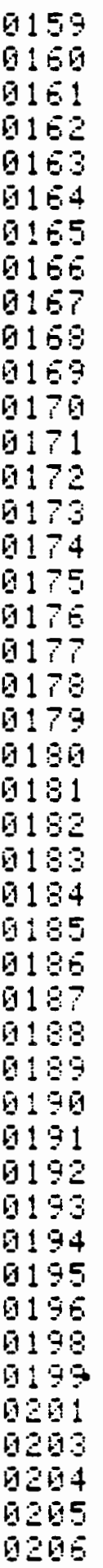 & 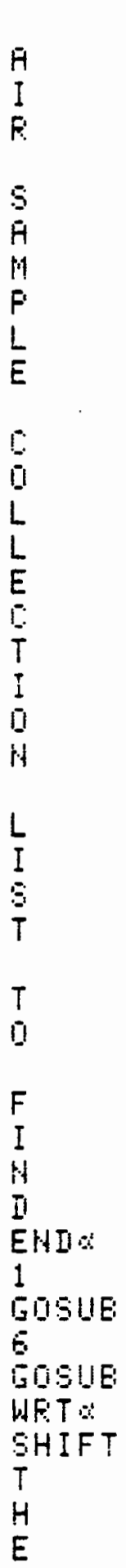 & $\begin{array}{l}461 \\
462 \\
3\end{array}$ & 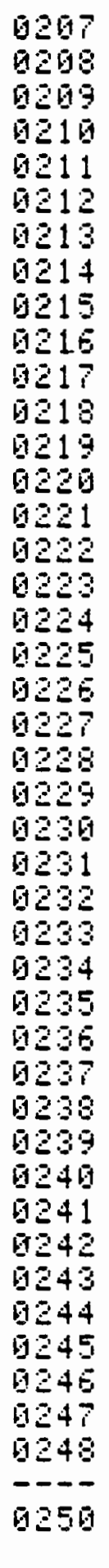 & 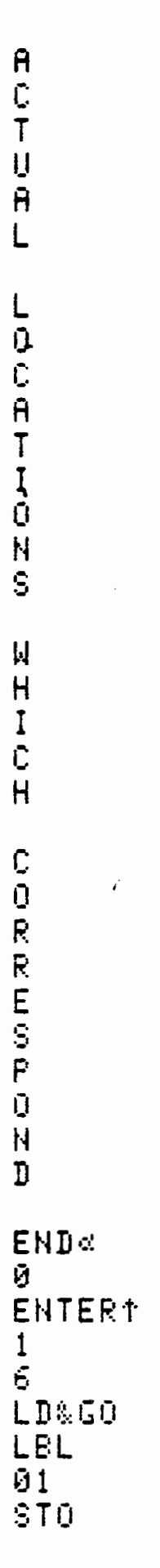 & $\begin{array}{l}0251 \\
0252 \\
0253 \\
0255 \\
0.5 \\
0257 \\
0258 \\
0259 \\
0269 \\
0262 \\
0264 \\
0255 \\
0265 \\
0267 \\
0-5 \\
0269 \\
0279 \\
0271 \\
0272 \\
0273 \\
0274 \\
0276 \\
0277 \\
0278\end{array}$ & 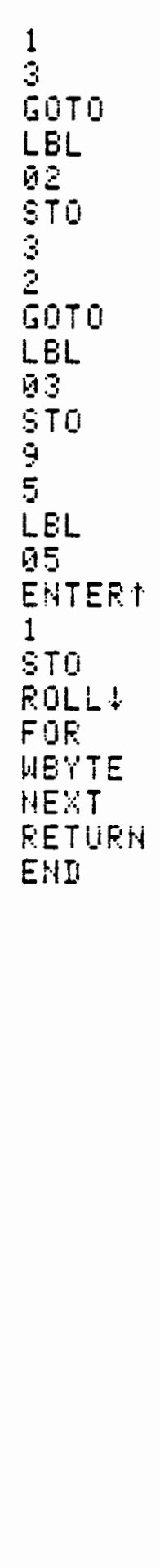 & $\begin{array}{l}E \\
B+E \\
3 \\
B\end{array}$ \\
\hline
\end{tabular}

File 15 Filter Exam (2/2) 


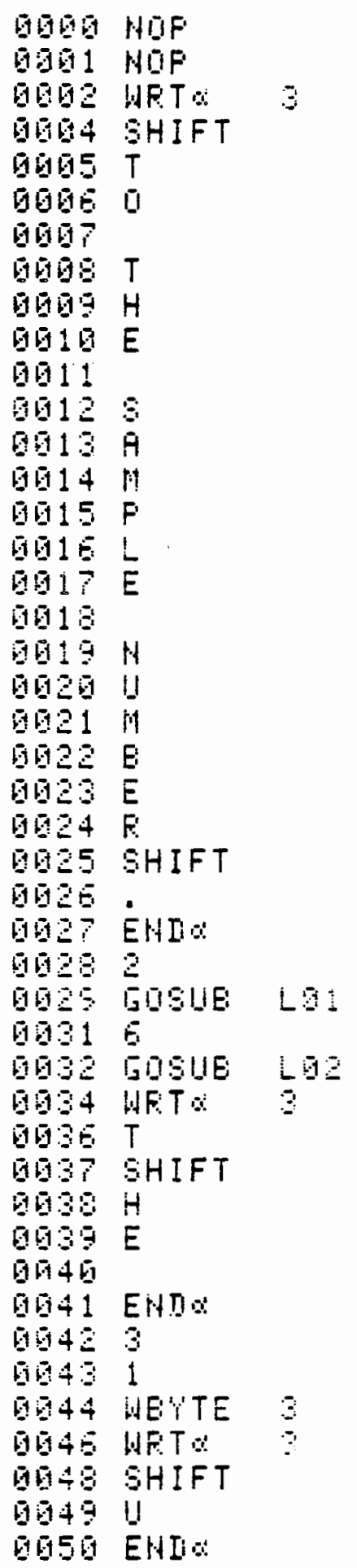

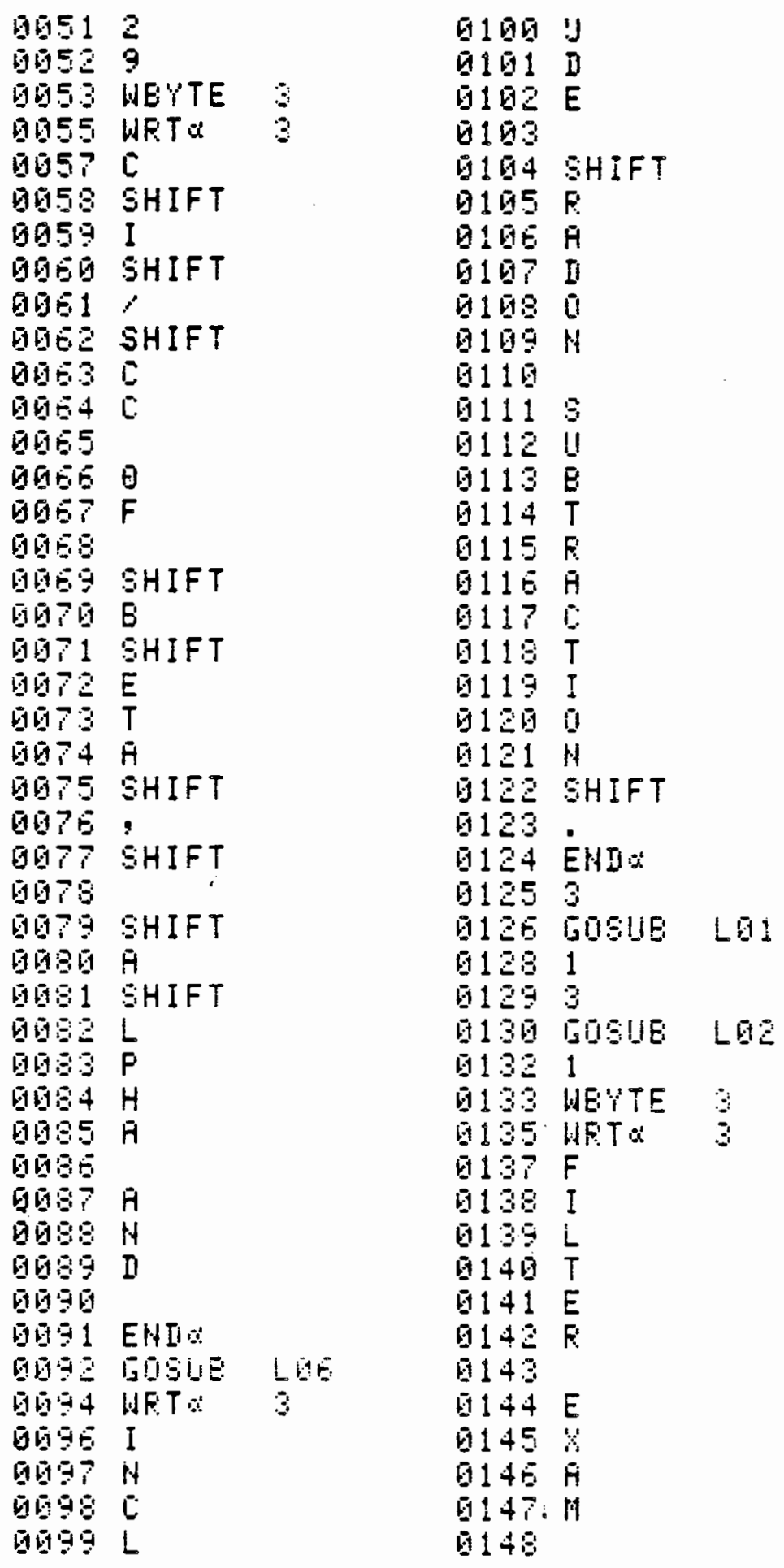

File 16 Filter Exam (1/2) 


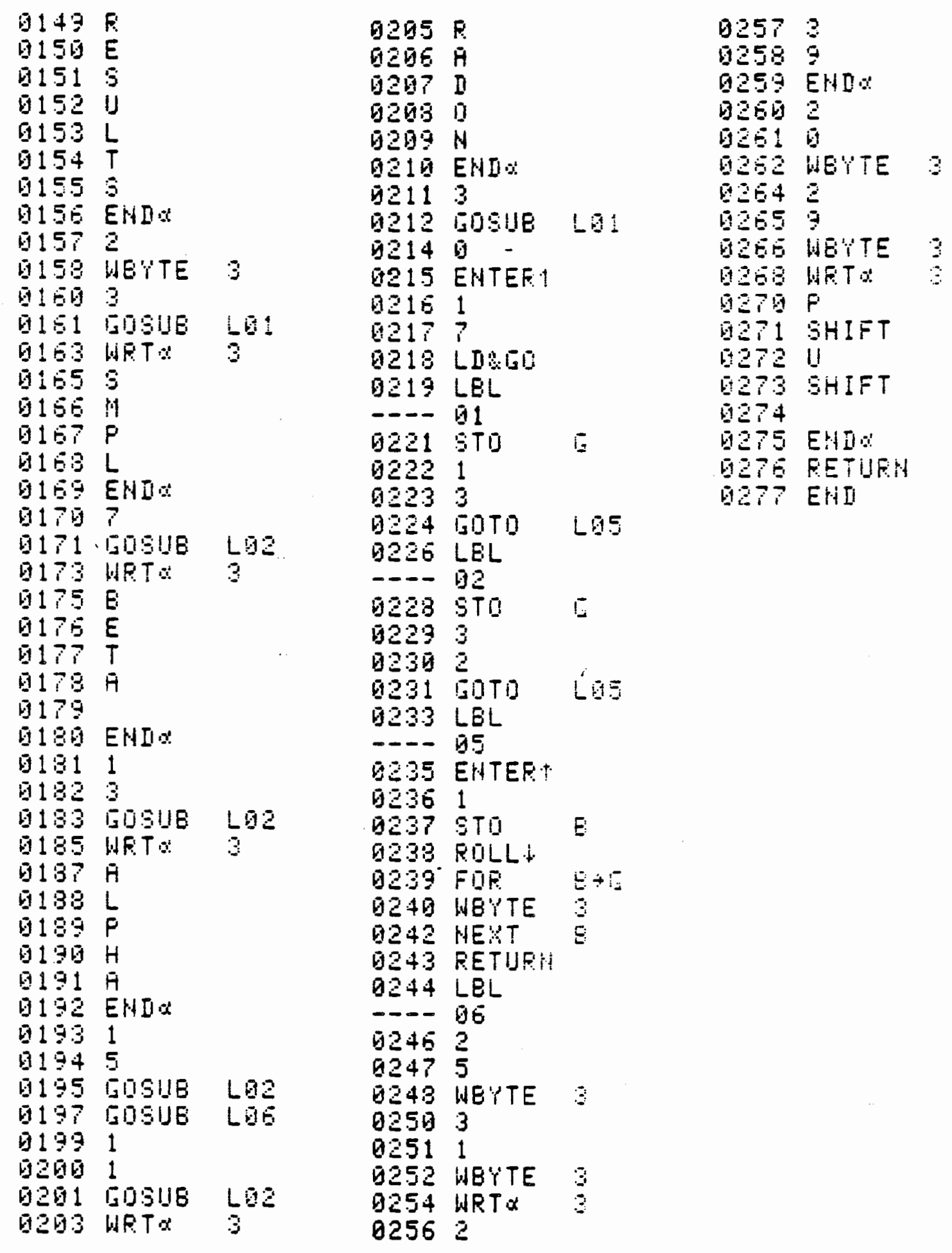

File 16 Filter Exam (2/2)

B. 35 


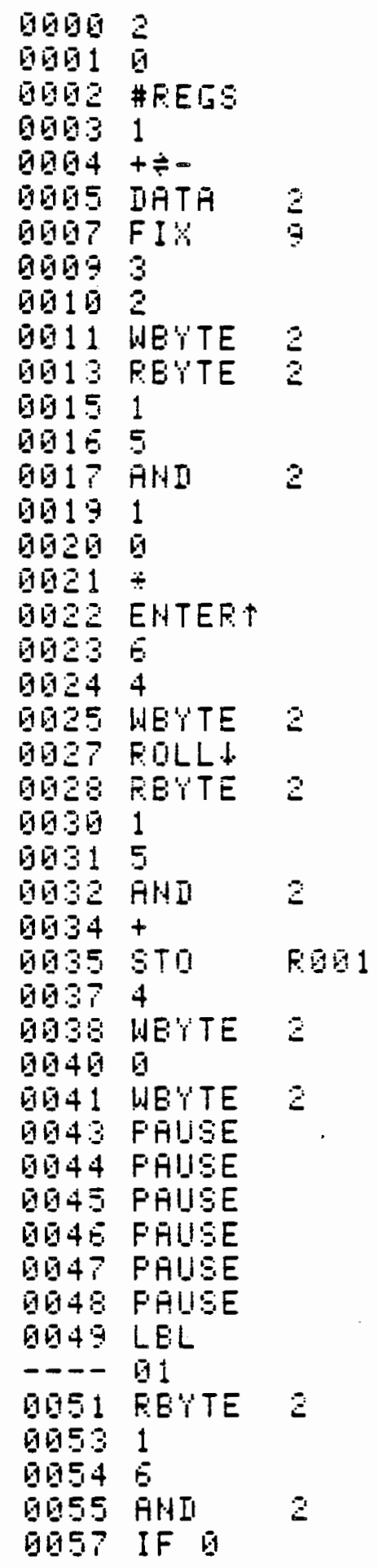

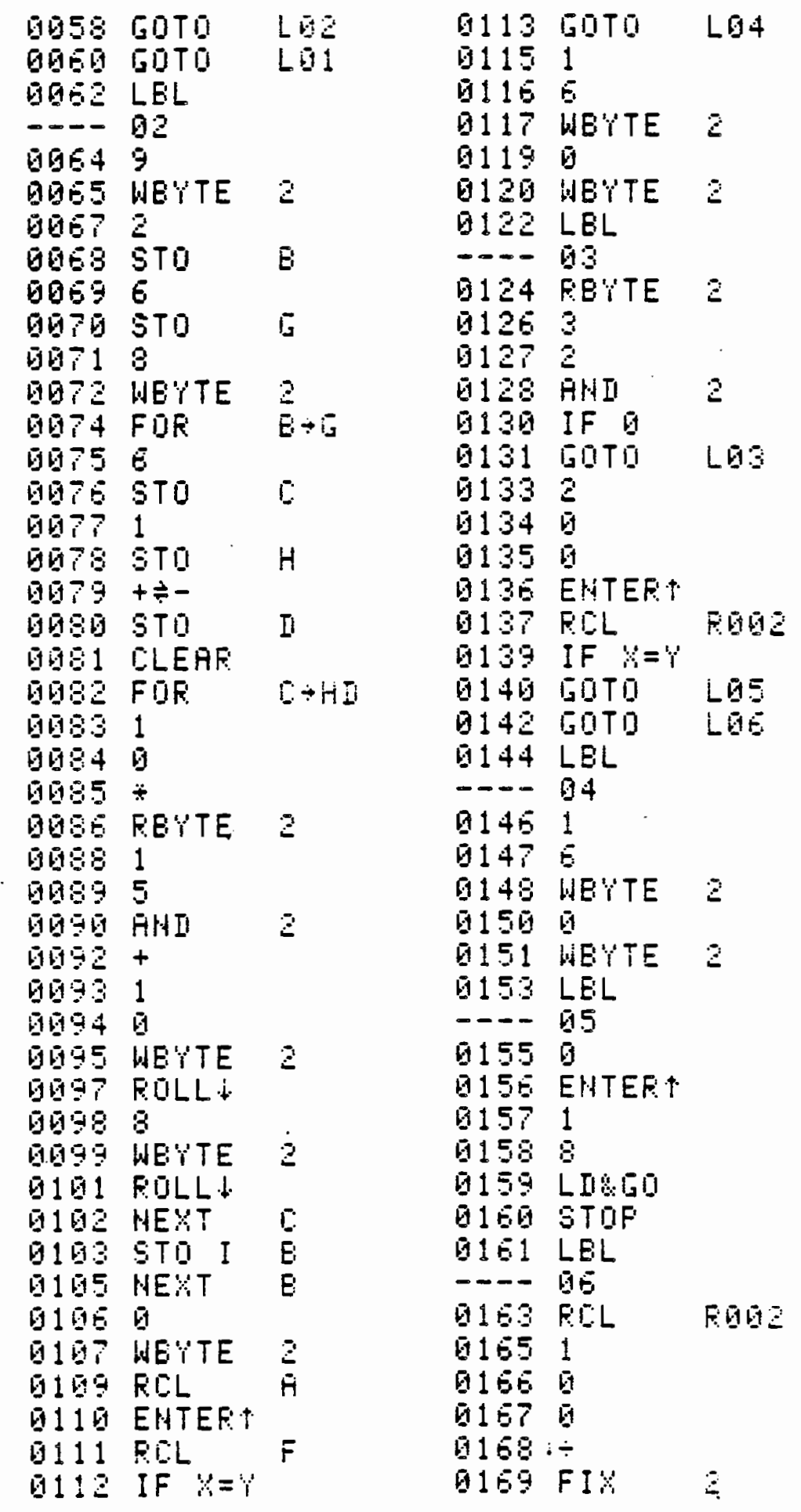

File 17A Filter Exam (1/2) 


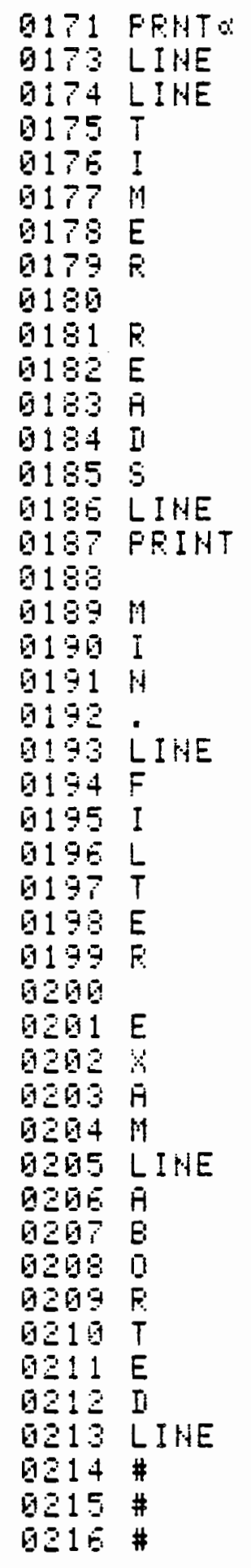

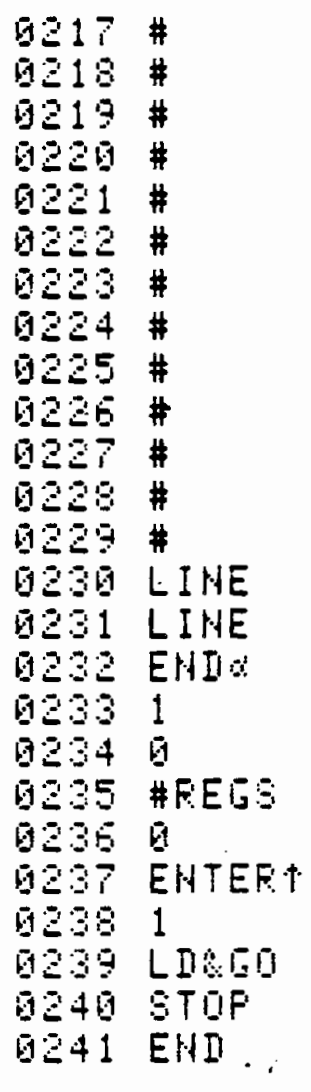

G218 \#

019

$021 \#$

0232

62:

1924

9225

1926 \#

1227

1290

1229

G23 LINE

GOI LINE

G232 EHII:

1931

6234

GOS \#EEE

0235 回

G37 ENTEFT

- 231

G23 LDER

1240 STIP

File 17A Filter Exam (2/2) 


\begin{tabular}{|c|c|c|c|c|c|c|c|c|}
\hline 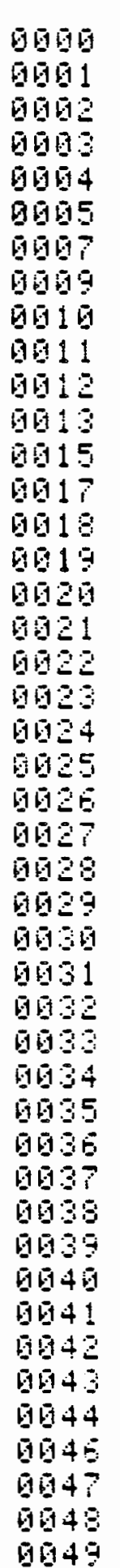 & 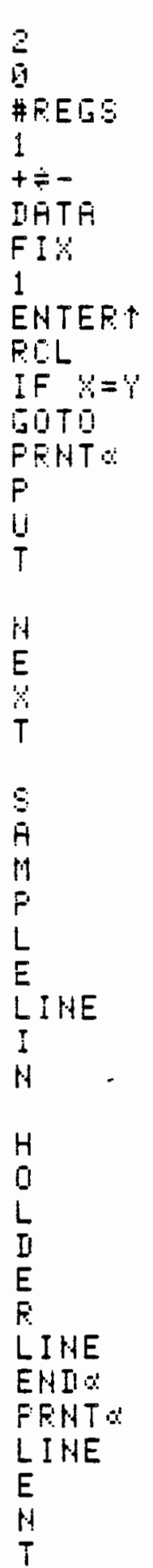 & $\begin{array}{l}8 \\
96 \div 4\end{array}$ & 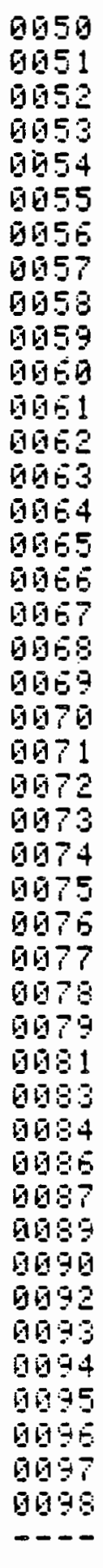 & 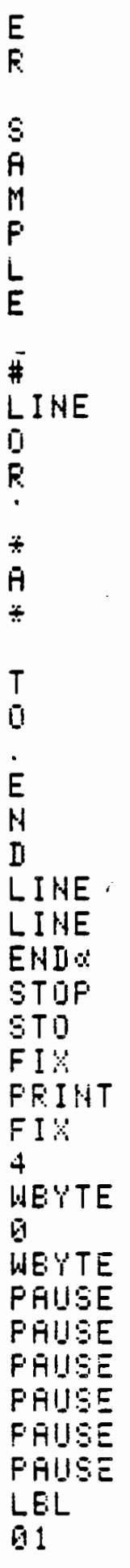 & $\begin{array}{l}601 \\
9 \\
2 \\
2\end{array}$ & 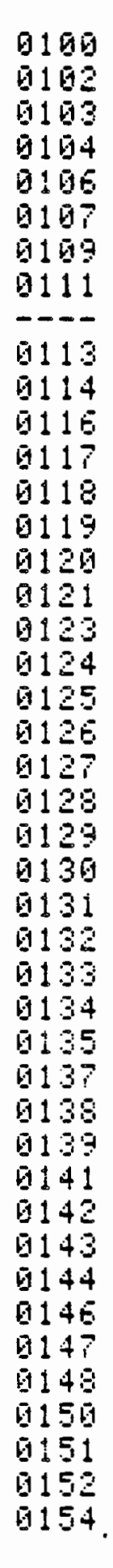 & 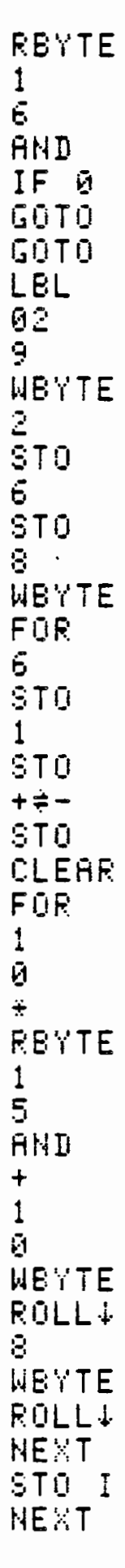 & $\begin{array}{l}2 \\
8 \\
3 \\
2 \\
E+5 \\
E \\
H \\
I \\
C+H I\end{array}$ \\
\hline
\end{tabular}

File 17M Filter Exam (1/2) 


\begin{tabular}{|c|c|c|c|c|c|c|c|}
\hline 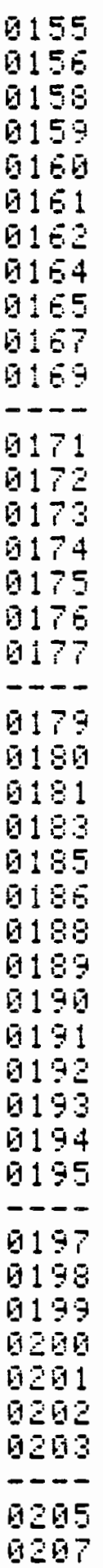 & 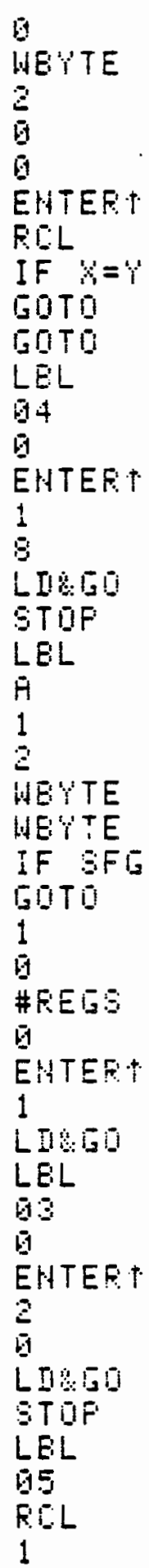 & $\begin{array}{l}5002 \\
-04=\end{array}$ & 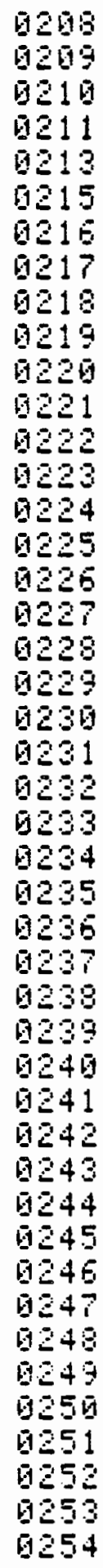 & 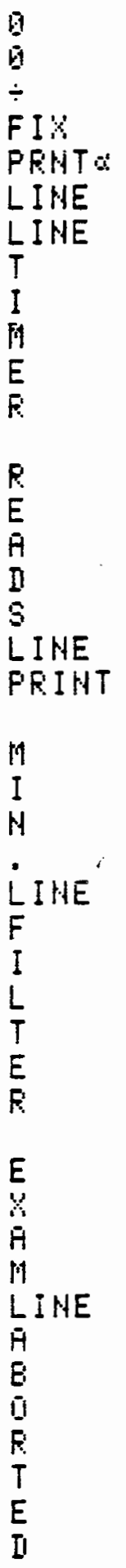 & 2 & 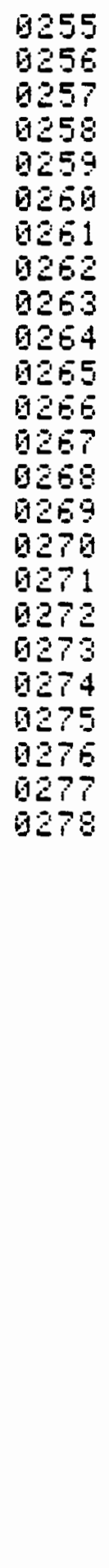 & 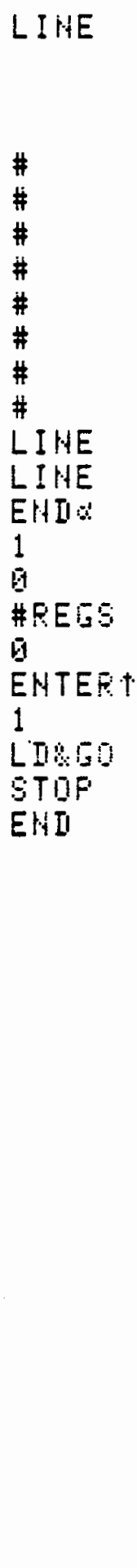 \\
\hline
\end{tabular}

File 17M Filter Exam (2/2)

B. 39 


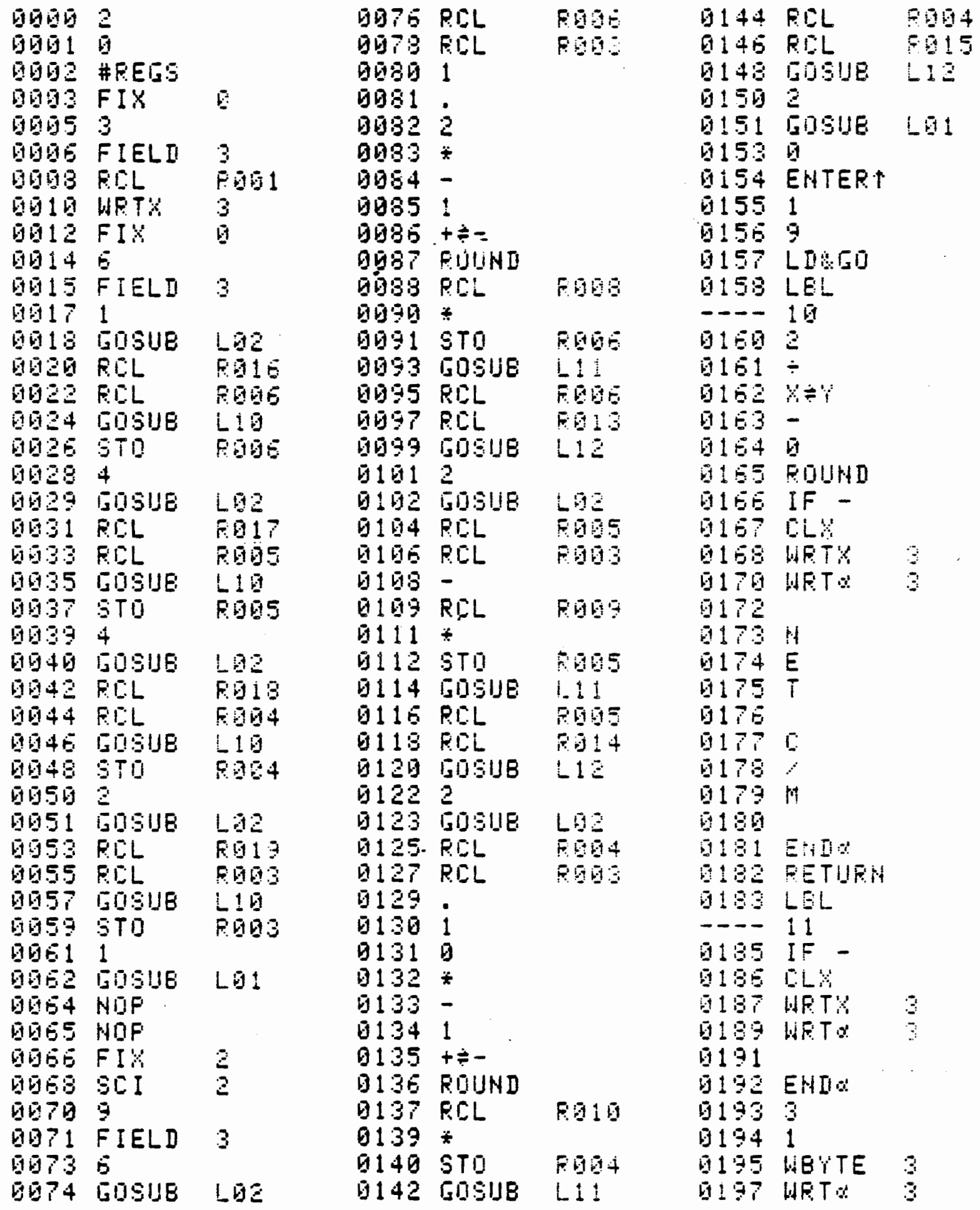

File 18 Filter Exam (1/2) 


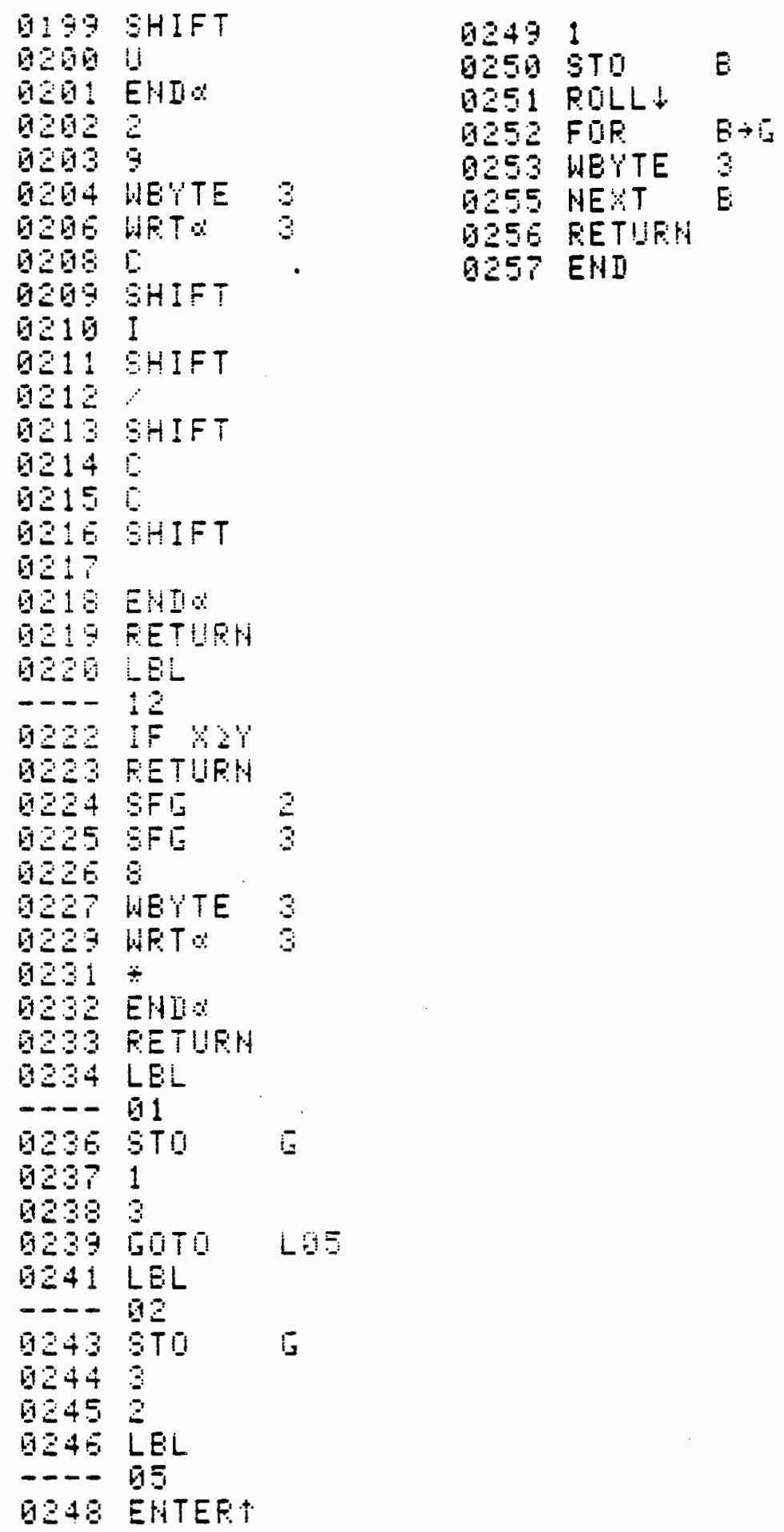




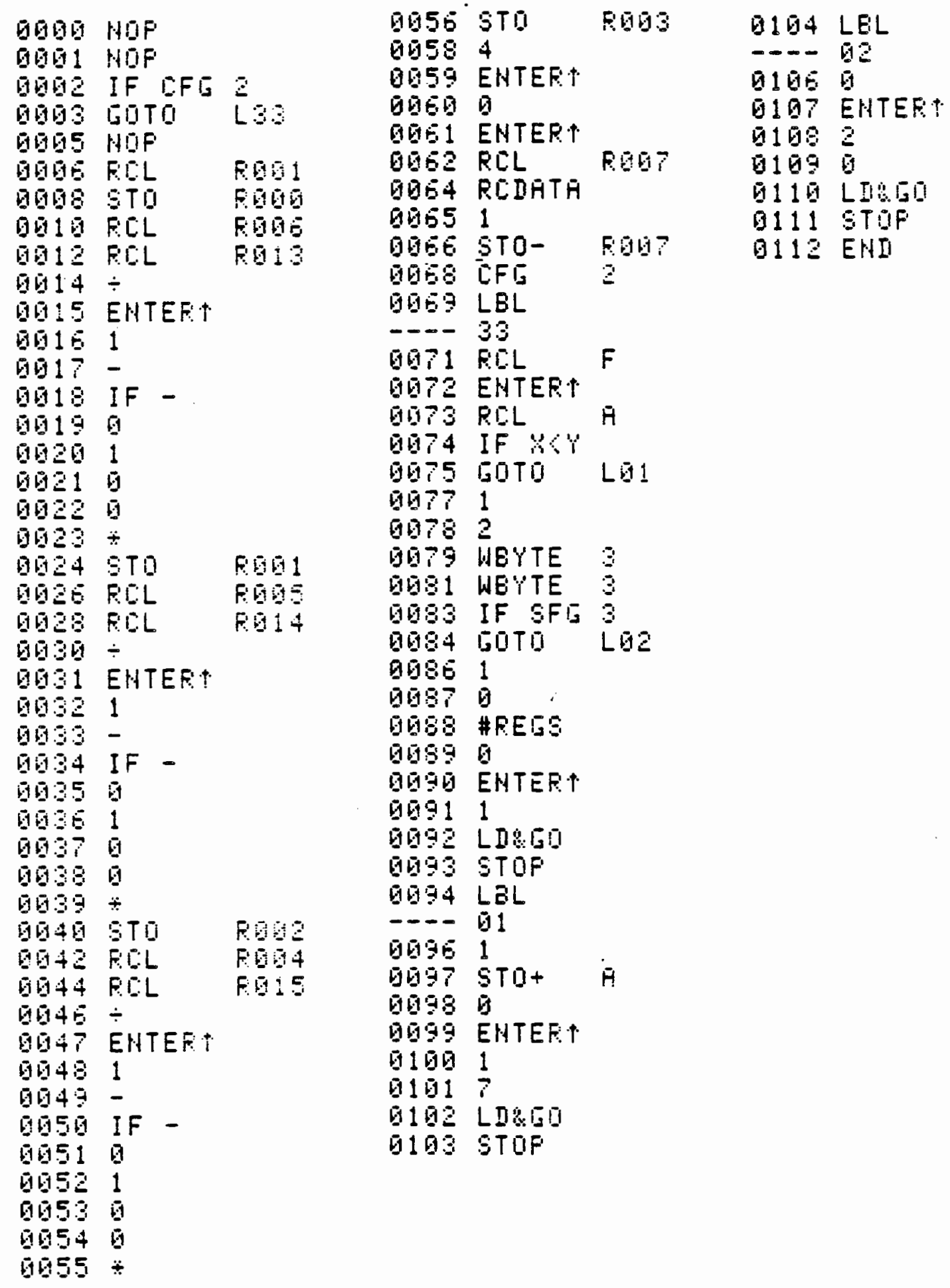

File 19 Filter Exam $(1 / 1)$ 


\begin{tabular}{|c|c|c|c|c|c|c|c|}
\hline 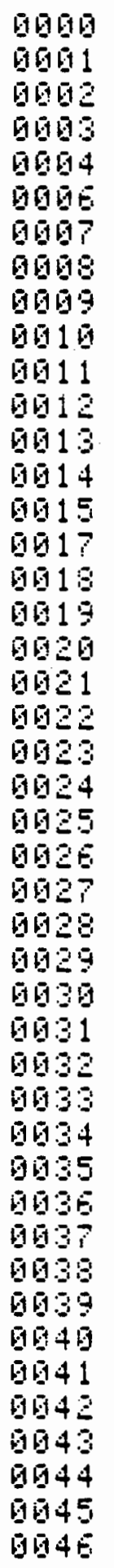 & 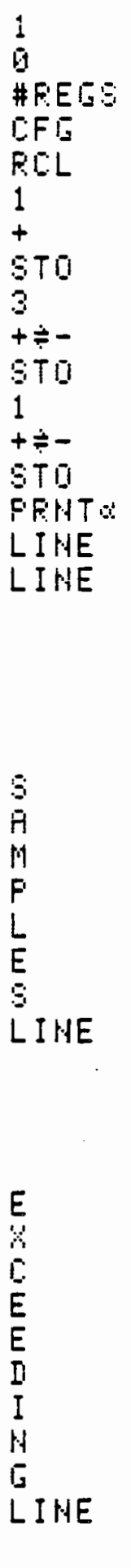 & $\begin{array}{l}3 \\
\text { EQ } 6107\end{array}$ & 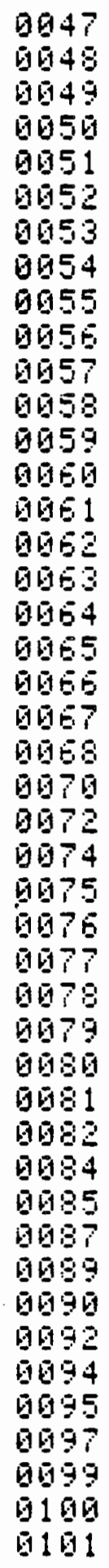 & 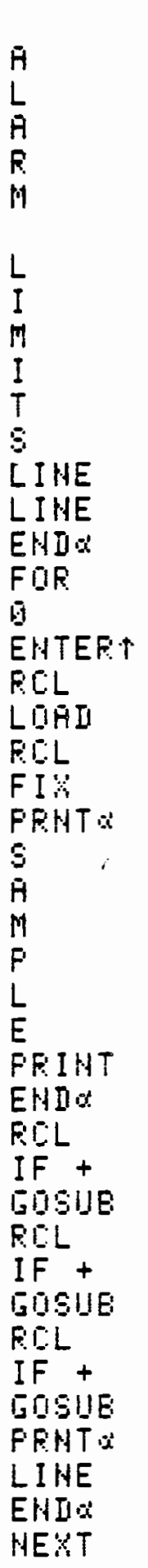 & 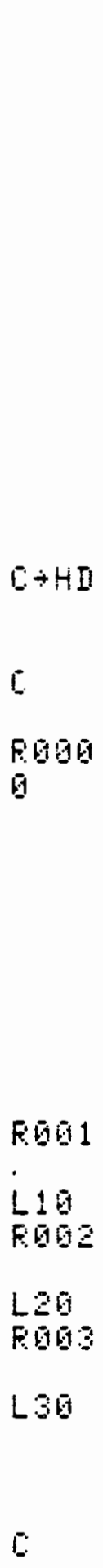 & 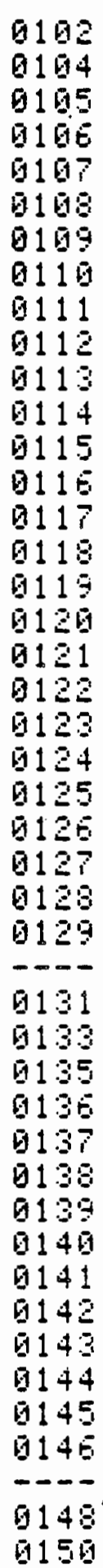 & 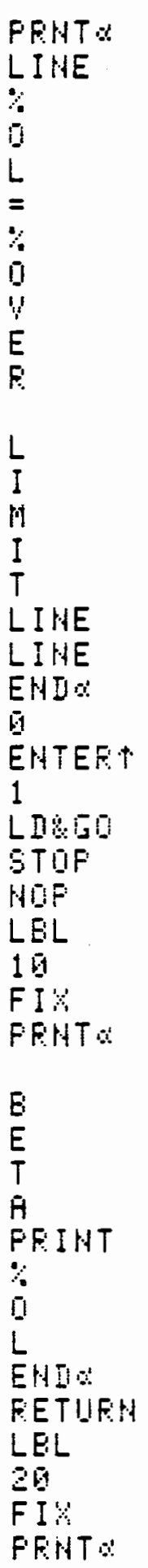 \\
\hline
\end{tabular}

File 20 Filter Exam (1/2) B. 43 


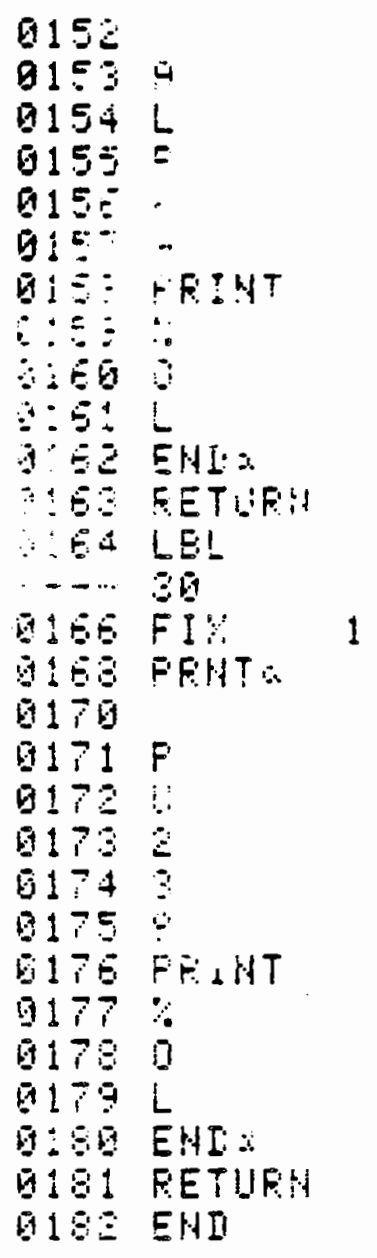

File 20 Filter Exam (2/2) 
APPENDIX C

DATA FILES ON CASSETTE 
DATA FILES ON CASSETTE

Three files on block 2 of the system's cassette are used to hold data which was either entered by the operator via the Initialize Parameters program or the results of the Background or Chi-Squared Tests. These files are numbers $-\emptyset,-1$, and -2 and each contains space for $1 \emptyset$ data. Their current use is:

File - 9

$$
\text { Data } \begin{aligned}
\emptyset & =\text { Background Test Count Time (minutes) } \\
1 & =\text { Background Ave. Beta (counts/min.) } \\
2 & =\text { Background Ave. Alpha (counts/min.) } \\
3 & =\text { Background Ave. PU-239 (counts/min.) } \\
4 & =\text { Background Ave. Radon (counts/min.) } \\
5 & =\text { unused } \\
6 & =\text { unused } \\
7 & =\text { unused } \\
8 & =\text { unused } \\
9 & =\text { unused }
\end{aligned}
$$

\section{File -1}

$$
\text { Data } \begin{aligned}
\emptyset & =\text { Mean Beta (counts/min.) } \\
1 & =\text { Mean A7pha (counts/min.) } \\
2 & =\text { Mean PU-239 (counts/min.) } \\
3 & =\text { Chi-Squared for Beta } \\
4 & =\text { Chi-Squared for Alpha } \\
5 & =\text { Chi-Squared for PU-239 } \\
6 & =\% \text { Efficiency for Beta } \\
7 & =\% \text { Efficiency for Alpha } \\
8 & =\% \text { Efficiency for PU-239 } \\
9 & =\text { unused }
\end{aligned}
$$


File-2

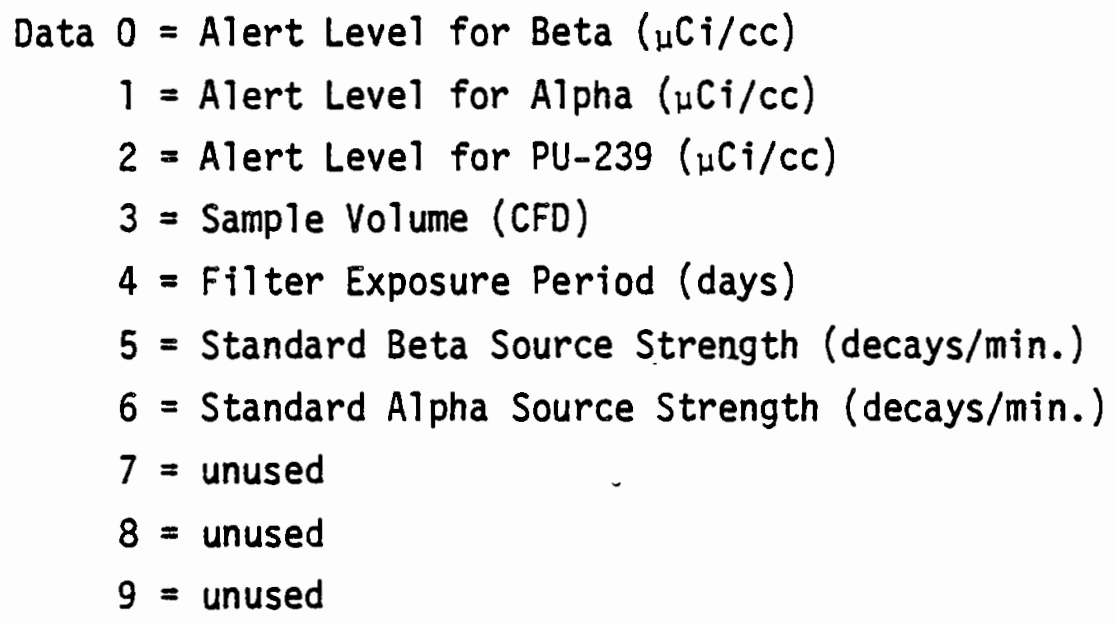


APPENDIX D

COPYING PROGRAM CASSETTES

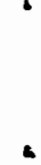




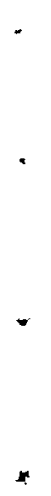

$+$

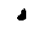




\section{COPYING PROGRAM CASSETTES}

The process to copy the program cassette takes about 15 to 30 minutes. Since the contents of the program cassette are vulnerable to being over-written, it is highly advisable to keep at least one copy as a backup. To make a copy, follow the steps outlined below. Read all steps before beginning.

1. Use HP \#9162-0061 Data Cartridge or equivalent (Stores Stock $\# 19-0431$-425) to make copies.

2. First, the new cassette must be pre-formatted or "marked" before loading programs.

a. Set the RECORD tab on the cassette to the right position.

b. Put the cassette into the drive of the calculator until it seats.

c. Enter the following key sequence:

$(5)(0)(0)$ (ENTER) (3)(0) (ENTER) (0) (gold key) (LOAD)

d. When the cassette stops, enter:

(8) (0) (ENTER) (3) (ENTER) (0) ( + ) (goid key) (LOAD)

e. When the cassette stops, enter:

(3) (2) (ENTER) ( 1$)(0)(0)$ (ENTER) (3) ( + ) (gold key) (LOAD)

$f$. When the cassette stops, enter: (REWIND)

3. Now, set the RECORD tab on the original program cassette to the left position to protect it during this process.

4. Remove the new cassette from the calculator and insert the original.

a. With the original cassette in place, enter: (0) (ENTER) (0) (LOAD)

b. When the cassette stops, remove it and insert the new one. Now enter: (RECORD)

C. Remove the new cassette when stopped, insert the original and enter: $(0)($ ENTER) $(X)(L O A D)$ where $X$ will be 1 through 20 . 
d. Repeat Step c. for the remaining files. There will be 21 files total that are copied $(0-20)$.

e. When stopped, remove the original, insert the new cassette, and enter: (REWIND).

5. Now that the programs are copied, they should be verified. To do this, first set the RECORD tabs of both cassettes to the left (protected) position.

6. Do the following steps ( $a$. and b.) for files $(x) 0$ through 16:

a. Insert the original cassette and enter:

(0) (ENTER) ( $X$ ) (LOAD)

b. When stopped, remove the original cassette, insert the new copy and enter:

(gold key) (REWIND)

This will verify each file. If no error occurs, no message is printed. If an error does occur, a message will be printed. If you find an error, confirm it by trying to verify the same file again. If it is still bad, go back to Step 4 and rewrite the new cassette. If it is still bad, try another cassette.

7. When finished, you have another exact duplicate of the original program cassette. However, no data is transferred. It will be necessary to run the Initialize Parameters program when the new cassette is used.

8. Remember to push the RECORD tab back to the right (no protection) before using it. 
APPENDIX E

TEST ROUTINES 


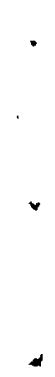


APPENDIX E

TEST ROUTINES

These routines are located on a separate tape entitled TEST RTN's. These routines exercise the scalers and sample charger wi thout the clutter of the applications programs. Comments have been added to provide the technician with a guide to how each step funtions. 


\begin{tabular}{|c|c|c|}
\hline $\begin{array}{l}=\text { ILE } \\
\text { YYFE } \\
\text { YSED } \\
M A \%\end{array}$ & $\begin{array}{l}5 \\
45 \\
586\end{array}$ & \\
\hline 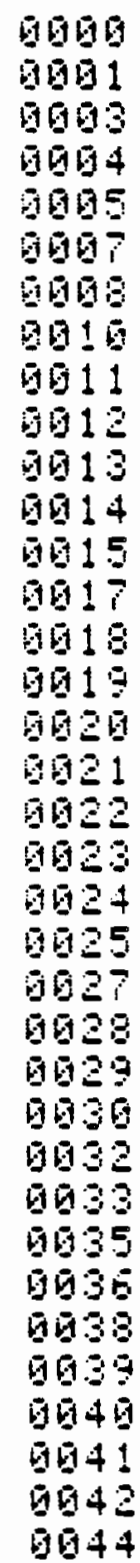 & 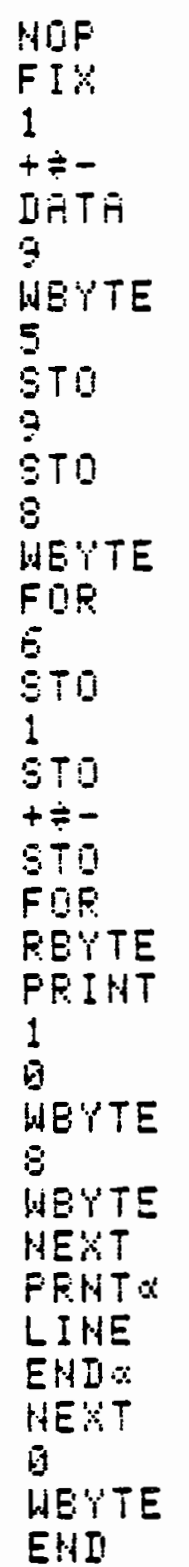 & $\begin{array}{l}2 \\
E \\
E \\
E \\
E \\
E \div E \\
C \\
H \\
D \\
E+H I\end{array}$ \\
\hline
\end{tabular}

This file reads each digit of each scaler. It prints the decimal number of all 8 bits on the input port but only the lower four bits represent the scaler digit. Does not initiate a count cycle.

Whole numbers only

Low = True

Bring lines (0) (PMF) and (0)3 (Print) low

Output it to scalers \& timer

Counter to 5 , also points to storage registers

which are not used in this routine

Counter to 9 , end point

Release line (0) 6 (PMF) keep line (0)3 low (Print)

Output to Scaler

For $B=5$ to 9 ( 5 scalers)

Set up counter for \# of digits in each scaler (6)

Start at 6 \& decrement counter $(-1)$ each time

Read input port

Print it

Bring line (0) 1 (Print Advance) low while keeping

line $(0) 8$ low

Send to Scalers (causes scaler to put next digit on 1 ine)

Release Print Advance

Out it

Read next digit ( 6 total)

Print a space (1ine) between scalers

Read next scaler ( 5 total)

Release all lines 


\section{Printout of Scaler Digits}

(A Pulser can be used to Drive Scalers)

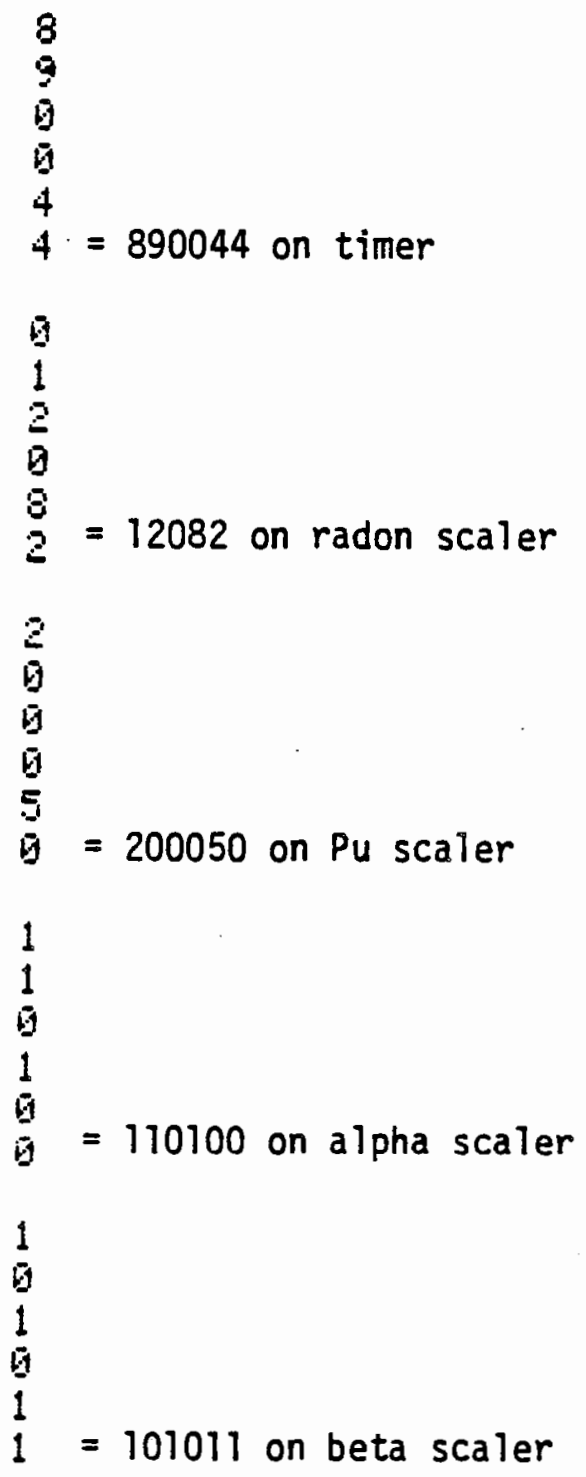

E. 3 


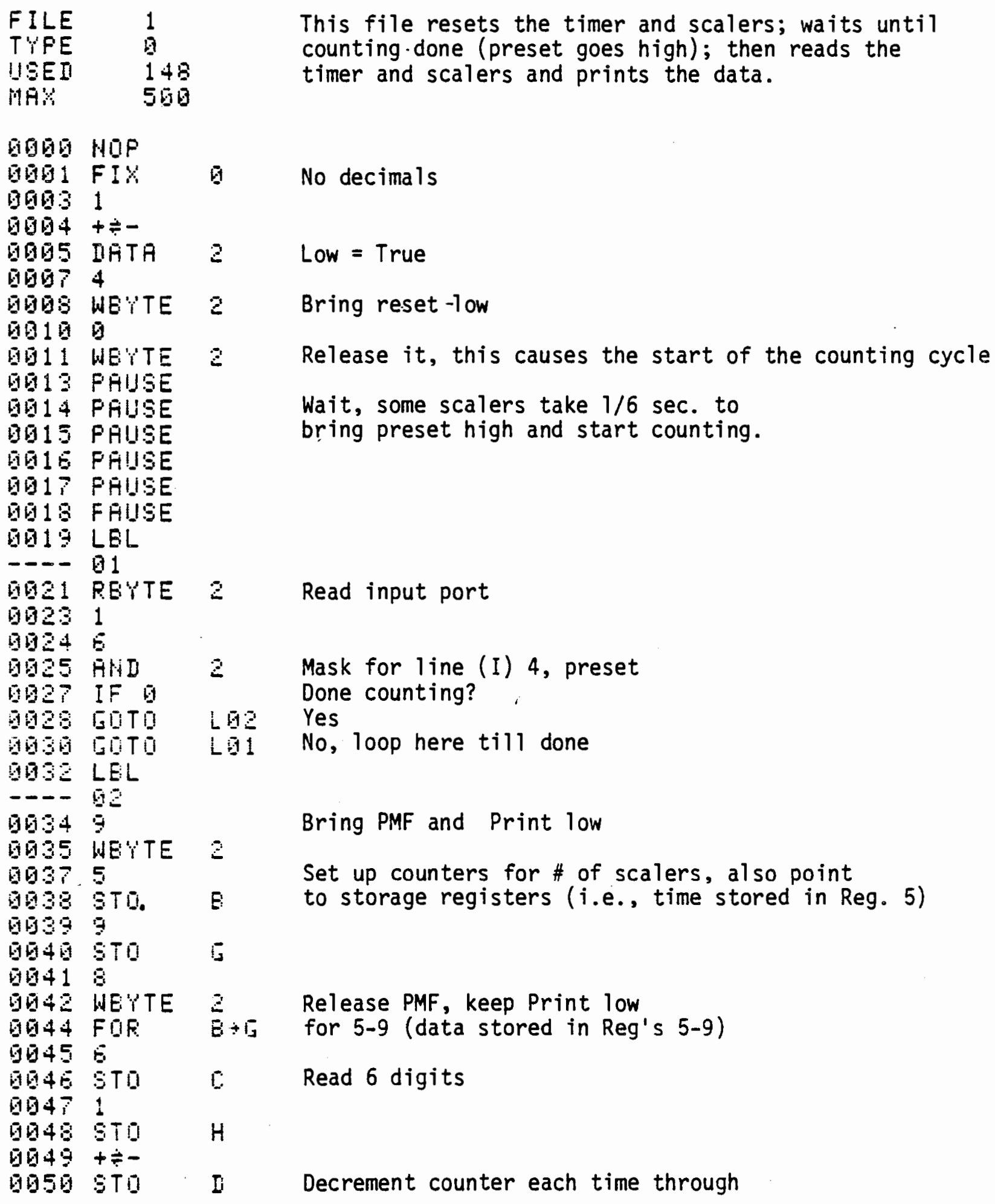




\section{File I, Cont'd}

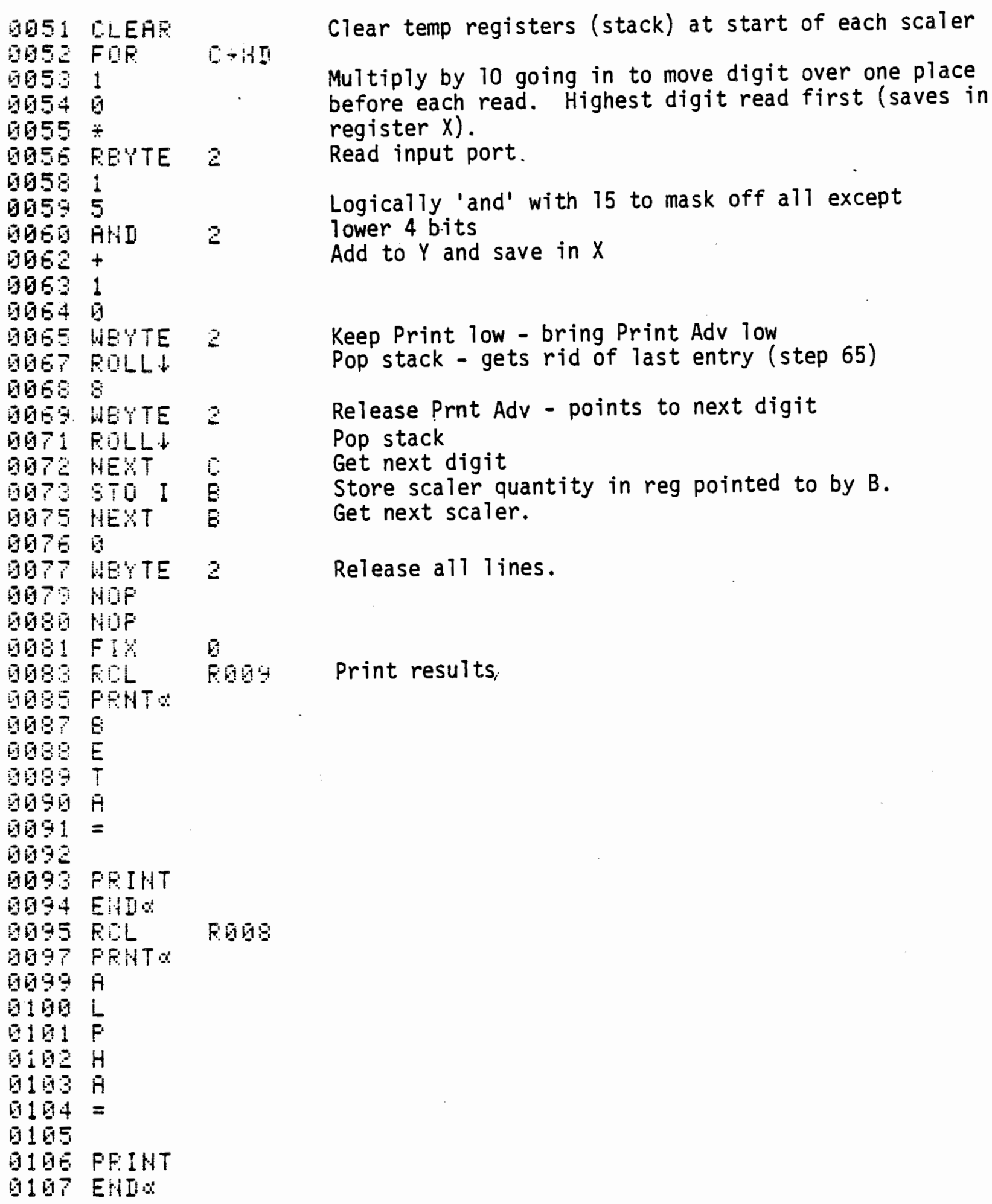

Clear temp registers (stack) at start of each scaler Muttiply by 10 going in to move digit over one place before each read. Highest digit read first (saves in register $X$ ).

Read input port.

Logicaliy 'and' with 15 to mask off all except lower 4 bits

Add to $Y$ and save in $X$

Keep Print low - bring Print Adv low

Pop stack - gets rid of last entry (step 65)

Release Prnt Adv - points to next digit

Pop stack

Get next digit

Store scaler quantity in reg pointed to by $B$. Get next scaler.

Release all 1 ines.

Fing Print results

F日勺 
File 1, Cont'd

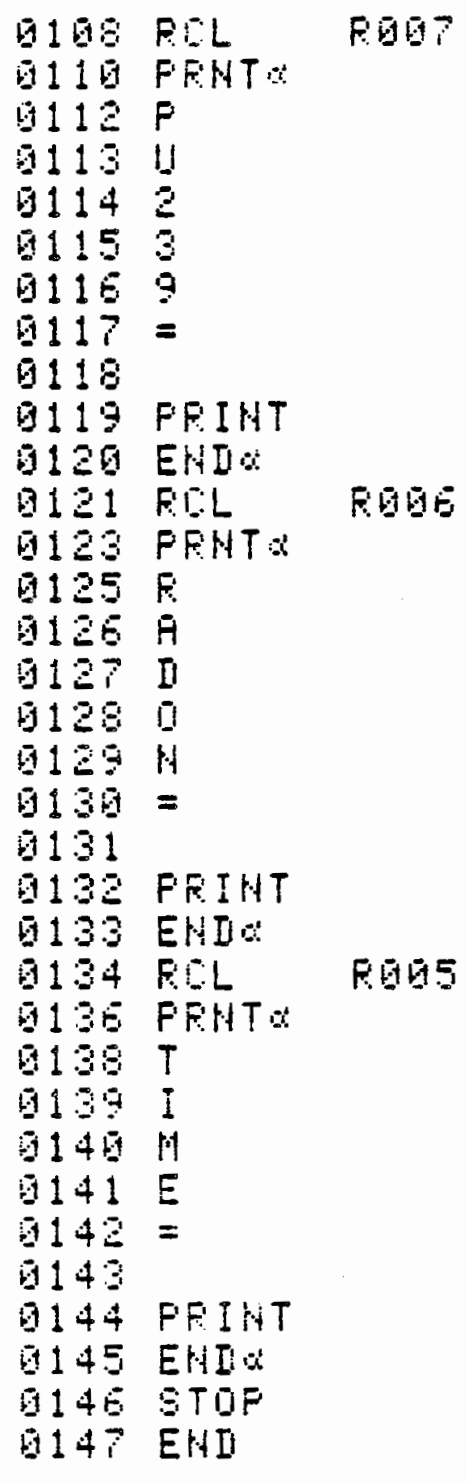

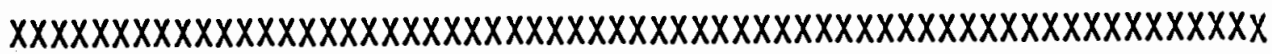

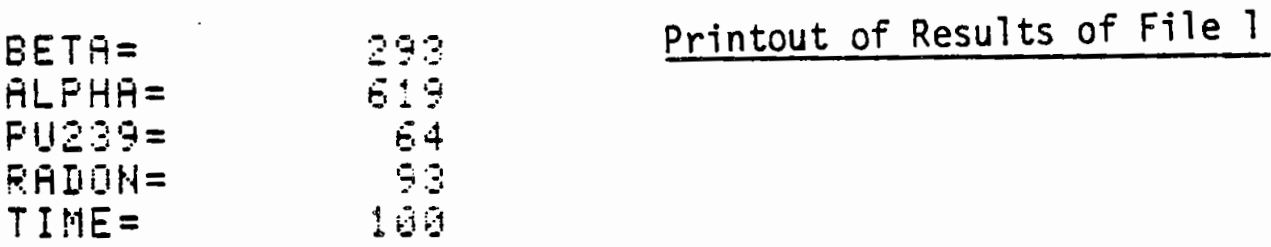

E.6 


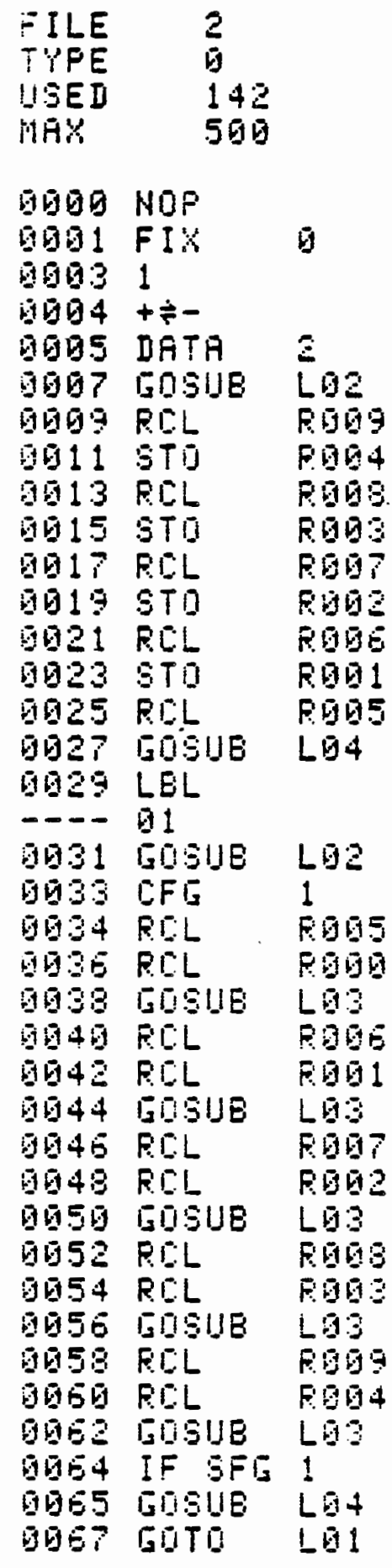

This file reads the timer \& scalers, prints the results, then re-reads them until stopped, comparing the first read to subsequent reads, only printing when the new readout is different. Use this to find a skipped or missing digit when problem is intermittent. May be a result of noise on Print Advance Iine.

Read scalers

Move data to lowered number registers and save

Print output of scalers lst time through

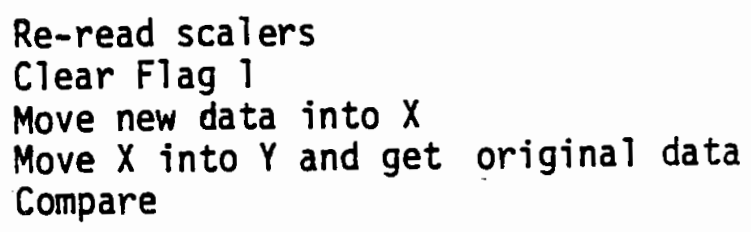

If any scaler output does not read as first print the data Do again; forever 
File 2, Cont'd.

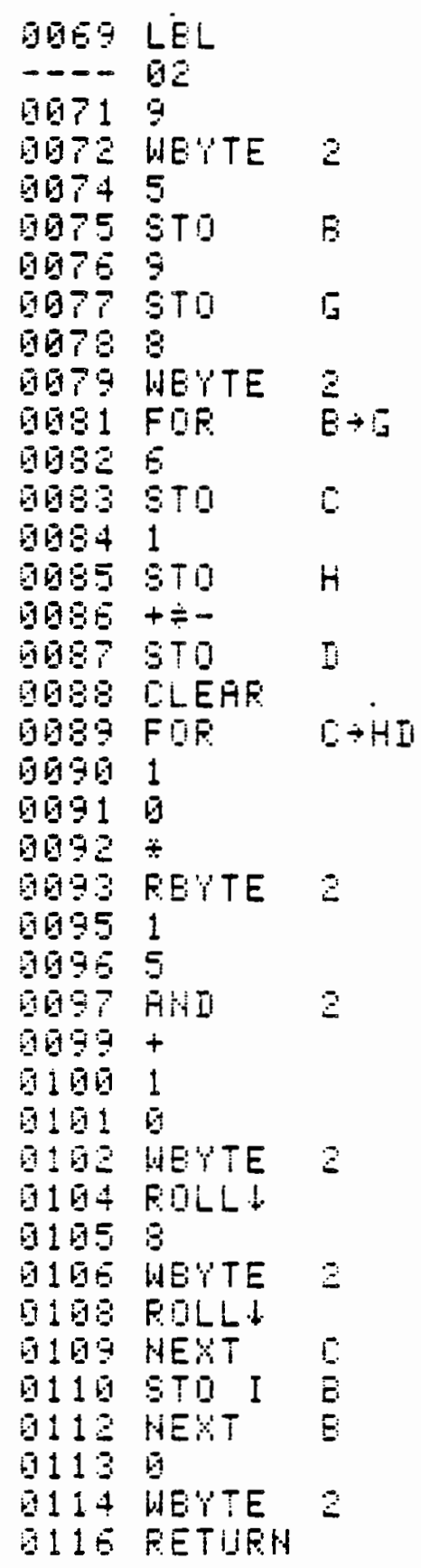

E.8 
File 2, Cont'd.

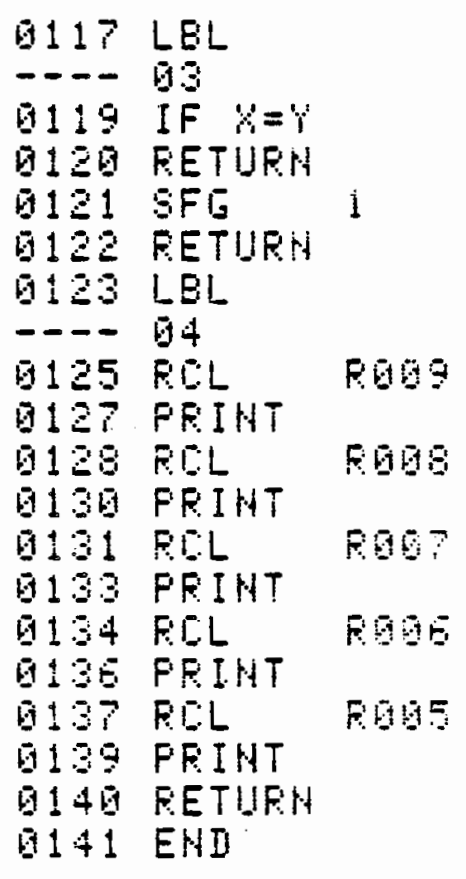


FILE 3

TYPE

USED 39
MAY $\quad 50$

This file reads a planchette number and prints it

Clear temp registers (stack)

No decima 1

BQG 1 FIY

b

00031

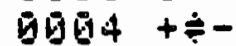

6085 DATA $z$ LOW = true.

60973

0063

9069 WBYTE 2 Set line (0) 5 low - puts high order digit to input

GQ1! REYTE $z$ Read it

09131

प6145

1915 AHI $2 \quad$ Mask off all except lower 4 bits

00171

09150

G日19\%

GQTE ENTEPA

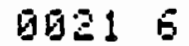

00224

GDES WEYTE 2 Set line (0) 6 low and return (0) 5 high. Puts Lo to input.

Q625 ROLL 4 Replace 64, above, with HO digit

GUES FETTE Z

19281

6925

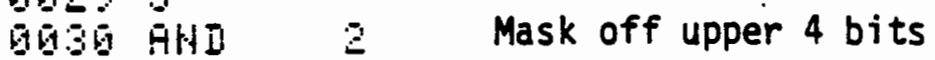

Q6032 + Add to H.O.

G0:3 PRIHT Print planchette number

06340

Q055 WETTE 2 Return all lines high

BG 37 STDP

BQSBS END

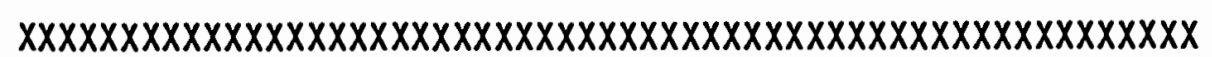

7
15
11
12
13
14

Printout of planchette numbers 


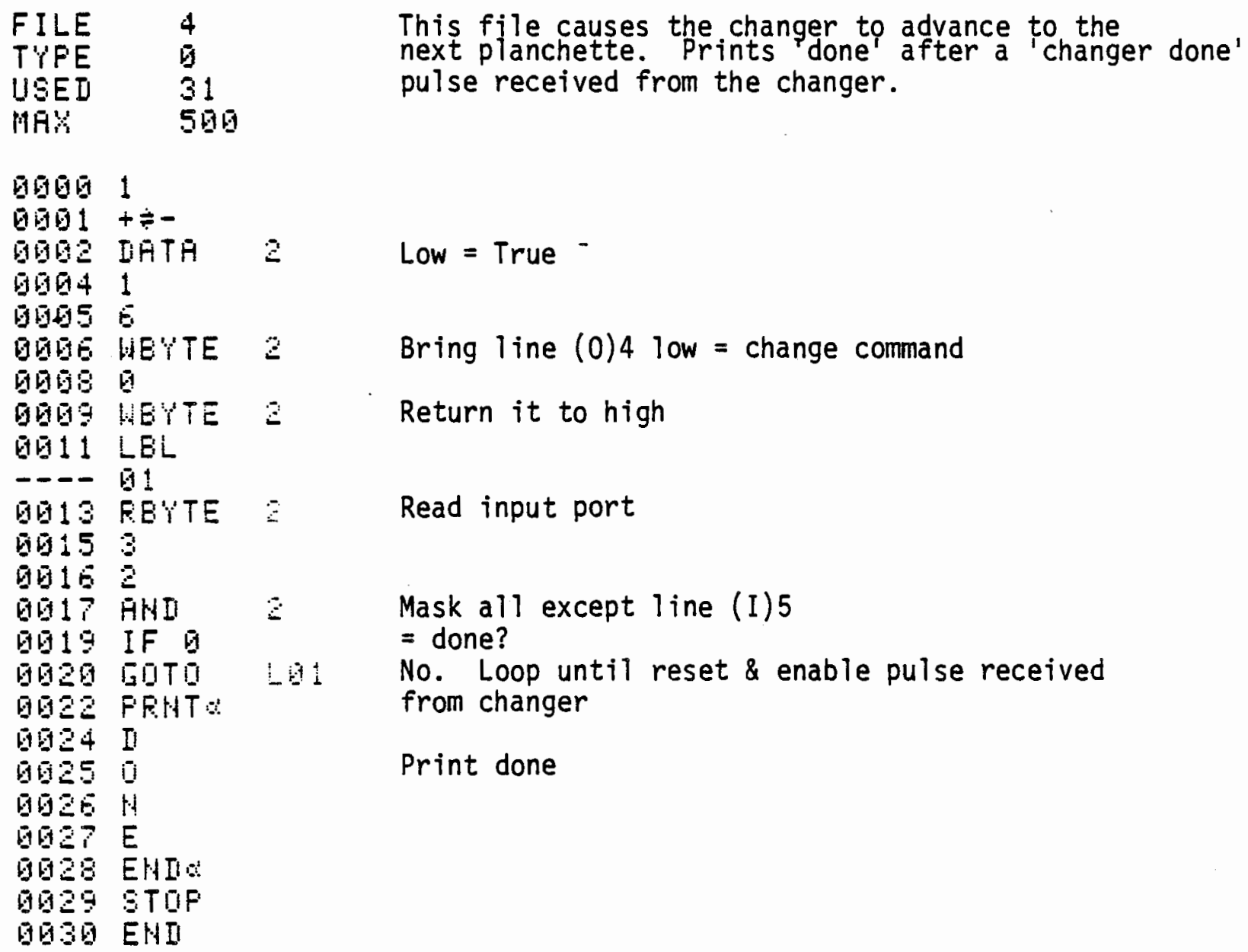




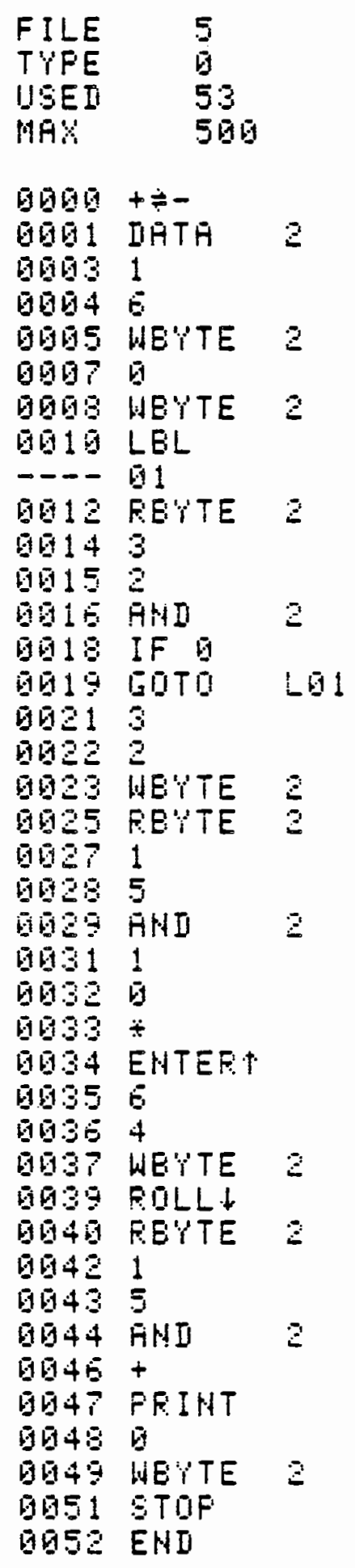

This file advances the changer one position, reads the planchette, and prints it. It is a combination of File 3 and File 4. 
PNL -5272

UC $-41,32,37$

\section{DISTRIBUTION}

No. of

Copies

OFFSITE

27 DOE Technical Information Center

ONSITE

6 DOE Richland Operations office

R. E. Austin

D. R. Elle

R. E. Gerton

H. E. Ransom

J. L. Rhoades

M. W. Tiernan

12 Westinghouse Hanford Company

D. E. Ames

H. F. Briggs

G. D. Carpenter

D. 0 . Hess

W. P. Howell (3)

W. C. Mallory (5)
No. of

Copies

30 Pacific Northwest Laboratory

J. R. Berry

P. E. Bramson

R. L. Dirkes

D. M. Fleming (3)

J. J. Jech

R. L. Kathren

H. V. Larson

M. A. Mckinney

A. P. Mi leham

C. R. Richey

K. L. Swinth

E. E. Stapleton (10)

Technical Information (5)

Publishing Coordination (2) 


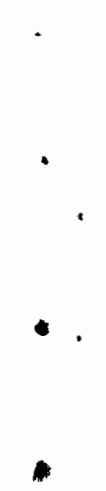

